NUREG/CR-5917

CNWRA 91-010

Vol. 1

\title{
Sensitivity and Uncertainty Analyses
}

Applied to One-Dimensional

Radionuclide Transport in a

Layered Fractured Rock

MULTFRAC - Analytic Solutions and Local Sensitivities

Iterative Performance Assessment - Phase 2

Prepared by

A. B. Gureghian, Y.-T. Wu, B. Sagar/CNWRA

R. B. Codell/NRC

Center for Nuclear Waste Regulatory Analyses

Southwest Research Institute

Prepared for

U.S. Nuclear Regulatory Commission
RECEIVED

FEB 241993

OSTI 


\section{AVAILABILITY NOTICE}

\section{Availability of Reference Materials Cited in NRC Publications}

Most documents clted in NRC publications will be avallable from one of the following sources:

1. The NRC Public Document Room, 2120 L Street, NW., Lower Level, Washington, DC 20555

2. The Superintendent of Documents, U.S. Government Printing Office, P.O. Box 37082, Washington, DC 20013-7082

3. The National Technical Information Service, Springfield, VA 22161

Although the llsting that follows represents the majority of documents clted in NRC publications, it is not intended to be exhaustive.

Referenced documents available for inspection and copying for a fee from the NRC Public Document Room Include NRC correspondence and internal NRC memoranda; NRC bulletins, circulars, information notices, Inspection and investigation notices; licensee event reports; vendor reports and correspondence; Commission papers; and applicant and licensee documents and correspondence.

The following documents in the NUREG series are available for purchase from the GPO Sales Program: formal NRC staff and contractor reports, NRC-sponsored conference proceedings, international agreement reports, grant publications, and NRC booklets and brochures. Also available are regulatory guides, NRC regulations in the Code of Federal Regulations, and Nuclear Regulatory Commission Issuances.

Documents avallable from the National Technical Information Service include NUREG-series reports and technical reports prepared by other Federal agencies and reports prepared by the Atomic Energy Commission, forerunner agency to the Nuclear Regulatory Commission.

Documents available from public and special technical libraries include all open literature items, such as books, Journal articles, and transactions. Federal Register notices, Federal and State legislation, and congressional reports can usually be obtained from these libraries.

Documents such as theses, dissertations, foreign reports and translations, and non-NRC conference proceedings are available for purchase from the organization sponsoring the publication cited.

Single copies of NRC draft reports are available free, to the extent of supply, upon written request to the Office of Administration, Distribution and Mail Services Section, U.S. Nuclear Regulatory Commission, Washington, DC 20555.

Copies of industry codes and standards used in a substantive manner in the NRC regulatory process are maintained at the NRC Library. 7920 Norfolk Avenue. Bethesda, Maryland, for use by the publlc. Codes and standards are usually copyrighted and may be purchased from the originating organization or, if they are American National Standards, from the American National Standards Institute, 1430 Broadway, New York, NY 10018.

\section{DISCLAIMER NOTICE}

This report was prepared as an account of work sponsored by an agency of the United States Government. Neither the United States Government nor any agency thereof, or any of their employees, makes any warranty, expressed or implied, or assumes any legal liability of responsibility for any third party's use, or the results of such use, of any information, apparatus, product or process disclosed in this report, or represents that its use by such third party would not infringe privately owned rights. 


\section{DISCLAIMER}

Portions of this document may be illegible in electronic image products. Images are produced from the best available original document. 


\section{Sensitivity and Uncertainty Analyses}

Applied to One-Dimensional

Radionuclide Transport in a

Layered Fractured Rock

MULTFRAC - Analytic Solutions and Local Sensitivities

Iterative Performance Assessment - Phase 2

Manuscript Completed: November 1992

Date Published: December 1992

Prepared by

A. B. Gureghian, Y.-T. Wu, B. Sagar, Center for Nuclear Waste Regulatory Analyses

R. B. Codell, NRC

Center for Nuclear Waste Regulatory Analyses .

Southwest Research Institute

6220 Culebra Road

San Antonio, TX 78228-0510

Prepared for

Division of High-Level Waste Management

Office of Nuclear Materials Safety \& Safeguards

U.S. Nuclear Regulatory Commission

Washington, DC 20555

NRC FIN D1035 
. 


\begin{abstract}
Exact analytical solutions based on the Laplace transforms are derived for describing the one-dimensional space-time-dependent, advective transport of a decaying species in a layered, saturated rock system intersected by a planar fracture of varying aperture. These solutions, which account for advection in fracture, molecular diffusion into the rock matrix, adsorption in both fracture and matrix, and radioactive decay, predict the concentrations in both fracture and rock matrix and the cumulative mass in the fracture. The solute migration domain in both fracture and rock is assumed to be semi-infinite with non-zero initial conditions. The concentration of each nuclide at the source is allowed to decay either continuously or according to some periodical fluctuations where both are subjected to either a step or band release mode. Two numerical examples related to the transport of Np-237 and $\mathrm{Cm}-245$ in a five-layered system of fractured rock were used to verify these solutions with several well established evaluation methods of Laplace inversion integrals in the real and complex domain. In addition, with respect to the model parameters, a comparison of the analytically derived local sensitivities for the concentration and cumulative mass of $\mathrm{Np}-237$ in the fracture with the ones obtained through a finite-difference method of approximation is also reported.
\end{abstract}





\section{CONTENTS}

Section

Page

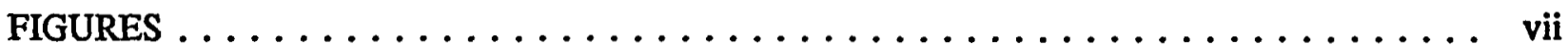

TABLES $\ldots \ldots \ldots \ldots \ldots \ldots \ldots \ldots \ldots \ldots \ldots \ldots \ldots \ldots \ldots \ldots \ldots \ldots$

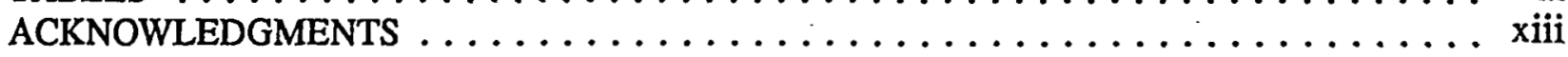

$1 \quad$ INTRODUCTION $\ldots \ldots \ldots \ldots \ldots \ldots \ldots \ldots \ldots \ldots \ldots \ldots \ldots \ldots \ldots$

$1.1 \quad$ PHYSICAL SYSTEM $\ldots \ldots \ldots \ldots \ldots \ldots \ldots \ldots \ldots \ldots \ldots \ldots \ldots \ldots$

2 ANALYTICAL CONCENTRATIONS AND CUMULATIVE MASS $\ldots \ldots \ldots \ldots$ 2-1

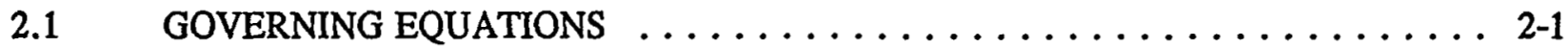

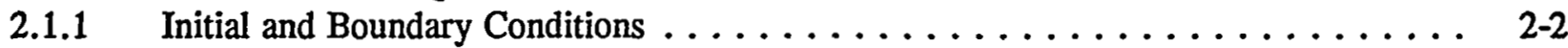

2.1.2 Concentrations of the Source . . . . . . . . . . . . . . . . . . . 2-3

2.1.3 Solution of Transport Equations for the Rock Matrix and Fracture . . . . . . . . 2-5

2.1.3.1 Rock Matrix ............................. 2-5

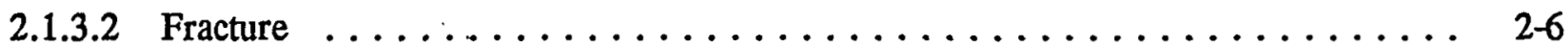

2.1.3.3 Rock Matrix .............................. $2-12$

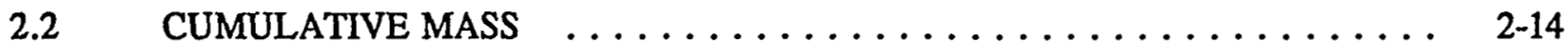

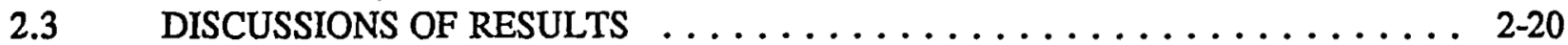

2.3.1 Case 1 Results . . . . . . . . . . . . . . . . . . . . . . 2-20

2.3.2 Case 2 Results . . . . . . . . . . . . . . . . . . 2-35

3 ANALYTICALLY DERIVED SENSITIVITIES IN THE FRACTURE $\ldots \ldots \ldots$

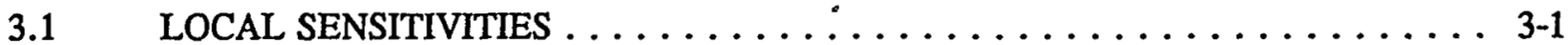

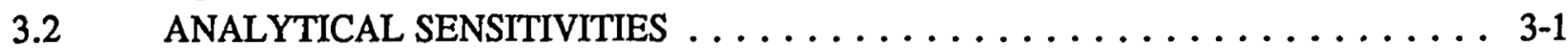

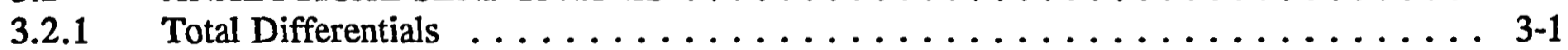

3.2.2 First-Order Derivatives of the Concentrations $\ldots \ldots \ldots \ldots \ldots \ldots \ldots \ldots$

3.2.3 First-Order Derivatives of the Cumulative Mass . . . . . . . . . . . . . . . 3-11

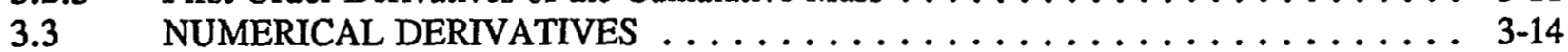

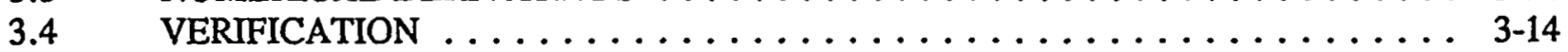

$4 \quad$ CONCLUSIONS $\ldots \ldots \ldots \ldots \ldots \ldots \ldots \ldots \ldots \ldots \ldots \ldots \ldots \ldots$

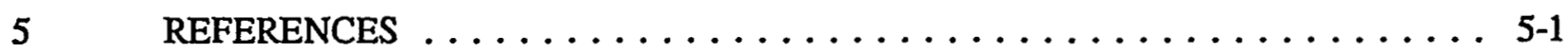




\section{CONTENTS (Cont'd)}

\section{APPENDICES}

A

B

C

D

E

F

$\mathbf{G}$
THEOREMS AND LAPLACE TRANSFORMS

EVALUATION OF ERROR FUNCTION AND PRODUCT OF EXPONENTIAL AND COMPLEMENTARY ERROR FUNCTION TERMS

SOME INTEGRALS INVOLVING THE ERROR FUNCTION AND OTHER FUNCTIONS

FIRST-ORDER DERIVATIVES OF THE COMPONENTS OF THE CONCENTRATION SOLUTION IN THE FRACTURE LAYERS

FIRST-ORDER DERIVATIVES OF THE COMPONENTS OF THE CUMULATIVE MASS SOLUTION IN THE FRACTURE LAYERS

NOTATIONS

MODEL PARAMETERS 


\section{FIGURES}

Figure

Page

1-1 Description of migration pathways in a system of homogeneous layers of fractured rock $\ldots \ldots \ldots \ldots \ldots \ldots \ldots \ldots \ldots \ldots \ldots \ldots \ldots \ldots \ldots$

2-1 Source models: (a) exponentially decaying, and (b) periodically fluctuating decaying ......................... $2-4$

2-2(a) Relative concentration of $\mathrm{Np}-237$ versus distance in the fracture at different times $T=1,000,5,000$, and 50,000 years (Exponentially decaying source and step and band release mode) .

2-2(b) Relative concentration of Np-237 in the fracture versus time at different positions $x=100,200$, and 500 meters (Exponentiallydecaying source and band release mode)

2-2(c) Cumulative mass of $\mathrm{Np}-237$ per unit in the fracture versus time at different positions $x=100,200$, and 500 meters (Exponentially decaying source and

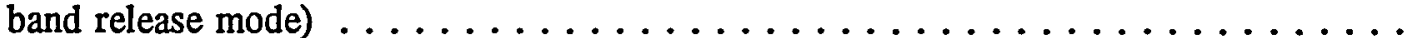

2-2(d) Relative concentration of $\mathrm{Np}-237$ in rock versus distance $\mathrm{z}$ at time $\mathrm{t}=5,000$ years and distances from the source $x=100,200$ and 500 meters (Exponentially decaying source and step release mode) $\ldots \ldots \ldots \ldots \ldots \ldots \ldots \ldots \ldots \ldots \ldots$ 2-31

2-2(e) Relative concentration of $\mathrm{Np}-237$ in rock versus distance at $t=50,000$ years (Exponentially decaying source and band release mode)

2-3(a) Relative concentration of $\mathrm{Cm}-245$ versus distance in the fracture at different times $\mathrm{t}=1,000,5,000$, and 50,000 years (Periodically fluctuating source with exponential decay, step and band release mode) . . . . . . . . . .

2-3(b) Relative concentration of $\mathrm{Cm}-245$ in the fracture versus time at different positions $x=100,200$, and 500 meters (Periodically fluctuating source with exponential decay, step and band release mode)

2-3(c) Cumulative mass of $\mathrm{Cm}-245$ per unit in the fracture versus time at different positions $x=100,200$, and 500 meters (Periodically fluctuating source with exponential decay)

2-3(d) Relative concentration of $\mathrm{Cm}-245$ in rock versus distance $\mathrm{z}$ at time $\mathrm{t}=5,000$ years and distances from the source $x=100,200$ and 500 meters (Periodically fluctuating source with exponential decay and step release mode) 


\section{FIGURES (Cont'd)}

Figure

Page ·

2-3(e) Relative concentration of $\mathrm{Cm}-245$ in rock versus distance at $\mathrm{t}=50,000$ years (Periodically fluctuating source with exponential decay and band release mode)

3-1(a) Sensitivity of concentration to half-thickness versus time for $\mathrm{Np}-237$ (Exponentially decaying source) $\ldots \ldots \ldots \ldots \ldots \ldots \ldots \ldots \ldots \ldots$. . . . . . . . . .

3-1(b) Sensitivity of concentration to pore diffusivity versus time for Np-237

(Exponentially decaying source) $\ldots \ldots \ldots \ldots \ldots \ldots \ldots \ldots \ldots \ldots \ldots$. . . . . . . . . .

3-1(c) Sensitivity of concentration to surface distribution coefficient in fracture versus time for $\mathrm{Np}-237$ (Exponentially decaying source)

3-1(d) Sensitivity of concentration to distribution coefficient in rock versus time for $\mathrm{Np}-237$ (Exponentially decaying source)

3-2(a) Sensitivity of cumulative mass to half-thickness versus time for $\mathrm{Np}-237$ (Exponentially decaying source)

3-2(b) Sensitivity of cumulative mass to pore diffusivity versus time for $\mathrm{Np}-237$ (Exponentially decaying source).

3-2(c) Sensitivity of cumulative mass to surface distribution coefficient in fracture versus time for $\mathrm{Np}-237$ (Exponentially decaying source) .

3-2(d) Sensitivity of cumulative mass to distribution coefficient in rock versus time for Np-237 (Exponentially decaying source) 


\section{TABLES}

Number

Page

2-1 Input parameters for Case 1 exponentially decaying source $\ldots \ldots \ldots \ldots \ldots$

2-2(a) Case 1 Results: Concentration of $\mathrm{Np}-237$ in the fracture at time

$t=1,000$ years (Exponentially decaying source and step release mode) $\ldots \ldots \ldots$ 2-26

2-2(b) Case 1 Results: Concentration of $\mathrm{Np}-237$ in the fracture at time

$t=5,000$ years (Exponentially decaying source and band release mode) $\ldots \ldots \ldots 2-26$

2-2(c) Case 1 Results: Concentration of $\mathrm{Np}-237$ in the fracture at time

$t=50,000$ years (Exponentially decaying source and step release mode) $\ldots \ldots \ldots$ 2-26

2-3(a) Case 1 Results: Concentration of $\mathrm{Np}-237$ in the fracture Layer 2, at distance $\mathrm{x}=100$ meters (Exponentially decaying source and

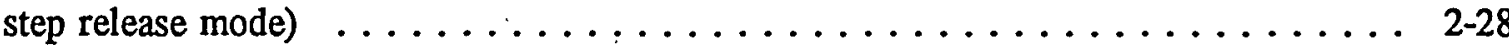

2-3(b) Case 1 Results: Concentration of $\mathrm{Np}-237$ in the fracture Layer 3,

at distance $x=200$ meters (Exponentially decaying source

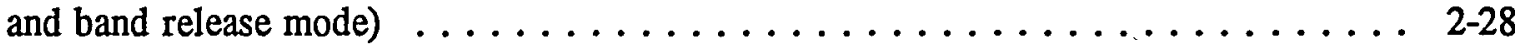

2-3(c) Case 1 Results: Concentration of $\mathrm{Np}-237$ in the fracture Layer 5 ,

at distance $\mathrm{x}=500$ meters (Exponentially decaying source

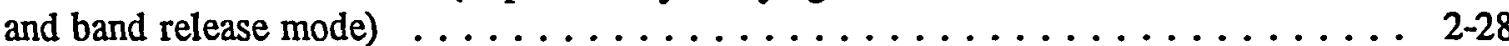

2-4(a) Case 1 Results: Cumulative mass of $\mathrm{Np}-237$ in the fracture at distance

$x=100$ meters (Exponentially decaying source and band release mode) . . . . . . 2-30

2-4(b) Case 1 Results: Cumulative mass of Np-237 in the fracture at distance

$x=200$ meters (Exponentially decaying source and band release mode) . . . . . . 2-30

2-4(c) Case 1 Results: Cumulative mass of $\mathrm{Np}-237$ in the fracture at distance

$x=500$ meters (Exponentially decaying source and band release mode)

2-5(a) Case 1 Results: Concentration of Np-237 in the rock matrix Layer 2, at distance $\mathrm{x}=100$ meters and time $\mathrm{t}=5,000$ years (Exponentially decaying source and step release mode)

2-5(b) Case 1 Results: Concentration of $\mathrm{Np}-237$ in the rock matrix Layer 3, at distance $\mathrm{x}=200$ meters and time $\mathrm{t}=5,000$ years (Exponentially decaying source and step release mode) 


\section{TABLES (Cont'd)}

Number

Page

2-5(c) Case 1 Results: Concentration of Np-237 in the rock matrix Layer 5, at distance $x=500$ meters and time $t=5,000$ years (Exponentially decaying source and step release mode)

2-6(a) Case 1 Results: Concentration of Np-237 in the rock matrix Layer 2, at distance $x=100$ meters and time $t=50,000$ years (Exponentially decaying source and band release mode)

2-6(b) Case 1 Results: Concentration of Np-237 in the rock matrix Layer 3, at distance $x=200$ meters and time $t=50,000$ years (Exponentially decaying source and band release mode)

2-6(c) Case 1 Results: concentration of Np-237 in the rock matrix Layer 3, at distance $x=500$ meters and time $t=50,000$ years (Exponentially decaying source and band release mode)

2-7 Input parameters for Case 2 periodically fluctuating source with exponential decay

2-8(a) Case 2 Results: Concentration of $\mathrm{Cm}-245$ in the fracture at time $t=1,000$ years (Periodically fluctuating source with exponential

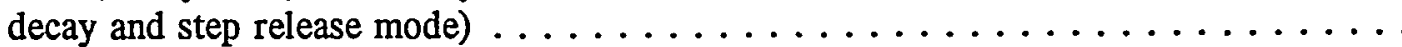

2-8(b) Case 2 Results: Concentration of Cm-245 in the fracture at time $t=5,000$ years (Periodically fluctuating source with exponential decay and band release mode) $\ldots \ldots \ldots \ldots \ldots \ldots \ldots \ldots \ldots$

2-8(c) Case 2 Results: Concentration of $\mathrm{Cm}-245$ in the fracture at time $t=50,000$ years (Periodically fluctuating source with exponential decay and band release mode)

2-9(a) Case 2 Results: Concentration of Cm-245 in the fracture in Layer 2, at distance $\mathrm{x}=100$ meters (Periodically fluctuating source with exponential decay and step release mode $) \ldots \ldots \ldots \ldots \ldots \ldots \ldots$

2-9(b) Case 2 Results: Concentration of Cm-245 in the fracture in Layer 3, at distance $\mathrm{x}=200$ meters (Periodically fluctuating source with exponential decay and band release mode). 


\section{TABLES (Cont'd)}

- Number

Page

2-9(c) Case 2 Results: Concentration of $\mathrm{Cm}-245$ in the fracture in Layer 5, at distance $\mathrm{x}=500$ meters (Periodically fluctuating source with exponential decay and band release mode) . . . . . . . . . . . . . . . 2-41

2-10(a) Case 2 Results: Cumulative mass of $\mathrm{Cm}-245$ in the fracture at distance $\mathrm{x}=100$ meters (Periodically fluctuating source with exponential decay and band release mode $) \ldots \ldots \ldots \ldots \ldots \ldots \ldots \ldots \ldots$

2-10(b) Case 2 Results: Cumulative mass of Cm-245 in the fracture at distance $\mathrm{x}=200$ meters (Periodically fluctuating source with exponential decay and band release mode) $\ldots \ldots \ldots \ldots \ldots \ldots \ldots \ldots$ 2-43

2-10(c) Case 2 Results: Cumulative mass of $\mathrm{Cm}-245$ in the fracture at distance $\mathrm{x}=500$ meters (Periodically fluctuating source with exponential decay and band release mode)

2-11(a) Case 2 Results: Concentration of $\mathrm{Cm}-245$ in the rock matrix Layer 2, at distance $x=100$ meters and time $t=5,000$ years (Periodically fluctuating source with exponential decay and step release mode) $\ldots \ldots \ldots \ldots$. . . . .

2-11(b) Case 2 Results: Concentration of $\mathrm{Cm}-245$ in the rock matrix Layer 3, at distance $\mathrm{x}=200$ meters and time $\mathrm{t}=5,000$ years (Periodically fluctuating source with exponential decay and step release mode) $\ldots \ldots \ldots \ldots$ 2-45

2-11(c) Case 2 Results: Concentration of $\mathrm{Cm}-245$ in the rock matrix Layer 5, at distance $x=500$ meters and time $t=5,000$ years (Periodically fluctuating source with exponential decay and step release mode)

2-12(a) Case 2 Results: Concentration of $\mathrm{Cm}-245$ in the rock matrix Layer 2, at distance $x=100$ meters and time $t=50,000$ years (Periodically fluctuating source with exponential decay and band release mode)

2-12(b) Case 2 Results: Concentration of $\mathrm{Cm}-245$ in the rock matrix Layer 3, at distance $x=200$ meters and time $t=50,000$ years (Periodically fluctuating source with exponential decay and band release mode)

2-12(c) Case 2 Results: Concentration of $\mathrm{Cm}-245$ in the rock matrix Layer 5, at distance $x=500$ meters and time $t=50,000$ years (Periodically fluctuating source with exponential decay and band release mode) 


\section{TABLES (Cont'd)}

Number

Page

3-1 First-order partial derivatives of $\theta_{\operatorname{mn}}$ with respect to input parameters $\alpha_{i} \ldots \ldots$. . . .

3-2 First-order partial derivatives of $\gamma_{\operatorname{ms}}$ with respect to input parameters $\alpha_{i} \ldots \ldots$. . . .

3-3 First-order partial derivatives of $c_{\tilde{n}}$ with respect to input parameters $\alpha_{i} \ldots \ldots \ldots$

3-4 First-order partial derivatives of $R_{i}$ with respect to input parameters $\alpha_{i} \ldots \ldots \ldots$

3-5 First-order partial derivatives of $R_{i}^{\prime}$ with respect to input parameters $\alpha_{i} \ldots \ldots \ldots$ 3-9

A.1 Laplace transforms $\ldots \ldots \ldots \ldots \ldots \ldots \ldots \ldots \ldots \ldots \ldots \ldots \ldots \ldots$ 


\section{ACKNOWLEDGMENTS}

Several people assisted in the preparation of this report. The authors would like to express their appreciation for their efforts which greatly helped the document to reach its final form. In particular, we would like to thank Drs. W. C. Patrick and R. Ababou, and Mr. R. G. Baca for their reviews, Mr. A. Johnson and Ms. L. Tweedy for their graphical contributions, Messrs. E. Perez and D. Saathoff, of the Computer and Telecommunication Center, and Mrs. M. A. Gruhlke, who assisted in the coordination and production of this document.

This report was prepared to document work performed by the Center for Nuclear Waste Regulatory Analyses (CNWRA) for the U.S. Nulcear Regulatory Commission under Contract No. NRC-02-88-005. The activities reported here were performed on behalf of the NRC Office of Nuclear Material Safety and Safeguards, Division of High-Level Waste Management. The report is an independent product of the CNWRA and does not necessarily reflect the views or regulatory position of the NRC. 


\section{INTRODUCTION}

Mathematical models are essential tools in performance assessment investigations, for estimating the potential impact of radionuclide migration out of a high-level waste (HLW) geologic repository to the biosphere. These models involve a mathematical description of hydro-geochemical and geophysical processes. Their predictive capabilities are usually commensurate with our understanding of the various classes of geologic media: porous and fractured rock. Currently, the candidate HLW disposal site is a fractured tuff. This geological medium is poorly understood because of its inherent uncertainties and currently there is only a limited basis to quantitatively describe hydro-geochemical processes in that medium. Consequently, the use of simplified mathematical models for a conservative probabilistic assessment of performance is appropriate. Moreover, in spite of their limitations, the high degree of precision of analytical models coupled with their computational efficiency have induced many investigators worldwide [Rosinger and Tremaine (1978), Hodgkinson and Maul (1985), Rasmuson and Neretnieks (1986), and Burkholder et al., (1976)] to adopt these for addressing some of the critical issues inherent in the containment characteristics of potential radioactive waste disposal sites.

Analytical solutions have played an important role in assessing the impact of burying radioactive waste in permeable porous media [Gureghian (1987), Gureghian and Jansen (1985, 1983), van Genuchten and Alves (1982), Pigford et al., (1980), Hadermann (1980), Burkholder et al., (1976), Rosinger and Tremaine (1978), Lester et al., (1975), and Shamir and Harleman (1966)], and fractured rock masses [Gureghian (1990(a,b), Ahn et al., (1985, 1986), Chen (1986), Hodgkinson and Maul (1985), Sudicky and Frind (1982, 1984), Grisak and Pickens (1981), Kanki et al., (1981), Chambre et al., (1982), Tang et al., (1981), and Neretnieks (1980)].

This report is presented in two volumes.

Volume 1 reports the derivation and verification of the closed form analytical solutions of the onedimensional non-dispersive and isothermal transport of a radionuclide in a layered system of saturated planar fractures coupled with diffusion into the adjacent saturated rock matrix. In addition to matrix diffusion effects as reported by Grisak et al., (1981), Grisak et al., (1980b), and Neretnieks (1980) [see also Gureghian (1990a) for a comprehensive list of references] on the one hand, and non-zero initial conditions in both fracture and rock as illustrated by Gureghian (1990b) on the other, three new features associated with: (i) the layered nature of the rock matrix; (ii) the length dependency of fracture aperture; and (iii) periodicity aspect of radionuclides released from the source have been implemented in these new solutions.

Volume 2 evaluates and demonstrates the use of several sensitivity and uncertainty analysis methods using . the analytical model developed in Volume 1.

The mathematical model "MULTFRAC" associated with Volume 1 of this report includes two modules. The first module predicts the space-time dependent concentration of a decaying species migrating within the fracture network and the surrounding rock matrix layers, including the cumulative mass at an arbitrary observation point within the fracture. Note that the steady unidirectional flow of water through the fracture is normal to the rock matrix layers. Moreover, the material properties of individual fracture and rock matrix layers assumed to be fully saturated are homogeneous and isotropic. The second module predicts the analytical and numerical local sensitivities, that is, the first-order derivatives of the concentration and cumulative mass with respect to the model parameters. These quantities are needed 
for parameter estimation or sampling design in the case of the concentration and for uncertainty analysis of cumulative releases of a typical species from the repository at a typical point in time along the fracture, as illustrated in Volume 2 of this report.

The analytical solutions are based on the Laplace transform method where the domains of radionuclide migration in both fractures and rock layers are one-dimensional and of the semi-infinite type, implying in this instance that radionuclide diffusion from the fractures wall to the rock matrix may extend to infinity. The sorption phenomena in both fracture and rock matrix layers are described by a linear equilibrium sorption isotherm. Two types of radionuclide release modes are considered: (i) the continuously decaying; and (ii) the periodically fluctuating decaying source, which may in turn be subject to step and band release modes. The initial concentrations in the fracture and rock matrix layers may be assigned spatially varying values in the first case, whereas uniform ones may be implemented in both cases.

The verification of the new analytical solutions pertaining to solute transport in fracture and rock matrix was performed by means of several well established numerical evaluation methods of Laplace inversion integral proposed by Talbot (1979), Durbin (1974), and Stefhest (1970). Two test cases involving the migration of $\mathrm{Np}-237$ and $\mathrm{Cm}-245$ in a five-layered fractured rock system were investigated. An evaluation of some of these inversion methods over the range of investigated parameters has also been reported. On the other hand, the verification of the analytical solutions for the local sensitivities of the concentration and cumulative mass in the fracture with respect to the parameters of the system was performed by means of numerical differentiation techniques based on the finite-difference method of approximation.

The deterministic solutions presented in Volume 1 of this paper are primarily applicable to performance assessment investigations of potential nuclear waste repository sites restricted to typical scenario analyses associated with long-term migration of radionuclides in an idealized fractured rock system. Although some limitations inherent to the nature of the solution method adopted here are to be considered, the present model may be useful in studying some aspects of sensitivity and uncertainty of the cumulative mass of a single radionuclide in an idealized fracture intersecting a layered geologic medium. The new predictive capabilities imbedded in the derived solutions are expected to improve the confidence of the investigator performing sensitivity and uncertainty analyses based on this model.

In spite of some limitations (i.e., assumptions of zero dispersion in the fracture and infinite matrix diffusion), the new features embedded in the reported solutions allow one'to deal with layered media having piece-wise constant properties, as well as nonzero initial conditions, coupled with a realistic option of a periodically fluctuating decaying source. These solutions are useful for verifying the accuracy of numerical codes designed to solve similar problems and, above all, cost effective for performing sensitivity and uncertainty analyses of scenarios likely to be adopted in performance assessment investigations of potential nuclear waste repositories.

The model MULTFRAC was written in VAX FORTRAN Version 4.8 using the G floating point option (REAL*16). The computation was executed on a VAX 8700 under VMS Version 4.7. 


\subsection{PHYSICAL SYSTEM}

In order to model transport in a heterogeneous geologic media, a new analytical solution was developed for an idealized saturated fractured rock system composed of $\mathrm{n}$ number of parallel fractured rock layers. In this solution, each layer is assumed to be characterized by constant parameters.

In this instance, the geometry of the cross section of such a fractured rock network corresponds to a series of connected parallel line segments of different thicknesses (see Figure 1-1). Computationally viable closed form analytical solutions, which satisfy some of the requirements of Volume 2 of this report (i.e., the section dealing with the uncertainties issues), are developed after assuming that transport through the fractures is predominantly caused by advection, and that matrix diffusion may extend to infinity. In a single layer situation, the solution with zero dispersion in the fracture has been shown by Ahn et.al., (1985) to yield close enough results to the one with nonzero dispersion, contingent on it satisfying a . criterion which will be subsequently reported. Furthermore, the solution corresponding to the infinite rock matrix diffusion case (i.e., single fracture) was proven by Gureghian (1990a) to yield similar results to the finite diffusion one (i.e., parallel fractures), as long as the resulting Fourier number, a dimensionless parameter, was less than or equal to 0.1 .

With the assumption that migration within the fracture is solely by advection, the mass flux $F$, at the exit or entry face of a typical fracture layer $i$ of unit width, may be written as

$$
F_{i}^{ \pm}=\left[2 b_{i} u_{i} A_{i}\right]^{ \pm}
$$

where

$\begin{array}{ll}A_{i} & \text { is the concentration in the fracture }\left(\mathrm{ML}^{-3}\right) \\ u_{i} & \text { is the average fluid velocity in the fracture }\left(\mathrm{LT}^{-1}\right) \\ 2 b_{i} & \text { is the thickness of the fracture }(\mathrm{L}) \\ + & \text { is the symbol of an entry face } \\ - & \text { is the symbol of an exit face }\end{array}$

Note that in Eq. (1-1) it is assumed that transport occurs under isothermal conditions, the fluid density is constant, and that concentrations are small such that these do not affect the properties of the fluid or rock. In addition, the transfer of fluid through the fracture walls is assumed negligible.

At the interface of two consecutive fracture layers $i-1$ and $i$, the steady-state continuity equation for fluid is given by

$$
\left[u_{i-1} b_{i-1}\right]^{-}=\left[u_{i} b_{i}\right]^{+}
$$

and from the mass conservation relation of the solute we have

$$
F_{i-1}^{-}=F_{i}^{+}
$$

with the notion that the flow rate within a typical fracture segment is constant under steady-state flow conditions, substituting Eqs. (1-1) and (1-2) into Eq. (1-3) yields 


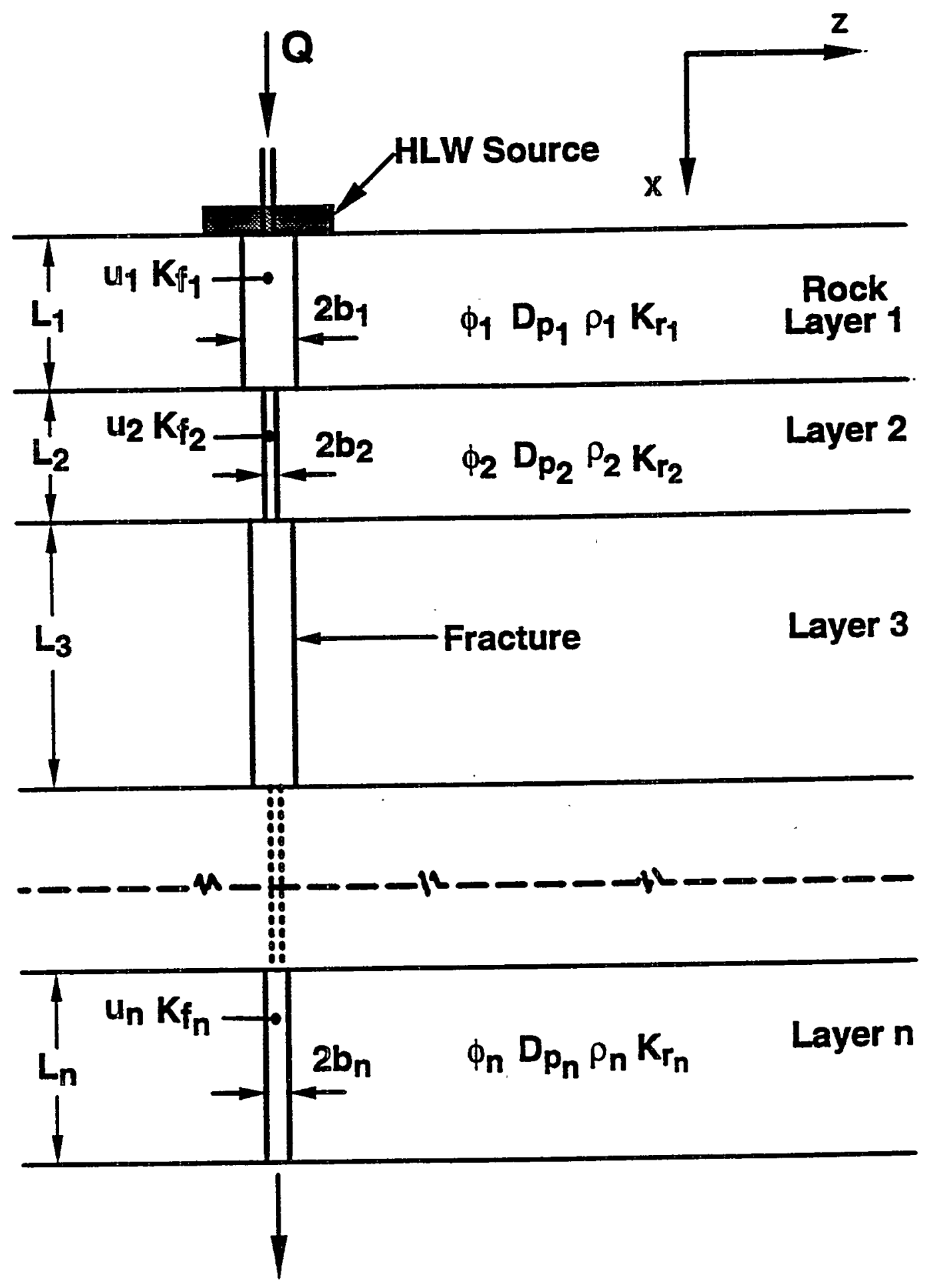

Figure 1-1. Description of migration pathways in a system of homogeneous layers of fractured rock 


$$
A_{i-1}^{-}=A_{i}^{+}
$$

which guarantees a continuity of concentration at the interface between fracture layers.

With the above requirements, the next step in the analytical process is to formulate the transport equations for the fractures and rock matrix. These applicable governing equations are presented and described in the subsequent sections. 


\section{ANALYTICAL CONCENTRATIONS AND CUMULATIVE MASS}

\subsection{GOVERNING EQUATIONS}

The governing one-dimensional equation describing the nondispersive movement of a typical nuclide in the ith layer of the fracture and rock matrix respectively (Neretnieks, 1980) is given by

(a) Fracture

$$
R_{i} \frac{\partial A_{i}}{\partial t}+u_{i} \frac{\partial A_{i}}{\partial x}+\lambda R_{i} A_{i}+\frac{J_{i}}{b_{i}}=0, \quad x_{i-1}<x \leq x_{i}
$$

(b) Rock Matrix

$$
\begin{gathered}
R_{i}^{\prime} \frac{\partial B_{i}}{\partial t}-D_{p i} \frac{\partial^{2} B_{i}}{\partial z^{2}}+\lambda R_{i}^{\prime} B_{i}=0 \\
t>0, x>0, z \geq b_{i}, i=1,2,3, \ldots, n
\end{gathered}
$$

where

$R_{i} \quad$ is the retardation in the fracture

$\lambda$ is the first-order rate constant for decay $\left(\mathrm{T}^{-1}\right)$

$\mathrm{J}_{\mathrm{i}} \quad$ is the diffusive rate of radionuclide at surface of fracture per unit area of fracture surface $\left(\mathrm{ML}^{-2} \mathrm{~T}^{-1}\right)$

$R_{i}^{\prime} \quad$ is the retardation factor in the rock matrix

$B_{i}$ is the concentration in the rock matrix $\left(\mathrm{ML}^{-3}\right)$

$D_{p i}$ is the pore diffusivity (i.e., $\left.D_{p i}=D_{d} g_{r i}\right)\left(L^{2} T^{-1}\right)$

$\mathrm{D}_{\mathrm{d}} \quad$ is the molecular diffusion of nuclide in water $\left(\mathrm{L}^{2} \mathrm{~T}^{-1}\right)$

$\mathrm{g}_{\tilde{\pi}} \quad$ is the geometric factor $\left(\delta_{\mathrm{di}} / \tau_{\mathrm{i}}^{2}\right)$ where

$\delta_{\mathrm{di}} \quad$ is constrictivity for diffusion $\left(\mathrm{L}^{\circ}\right)$

$\tau_{i} \quad$ is tortuosity of rock matrix $\left(\mathrm{L}^{\circ}\right)$

$\mathrm{x} \quad$ is the spatial coordinate in the fracture (L)

$z$ is the spatial coordinate in the rock matrix $(\mathrm{L})$

$t$ is the time (T)

i is the index related to the particular layer of fracture and surrounding rock matrix

$\mathrm{n}$ is the total number of fractured rock layers

A complete list of symbols and their meanings is given in Appendix F.

The diffusive rate of a nuclide into the ith layer of the rock matrix is assumed to obey Fick's law of diffusion written as 


$$
J_{i}=-\left.D_{e i} \frac{\partial B_{i}}{\partial z}\right|_{z=b_{l}}
$$

where $D_{\mathrm{c}}$ is the effective diffusivity in the typical section of the rock matrix (see Neretnieks, 1980) defined as

$$
D_{e i}=\phi_{i} D_{p i}
$$

where $\Phi_{\mathrm{i}} \mathrm{s}$ the rock porosity.

The retardation factor in the ith layer of the fracture $\left(\mathrm{R}_{\mathrm{i}}\right)$ and the rock matrix $\left(R_{i}^{l}\right)$, respectively (see Neretnieks et al., 1982), are given by:

$$
\begin{gathered}
R_{i}=1+\frac{K_{f i}}{b_{i}} \\
R_{i}^{\prime}=1+\left[\left(1-\Phi_{i}\right) / \Phi_{i}\right] \rho_{r i} K_{r i}
\end{gathered}
$$

where

$\rho_{\mathrm{r}} \quad$ is the bulk rock density $\left(\mathrm{ML}^{-3}\right)$

$\mathrm{K}_{\mathrm{fi}}$ is the surface distribution coefficient in the fracture (L)

$K_{r i}$ is the distribution coefficient in the rock matrix $\left(\mathrm{L}^{3} \mathrm{M}^{-1}\right)$

\subsubsection{Initial and Boundary Conditions}

The set of differential equations, Eqs. (2-1) and (2-2), are subject to the initial conditions:

$$
A_{i}(x, 0)=a_{1 i}+a_{2 i} e^{-\alpha_{1} x_{i}}, x_{i-1}<x \leq x_{i}
$$

where

$$
\begin{aligned}
& x_{i}=\left\{\begin{array}{l}
x, i=1 \\
x-x_{i-1}=x-\sum_{j=1}^{i-1} L_{j}, i>1
\end{array}\right. \\
& B_{i}(x, z, 0)=b_{1 i}, x_{i-1}<x \leq x_{i}, x>0, z \geq b_{i}
\end{aligned}
$$

where $a_{1 i}, a_{2}, b_{1 i}\left(\right.$ all $\left.M L^{-3}\right)$, and $\alpha_{i}\left(L^{-1}\right)$ are constant for each layer $i$ of the fracture rock system and time invariant, and independent of boundary conditions in the fracture and rock matrix. The boundary conditions in the fracture are given by

$$
A_{1}(0, t)=\tilde{A}(t), t>0
$$




$$
\frac{\partial A_{n}(\infty, t)}{\partial x}=0, t>0
$$

where $\tilde{A}(t)$ is the concentration at the source.

For the ith layer of the rock matrix, the corresponding boundary conditions are:

$$
\begin{gathered}
B_{i}\left(x, b_{i}, t\right)=A_{i}(x, t), t>0, x>0, x_{i-1}<x \leq x_{i} \\
\frac{\partial B_{i}(x, \infty, t)}{\partial z}=0, t>0, x>0, x_{i-1}<x \leq x_{i}
\end{gathered}
$$

\subsubsection{Concentrations of the Source}

For a step release mode, the concentration of a typical nuclide at the source $\tilde{A}(t)$ decaying either continuously or subject to periodical fluctuations are given by

(a) Exponentially Decaying Source

$$
\tilde{A}(t)=A^{0} e^{-\lambda t}, t>0 .
$$

(b) Periodically Fluctuating Source with Exponential Decay

$$
\tilde{A}(t)=A^{0} e^{-\lambda t}\left[v_{a}-v_{b} \sin \omega t\right], t>0
$$

where $\mathrm{A}^{0}$ is the concentration of the species at time equals zero, $\nu_{\mathrm{a}}$ and $\nu_{\mathrm{b}}$ are constants which sum corresponds to one, with $\nu_{b} \leq \nu_{a}$, and the time period $T_{p}$ of a complete cycle of variation is $2 \pi / \omega$. These source types are illustrated in Figure 2-1.

For a band release mode, the boundary condition at the fracture inlet may be written as

$$
A_{1}(0, t)=\tilde{A}(t)[U(t)-U(t-T)], t>0
$$

where $T$ is the leaching time and $U(t-T)$ is the Heaviside function defined as

$$
U(t-T)= \begin{cases}1, & t>T \\ \frac{1}{2}, & t=T \\ 0, & t<T\end{cases}
$$

The general form of the solutions for the band release mode in the ith layer of the fracture and rock matrix based on a boundary condition given by Eq. (2-16) and which uses the superposition method (Foglia et al. 1979) may be written as: 


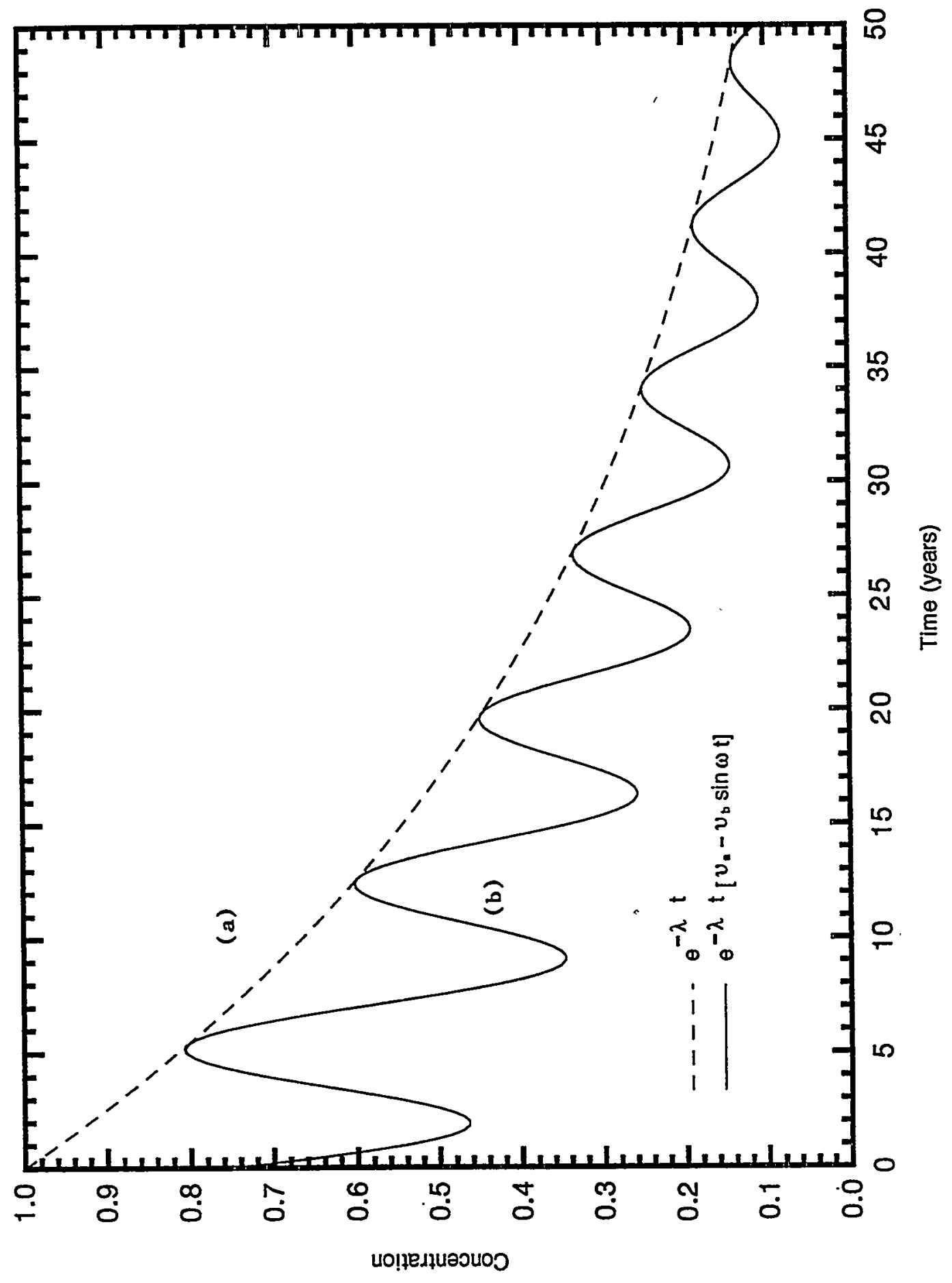

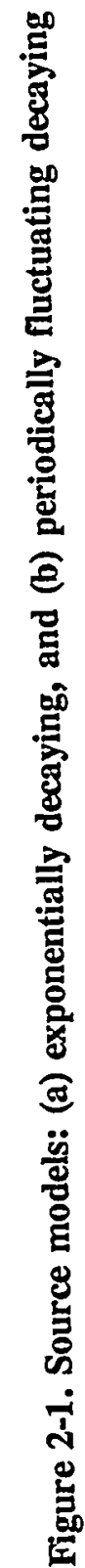




$$
\begin{gathered}
{ }^{b} A_{i}(x, t)=A_{i}\left(x, t ; \tilde{A}(t), A_{i}(x, 0), B_{i}(x, z, 0)\right) U(t) \\
-e^{-\lambda T_{i}} A_{i}(x, t-T ; \tilde{A}(t-T)) U(t-T) \\
{ }^{b} B_{i}(x, z, t)=B_{i}\left(x, z, t ; \tilde{A}(t), A_{i}(x, 0), B_{i}(x, z, 0)\right) U(t) \\
-e^{-\lambda T} B_{i}(x, z, t-T ; \tilde{A}(t-T)) U(t-T)
\end{gathered}
$$

where ${ }^{b} A_{i}(x, t)$ and ${ }^{b} B_{i}(x, z, t)$ correspond to the band-release solutions.

At the interface of two consecutive fracture layers we have:

$$
A_{i}(x, t)=A_{i-1}(x, t), \quad i>1
$$

\subsubsection{Solution of Transport Equations for the Rock Matrix and Fracture}

\subsubsection{Rock Matrix}

The Laplace transformation of Eq. (2-2), with its associated initial and boundary condition Eqs. (2-9), (2-12), and (2-13), may be written as

$$
D_{p i} \frac{d^{2} \overline{B_{i}}}{d z^{2}}-R_{i}^{\prime}(s+\lambda) \overline{B_{i}}=-R_{i}^{\prime} b_{1 i}
$$

with

$$
\bar{B}_{i}\left(x, b_{i}, s\right)=\bar{A}_{i}(x, s)
$$

and

$$
\frac{\partial \bar{B}_{i}(x, \infty, s)}{\partial z}=0
$$

where

$$
\bar{B}_{i}=\int_{0}^{\infty} B_{i} e^{-s t} d t
$$

The general solution of Eq. (2-21) yielding the concentration in the ith layer of the rock matrix is given by

$$
\overline{B_{i}}(x, z, s)=\left(\overline{A_{i}}-\frac{b_{1 i}}{s+\lambda}\right) e^{-r_{b_{1}}\left(z-b_{i}\right)}+\frac{b_{1 i}}{s+\lambda}
$$

with 


$$
r_{b i}=c_{r i}(s+\lambda)^{1 / 2}
$$

and

$$
c_{r i}=\left(R_{i}^{\prime} / D_{p i}\right)^{1 / 2}
$$

Note that the inverse Laplace transform of $B_{i}$ might be sought once $A_{i}$ is identified as shown in the subsequent section.

The Laplace transform of the diffusive flux Eq. (2-3) prevailing at the interface of the fracture and rock matrix within a typical layer $i$ is given by

$$
\bar{J}_{i}=-\phi_{i} D_{p i} \frac{\partial \bar{B}_{i}\left(x, b_{i} s\right)}{\partial z}=\phi_{i} D_{p i} r_{b i}\left(\bar{A}_{i}(x, s)-\frac{b_{1 i}}{s+\lambda}\right)
$$

Note that $r_{\mathrm{bi}}$ in Eq. (2-27) is given by Eq. (2-25).

\subsubsection{Fracture}

After proper substitution of the transform of the diffusive flux given by Eq. (2-27) into the Laplace transformation of Eq. (2-1)

$$
u_{i} \frac{\partial \bar{A}_{i}}{\partial x}+\left[R_{i}(s+\lambda)+c_{f i}(s+\lambda)^{1 / 2}\right] \bar{A}_{i}=R_{i}\left(a_{1 i}+a_{21} e^{-\alpha_{i} x_{j}}\right)+\frac{c_{f} b_{1 i}}{(s+\lambda)^{1 / 2}}
$$

with

$$
c_{f i}=\frac{\Phi_{i}}{b_{i}}\left(R_{i}^{\prime} D_{p i}\right)^{1 / 2}
$$

Note that the initial conditions given by Eq. (2-7) are included into Eq. (2-28) by virtue of Theorem (A.1-4) of Appendix A.

Similarly, the boundary conditions given by Eqs. (2-14) and (2-15) are obtained using the appropriate Laplace transforms given in Appendix A. Hence,

(a) Exponentially Decaying Source

$$
\bar{A}_{1}(0, s)=\frac{A^{0}}{s+\lambda}
$$

(b) Periodically Fluctuating Decaying Source

$$
\bar{A}_{1}(0, s)=A^{0}\left[\frac{v_{a}}{s+\lambda}-\frac{v_{b} \omega}{(s+\lambda)^{2}+\omega^{2}}\right]
$$




\section{First Layer}

The solution of Eq. (2-28) for the first layer (i.e., with i set to one), subject to its initial and boundary conditions given by Eqs. (2-7), (2-10), and (2-11), may be written as

$$
\bar{A}_{1}(x, s)=\left[\bar{F}_{0}-\bar{F}_{1}^{\prime}\right] e^{-r_{a l} \eta_{1}}+\bar{F}_{1}
$$

where

$$
\begin{aligned}
& \bar{F}_{0}=\bar{A}_{1}(0, s) \\
& \bar{F}_{i}^{\prime}=\sum_{j=1}^{3} f_{j i}(s) \\
& \bar{F}_{i}=\sum_{j=1}^{4} f_{j i}(s) \\
& j \neq 2
\end{aligned}
$$

with

$$
\begin{gathered}
f_{1 i}(s)=\frac{R_{i} a_{1 i}}{r_{a i}} \\
f_{2 i}(s)=\frac{R_{i} a_{2 i}}{r_{a i}-p_{i}} \\
f_{3 i}(s)=\frac{c_{f i} b_{i}}{r_{c i}} \\
f_{4 i}(x, s)=f_{2 i}(s) e^{-\alpha_{i} x_{i}}
\end{gathered}
$$

and

$$
\begin{gathered}
r_{a i}=R_{i}(s+\lambda)+c_{f i}(s+\lambda)^{1 / 2} \\
p_{i}=u_{i} \alpha_{i} \\
r_{c i}=r_{a i}(s+\lambda)^{1 / 2}
\end{gathered}
$$




$$
\begin{gathered}
\overline{\eta_{i}}=\frac{L_{i}}{u_{i}} \\
\eta_{i}=\frac{\chi_{i}}{u_{i}}
\end{gathered}
$$

Note that subscript $i$ refers to a typical layer and $\chi_{i}$ given by Eq. (2-8) corresponds to the distance within the portion of the fracture network stretching between the exit face of layer $i-1$ and the location of the observation point in layer $i$.

\section{Second Layer}

With the assumption that the upstream boundary condition of the second layer will correspond to the prevailing concentration at the downstream end of the first layer [see Eq. (1-4)], we may write

$$
\bar{A}_{2}(0, s)=\bar{A}_{1}\left(L_{1}, s\right)
$$

hence the solution of Eq. (2-28), related to the second fracture layer, may be written as

$$
\left.\overline{A_{2}}(x, s)=\overline{\left(\bar{F}_{0}\right.}-\overline{F_{1}^{\prime}}\right) e^{-\left[r_{a 1} \overline{\eta_{1}}+r_{a 2} \eta_{2}\right]}+\left(\overline{F_{1}}-\overline{F_{2}^{\prime}}\right) e^{-r_{a 2} \eta_{2}}+\overline{F_{2}}
$$

Nth Layer

Applying successively the above approach to the subsequent portions of the fracture layers, the solution of Eq. (2-28) corresponding to the nth layer may be written as

$$
\begin{aligned}
& \bar{A}_{n}(x, s)=\left[\bar{F}_{0}-\bar{F}_{1}^{\prime}\right] e^{-r_{a n} \eta_{n}} \prod_{i=1}^{n-1} e^{-r_{\alpha d} \bar{\eta}_{i}} \\
& +\sum_{i=2}^{n}\left(\bar{F}_{i-1}-\bar{F}_{i}^{\prime}\right) e^{-r_{a n} \eta_{n}} \prod_{j=i}^{n-1} e^{-r_{\alpha i} \bar{\eta}_{i}}+\bar{F}_{n}
\end{aligned}
$$

Using the following notations 


$$
\begin{gathered}
\theta_{m n}=\sum_{i=m}^{n-1} c_{f i} \bar{\eta}_{i}+c_{f n} \eta_{n} \\
\gamma_{m n}=\sum_{i=m}^{n-1} R_{i} \bar{\eta}_{i}+R_{n} \eta_{n} \\
g_{m n}(x, s)=e^{-r_{m a n} \eta_{n}} \prod_{i=m}^{n-1} e^{-r_{d i} \bar{\eta}_{i}}=e^{-\gamma_{m n}(s+\lambda)-\theta_{m}(s+\lambda)^{1 / 2}}
\end{gathered}
$$

the inverse Laplace transform of Eq. (2-38) yielding the closed form solution of the concentration of a typical species in the nth fracture layer is obtained by means of the various theorems and Laplace transforms reported in Table A.1 of Appendix A. This may be written as

$$
\begin{gathered}
A_{n}(x, t)=F_{0_{1 n}}(x, t)-\sum_{i=1}^{n} F_{i i n}^{\prime}(x, t)+ \\
\sum_{i=2}^{n} F_{i-1 i n}(x, t)+F_{n}(x, t)
\end{gathered}
$$

The various components of Eq. (2-42) correspond to

$$
\begin{gathered}
F_{0_{1 n}}(x, t)=L^{-1}\left[\bar{F}_{0} \cdot g_{1 n}(x, s)\right] \\
F_{i m n}^{\prime}(x, t)=\sum_{j=1}^{3} L^{-1} f_{j i}(s) \cdot g_{m n}(x, s) \\
F_{i m n}(x, t)=\sum_{j=1}^{3} L^{-1} f_{j i}(s) \cdot g_{m n}(s)+L^{-1} f_{4 i}(x, s) \cdot g_{m n}(x, s) \\
F_{n}(x, t)=\sum_{j=1}^{3} L^{-1} f_{j n}(s)+L^{-1} f_{4 n}(x, s)
\end{gathered}
$$

where $\bar{F}_{0}, f_{j}(s)$, and $g_{m n}(x, s)$ are given by Eqs. (2-33a), (2-34), and (2-41), respectively.

The components of functions $F_{01 n}(x, t), F_{i m n}^{\prime}(x, t), F_{i m n}(x, t)$, and $F_{n}(x, t)$ are now given by:

(a) Exponentially Decaying Source 


$$
F_{0_{1 n}}(x, t)=L^{-1}\left[\bar{F}_{0} \cdot g_{1 n}(x, s)\right]=A^{0} e^{-\lambda t} \operatorname{erfc}\left[\frac{\theta_{1 n}}{2\left(t-\gamma_{1 n}\right)^{1 / 2}}\right] U\left(t-\gamma_{1 n}\right)
$$

(b) Periodically Fluctuating Source with Exponential Decay

$$
\begin{gathered}
F_{0_{1 n}}(x, t)=L^{-1}\left|\bar{F}_{0} \cdot g_{1 n}(x, s)\right|=A^{0} e^{-\lambda t}\left[v_{a} e r f c\left[\frac{\theta_{1 n}}{2\left(t-\gamma_{1 n}\right)^{1 / 2}}\right]-\right. \\
\left.\frac{v_{b}}{4 i}\left[E\left(t-\gamma_{1 n}, \theta_{1 n}, i \omega\right)-E\left(t-\gamma_{1 n}, \theta_{1 n},-i \omega\right)\right]\right] U\left(t-\gamma_{1 n}\right)
\end{gathered}
$$

The reader may refer to Appendix A, Eq. (A.2-3) for a full definition of function E( $\cdot)$. Note that the second member of Eq. (2-44b), which includes a combination of exponential and complementary error functions with complex arguments, has been shown to yield a real number (see Appendix B, Section B.3). given by

The inverse Laplace transforms of the right-hand side of Eqs. (2-43b), (2-43c), and (2-43d) are

$$
\begin{aligned}
& L^{-1}\left[f_{1 i}(s) \cdot g_{m n}(x, s)\right]=e^{-\lambda t} a_{1 i} \exp \left[\frac{\theta_{m n} c_{f i}}{R_{i}}\right] \exp \left[\left(\frac{c_{f i}}{R_{i}}\right)^{2}\left(t-\gamma_{m n}\right)\right] \text {. } \\
& \operatorname{erfc}\left[\frac{c_{f i}}{R_{i}}\left(t-\gamma_{m n}\right)^{1 / 2}+\frac{\theta_{m n}}{2\left(t-\gamma_{m n}\right)^{1 / 2}}\right] U\left(t-\gamma_{m n}\right) \\
& L^{-1}\left[f_{2 i}(s) \cdot g_{m n}(x, s)\right]=\sum_{j=1}^{2}(-1)^{j} e^{-\lambda t} \frac{a_{2 i} \beta_{j i}}{q_{i}} \exp \left[\beta_{j i} \theta_{m n}+\beta_{j i}^{2}\left(t-\gamma_{m n}\right)\right] \\
& \operatorname{erfc}\left[\beta_{j i}\left(t-\gamma_{m n}\right)^{1 / 2}+\frac{\theta_{m n}}{2\left(t-\gamma_{m n}\right)^{1 / 2}}\right] U\left(t-\gamma_{m n}\right) \\
& L^{-1}\left[f_{3 i}(s) \cdot g_{m n}(x, s)\right]=e^{-\lambda t} b_{i}\left[\operatorname{erfc}\left(\frac{\theta_{m n}}{2\left(t-\gamma_{m n}\right)^{1 / 2}}\right)-\exp \left[\frac{\theta_{m n} c_{f i}}{R_{i}}\right]\right. \\
& \exp \left[\left(\frac{c_{f i}}{R_{i}}\right)^{2}\left(t-\gamma_{m n}\right)\right] \operatorname{erfc}\left[\frac{c_{f i}}{R_{i}}\left(t-\gamma_{m n}\right)^{1 / 2}+\frac{\theta_{m n}}{2\left(t-\gamma_{m n}\right)^{1 / 2}}\right] U\left(t-\gamma_{m n}\right) \\
& L^{-1}\left[f_{4 i}(x, s) \cdot g_{m n}(x, s)\right]=e^{-\alpha_{l} x_{i}} L^{-1}\left[f_{2 i}(s) \cdot g_{m n}(x, s)\right]
\end{aligned}
$$

with 


$$
\begin{gathered}
L^{-1} \cdot\left[f_{1 i}(s)\right]=e^{-\lambda t} a_{1 i} \exp \left[\left(\frac{c_{f i}}{R_{i}}\right)^{2} t\right] \operatorname{erfc}\left[\frac{c_{f i}}{R_{i}} t^{1 / 2}\right] \\
L^{-1}\left[f_{4 i}\left(x_{s} s\right)\right]=\sum_{j=1}^{2}(-1)^{i} \frac{a_{2 i} e^{-\alpha_{1} x_{i}} \beta_{j l}}{q_{i}} e^{-\left(\lambda-\beta_{j i}^{2} t t\right.} \operatorname{erfc}\left(\beta_{j i} t^{1 / 2}\right) \\
L^{-1}\left[f_{3 i}(s)\right]=e^{-\lambda t} b_{1 i}\left[1-\exp \left[\left(\frac{c_{f i}}{R_{i}}\right)^{2} t\right] \operatorname{erfc}\left[\frac{c_{f i}}{R_{i}} t^{1 / 2}\right]\right]
\end{gathered}
$$

with

$$
q_{i}=2\left[\left(\frac{c_{f i}}{2 R_{i}}\right)^{2}+\frac{p_{i}}{R_{i}}\right]^{1 / 2}
$$

and

$$
\beta_{j i}=\frac{c_{f i}}{2 R_{i}}+(-1)^{j} \frac{q_{i}}{2}
$$

Note that $\beta_{1 \mathrm{i}}$ and $\beta_{2 \mathrm{i}}$ have dimensions of $\mathrm{t}^{-1 / 2}$.

Grouping the components of $F_{i m n}^{\prime}(x, t), F_{i m n}(x, t)$, and $F_{n}(x, t)$, one may then write

$$
\begin{gathered}
F_{i m n}^{\prime}(x, t)={ }_{1} F_{i m n}(x, t)+{ }_{2} F_{i m n}(x, t) \\
F_{i m n}(x, t)={ }_{1} F_{i m n}(x, t)+e^{-\alpha_{i} x_{i}}{ }_{2} F_{i m n}(x, t)
\end{gathered}
$$

where

$$
\begin{gathered}
{ }_{1} F_{i m n}(x, t)=e^{-\lambda t}\left[b_{1 i} e r f c\left[\frac{\theta_{m n}}{2\left(t-\gamma_{m n}\right)^{1 / 2}}\right]+\left(a_{1 i}-b_{1 i}\right) \exp \left[\frac{\theta_{m n} c_{f i}}{R_{i}}\right] .\right. \\
\left.\exp \left[\left(\frac{c_{f i}}{R_{i}}\right)^{2}\left(t-\gamma_{m n}\right)\right] \operatorname{erfc}\left[\frac{c_{f i}}{R_{i}}\left(t-\gamma_{m n}\right)^{1 / 2}+\frac{\theta_{m n}}{2\left(t-\gamma_{m n}\right)^{1 / 2}}\right]\right] U\left(t-\gamma_{m n}\right)
\end{gathered}
$$

and 


$$
\begin{gathered}
{ }_{2} F_{i m n}(x, t)=e^{-\lambda t} \sum_{j=1}^{2}(-1)^{j} \frac{a_{2 i} \beta_{j i}}{q_{i}} \exp \left[\beta_{j i} \theta_{m n}+\beta_{j i}^{2}\left(t-\gamma_{m n}\right)\right] \\
\quad \operatorname{erfc}\left[\beta_{j i}\left(t-\gamma_{m n}\right)^{1 / 2}+\frac{\theta_{m n}}{2\left(t-\gamma_{m n}\right)^{1 / 2}}\right] U\left(t-\gamma_{m n}\right) \\
F_{n}(x, t)=\sum_{i=1}^{2}(-1)^{i} \frac{a_{2 n} \beta_{i n} e^{-\alpha_{n} x_{n}}}{q_{n}} e^{-\left(\lambda-\beta_{m n}^{2}\right) t} \operatorname{erfc}\left(\beta_{i n} t^{1 / 2}\right)+ \\
e^{-\lambda t}\left[b_{1 n}+\left(a_{1 n}-b_{1 n}\right) \exp \left[\left(\frac{\left.c_{f n}\right)^{2}}{R_{n}}\right)^{t}\right] \operatorname{erfc}\left(\frac{c_{f n}}{R_{n}} t^{1 / 2}\right)\right]
\end{gathered}
$$

Note that the evaluation of expressions involving products of exponential and complementary error functions are presented in Appendix B.

\subsubsection{Rock Matrix}

Substitution of Eq. (2-38) in Eq. (2-24) gives the Laplace transform solution of the concentration in the nth layer of the rock matrix

$$
\begin{aligned}
\bar{B}_{n}(x, z, s)=\left[\overline{F_{0}}\right. & \left.-\overline{F_{1}^{\prime}}\right] e^{-\left[r_{a n} \eta_{z}+r_{b x}\left(z-b_{k}\right)\right]} \prod_{i=1}^{n-1} e^{-r_{a l} \bar{\eta}_{i}}+ \\
& \sum_{i=2}^{n}\left(\bar{F}_{i-1}-\bar{F}_{i}^{\prime}\right) e^{-\left[r_{a n} \eta_{n}+r_{b n}\left(z-b_{n}\right)\right]} \prod_{j=i}^{n-1} e^{-r_{a l} \bar{\eta}_{i}}+ \\
& \bar{F}_{n} e^{-r_{b n}\left(z-b_{n}\right)}+\frac{b_{1 n}}{s+\lambda}\left(1-e^{-r_{b n}\left(z-b_{n}\right)}\right)
\end{aligned}
$$

The inverse Laplace transform of Eq. (2-54), yielding the closed form solution of the concentration in the nth layer of the rock matrix, is then obtained by means of the various theorems and Laplace transforms reported in Appendix A. This may be written as

$$
\begin{array}{r}
B_{n}(x, z, t)=G_{0_{1 n}}(x, z, t)-\sum_{i=1}^{n} G_{i i n}^{\prime}(x, z, t)+ \\
\sum_{i=2}^{n} G_{i-1 i n}(x, z, t)+G_{n}(x, z, t)
\end{array}
$$

The components of functions $\mathrm{G}_{\mathrm{o}_{\mathrm{ln}}}(\mathrm{x}, \mathrm{z}, \mathrm{t}), \mathrm{G}_{\mathrm{imn}}^{\prime}(\mathrm{x}, \mathrm{z}, \mathrm{t}), \mathrm{G}_{\mathrm{imn}}^{\prime}(\mathrm{x}, \mathrm{z}, \mathrm{t})$, and $\mathrm{G}_{\mathrm{n}}(\mathrm{x}, \mathrm{z}, \mathrm{t})$ are now given by: 
(a) Exponentially Decaying Source

$$
G_{0_{1 n}}(x, z, t)=A^{0} e^{-\lambda t} \operatorname{erfc}\left[\frac{\theta_{1 n}^{\prime}}{2\left(t-\gamma_{1 n}\right)^{1 / 2}}\right] U\left(t-\gamma_{1 n}\right)
$$

(b) Periodically Fluctuating Source with Exponential Decay

$$
\begin{gathered}
G_{0_{1 n}}(x, z, t)=L^{-1}\left|\vec{F}_{0} \cdot g_{1 n}(x, s)\right|=A^{0} e^{-\lambda t}\left[v_{a} \operatorname{erfc}\left[\frac{\theta_{1 n}^{\prime}}{2\left(t-\gamma_{1 n}\right)^{1 / 2}}\right]-\right. \\
\left.\frac{v_{b}}{4 i}\left[E\left(t-\gamma_{1 n}, \theta_{1 n}^{\prime}, i \omega\right)-E\left(t-\gamma_{1 n}, \theta^{\prime}{ }_{1 n},-i \omega\right)\right]\right] U\left(t-\gamma_{1 n}\right)
\end{gathered}
$$

where function $\mathrm{E}(\cdot)$ is given in Appendix A, Eq. (A.2-3).

$$
\begin{gathered}
G_{i m n}^{\prime}(x, z, t)={ }_{1} G_{i m n}^{\prime}(x, z, t)+{ }_{2} G_{i m n}^{\prime}(x, z, t) \\
G_{i m n}(x, z, t)={ }_{1} G_{i m n}^{\prime}(x, z, t)+e^{-\alpha_{i} x_{t}}{ }_{2} G_{i m n}^{\prime}(x, z, t)
\end{gathered}
$$

where

$$
\begin{aligned}
& { }_{1} G_{i m n}^{\prime}(x, t)=e^{-\lambda t}\left[b_{1 i} e r f c\left[\frac{\theta_{m n}^{\prime}}{2\left(t-\gamma_{m n}\right)^{1 / 2}}\right]+\left(a_{1 i}-b_{1 i}\right) \exp \left[\frac{\theta_{m n}^{\prime} c_{f i}}{R_{i}}\right] .\right. \\
& \left.\exp \left[\left(\frac{c_{f i}}{R_{l}}\right)^{2}\left(t-\gamma_{m n}\right)\right] \operatorname{erfc}\left[\frac{c_{f i}}{R_{i}}\left(t-\gamma_{m n}\right)^{1 / 2}+\frac{\theta_{m n}^{\prime}}{2\left(t-\gamma_{m n}\right)^{1 / 2}}\right]\right] U\left(t-\gamma_{m n}\right) \\
& { }_{2} G_{i m n}^{\prime}(x, z, t)=e^{-\lambda t} \sum_{j=1}^{2}(-1)^{j} \frac{a_{2 i} \beta_{j i}}{q_{i}} \exp \left[\beta_{j i} \theta_{m n}^{\prime}+\beta_{j i}^{2}\left(t-, \gamma_{m n}\right)\right] \\
& \operatorname{erfc}\left[\beta_{j l}\left(t-\gamma_{m n}\right)^{1 / 2}+\frac{\theta_{m n}^{\prime}}{2\left(t-\gamma_{m n}\right)^{1 / 2}}\right] U\left(t-\gamma_{m n}\right)
\end{aligned}
$$




$$
\begin{gathered}
G_{n}(x, z, t)=e^{-\lambda t} \sum_{i=1}^{2}(-1)^{i} \frac{a_{2 n} \beta_{i n} e^{-\alpha_{n} x_{n}}}{q_{n}} \exp \left[\beta_{i n}^{2} t+\beta_{i n} c_{r n}\left(z-b_{n}\right)\right] \\
\operatorname{erfc}\left[\beta_{i n} t^{1 / 2}+\frac{c_{r n}\left(z-b_{n}\right)}{2 t^{1 / 2}}\right]+e^{-\lambda t}\left[b_{1 n}+\left(a_{1 n}-b_{1 n}\right) \exp \left[c_{r n}\left(z-b_{n}\right) \frac{c_{f n}}{R_{n}}\right] .\right. \\
\left.\exp \left[\left(\frac{c_{f n}}{R_{n}}\right)^{2} t\right] \operatorname{erfc}\left[\frac{c_{f n}}{R_{n}} t^{1 / 2}+\frac{c_{r n}\left(z-b_{n}\right)}{2 t^{1 / 2}}\right]\right] \\
\theta_{m n}^{\prime}=\theta_{m n}+c_{r n}\left(z-b_{n}\right)
\end{gathered}
$$

\subsection{CUMULATIVE MASS}

The cumulative mass per unit width at any point within the fracture is given by

$$
\begin{gathered}
M(x, t)=\int_{0}^{t} u_{n} 2 b_{n} A_{n}(x, \tau) d \tau=u_{n} 2 b_{n}\left[Q_{0_{1 n}}(x, t)-\sum_{i=1}^{n} Q_{i i n}^{\prime}(x, t)\right. \\
\left.+\sum_{i=2}^{n} Q_{i-1 i n}(x, t)+Q_{n}(x, t)\right]
\end{gathered}
$$

where $A_{n}(x, t)$ the concentration in the fracture is given by Eq. (2-42). In Eq. (2-62), the components of

functions $Q_{0_{\text {la }}}(x, t), Q_{i \text { in }}^{\prime}(x, t), Q_{\text {iin }}(x, t)$, and $Q_{n}(x, t)$ are evaluated based on the various integrals derived in Appendix C, and are given by

(a) Exponentially Decaying Source

$$
Q_{0_{2 n}}(x, t)=\int_{\gamma_{1 n}}^{t} F_{0_{1 n}}(\tau) d \tau=A^{0} I_{1}\left(t, \lambda, \frac{\theta_{1 n}}{2}, \gamma_{1 n}\right) U\left(t-\gamma_{1 n}\right)
$$

(b) Periodically Fluctuating Source with Exponential Decay

$$
\begin{gathered}
Q_{0_{1 n}}(x, t)=\int_{\gamma_{1 n}}^{t} F_{0_{1 n}}(\tau) d \tau= \\
A^{0}\left[\nu_{a} I_{1}\left(t, \lambda, \frac{\theta_{1 n}}{2}, \gamma_{1 n}\right)-v_{b} \omega I_{4}\left(t, \theta_{1 n}, i \omega, \lambda, \gamma_{1 n}\right)\right] U\left(t-\gamma_{1 n}\right)
\end{gathered}
$$




$$
\begin{aligned}
& Q_{i m n}^{\prime}(x, t)=\int_{\gamma_{m n}}^{t} F_{i m n}^{\prime}(x, \tau) d \tau={ }_{1} Q_{i m n}^{\prime}(x, t)+{ }_{2} Q_{i m n}^{\prime}(x, t) \\
& Q_{i m n}(x, t)=\int_{\gamma_{m m}}^{t} F_{i m n}(x, \tau) d \tau={ }_{1} Q_{i m n}^{\prime}(x, t)+e^{-\alpha_{i} x_{i}}{ }_{2} Q_{i m n}^{\prime}(x, t)
\end{aligned}
$$

where

$$
\begin{aligned}
& { }_{1} Q_{i m n}^{\prime}(x, t)=\int_{\gamma_{m s}}^{t}{ }_{1} H_{i m n}(x, \tau) d \tau=\left[b_{1 i} I_{1}\left(t, \lambda, \frac{\theta_{m n}}{2}, \gamma_{m n}\right)\right. \\
& \left.+\left(a_{1 i}-b_{1 i}\right) \exp \left[\frac{c_{f f}}{R_{i}}\left(\theta_{m n}-\frac{c_{f f} \gamma_{m n}}{R_{i}}\right)\right] I_{2}\left(t_{,}\left(\frac{c_{f i}}{R_{i}}\right)^{2}-\lambda, \frac{c_{f f}}{R_{i}}, \frac{\theta_{m n}}{2}, \gamma_{m n}\right)\right] U\left(t-\gamma_{m n}\right) \\
& { }_{2} Q_{i m n}^{\prime}(x, t)=\int_{\gamma_{m n}}^{s}{ }_{2} H_{i m n}(x, \tau) d \tau=\sum_{j=1}^{2}(-1)^{j} \frac{a_{2 i} \beta_{j i}}{q_{i}} \exp \left[\beta_{j i}\left(\theta_{m n}-\beta_{j i} \gamma_{m n}\right)\right] \\
& I_{2}\left(t,\left(\beta_{j i}^{2}-\lambda\right), \beta_{j i} \frac{\theta_{m n}}{2}, \gamma_{m n}\right) U\left(t-\gamma_{m n}\right) \\
& Q_{n}(x, t)=\int_{0}^{t} F_{n}(x, t)=\sum_{i=1}^{2}(-1)^{i} \frac{a_{2 n} \beta_{i n}}{q_{n}} e^{-\alpha_{n} x_{n}} I_{3}\left(0, t,\left(\beta_{i n}^{2}-\lambda\right), \beta_{i n}\right) \\
& +\left[\frac{b_{1 n}}{\lambda}\left(1-e^{-\lambda \eta}\right)+\left(a_{1 n}-b_{1 n}\right) I_{3}\left(0, t,\left(\left(\frac{c_{f n}}{R_{n}}\right)^{2}-\lambda\right), \frac{c_{f n}}{R_{n}}\right)\right]
\end{aligned}
$$

More explicitly, using the definitions of $I_{1}$ through $I_{4}$ reported in Appendix C, Eqs. (2-63) through (2-67) may be written as 
(a) Exponentially Decaying Source

$$
\begin{gathered}
Q_{0_{1 n}}(x, t)=A_{1}^{0}\left\{-\frac{e^{-\lambda t}}{\lambda} \operatorname{erfc}\left[\frac{\theta_{1 n}}{2\left(t-\gamma_{1 n}\right)^{1 / 2}}\right]+\right. \\
\frac{e^{-\lambda \gamma_{1 n}}}{2 \lambda}\left[e^{\theta_{12} \sqrt{\lambda}} e r f c\left[\frac{\theta_{1 n}}{2\left(t-\gamma_{1 n}\right)^{1 / 2}}+\sqrt{\lambda\left(t-\gamma_{1 n}\right)}\right]+\right. \\
\left.\left.e^{-\theta_{L \nu} \sqrt{\lambda}} \operatorname{erfc}\left[\frac{\theta_{1 n}}{2\left(t-\gamma_{1 n}\right)^{1 / 2}}-\sqrt{\lambda\left(t-\gamma_{1 n}\right)}\right]\right]\right\} U\left(t-\gamma_{1 n}\right)
\end{gathered}
$$

(2-68a)

2-16 
(b) Periodically Fluctuating Source with Exponential Decay

$$
\begin{gathered}
Q_{0_{1 n}}(x, t)=A^{0}\left[v _ { a } \left\{-\frac{e^{-\lambda t}}{\lambda} \operatorname{erfc}\left[\frac{\theta_{1 n}}{2\left(t-\gamma_{1 n}\right)^{1 / 2}}\right]+\right.\right. \\
\frac{e^{-\lambda \gamma_{1 n}}}{2 \lambda}\left[e^{\theta_{1 n} \sqrt{\lambda}} e r f c\left[\frac{\theta_{1 n}}{2\left(t-\gamma_{1 n}\right)^{1 / 2}}+\sqrt{\lambda\left(t-\gamma_{1 n}\right)}\right]+\right. \\
-v_{b} \omega\left\{-\frac{e^{-\lambda t}}{4\left(\lambda^{2}+\omega^{2}\right)}\left(\left[e^{-i \omega t} E\left(t-\gamma_{1 n}, \theta_{1 n}, i \omega\right)+e^{i \omega t} E\left(t-\gamma_{1 n}, \theta_{1 n},-i \omega\right)\right]\right.\right. \\
+\frac{\lambda}{i \omega}\left[e^{-i \omega t} E\left(t-\gamma_{1 n}, \theta_{1 n}, i \omega\right)-e^{i \omega t} E\left(t-\gamma_{1 n}, \theta_{1 n},-i \omega\right)\right] \\
\left.\left.e r f c\left[\frac{\theta_{1 n}}{2\left(t-\gamma_{1 n}\right)^{1 / 2}}-\sqrt{\lambda\left(t-\gamma_{1 n}\right)}\right]\right]\right\} \\
+e^{-\lambda \gamma_{1 n}}\left(\frac{\lambda \sin \left(\omega \gamma_{1 n}\right)+\omega \cos \left(\omega \gamma_{1 n}\right)}{2 \omega\left(\lambda^{2}-\omega^{2}\right)}\right) \cdot \\
\left.\left.+e^{-\theta_{1 n} \sqrt{\lambda}} e r f c\left(\frac{\theta_{1 n}}{2\left(t-\gamma_{1 n}\right)^{1 / 2}}-\sqrt{\lambda\left(t-\gamma_{1 n}\right)}\right)\right]\right\} U\left(t-\gamma_{1 n}\right) \\
{\left[e^{\theta_{1 n} \sqrt{\lambda}} \operatorname{erfc}\left(\frac{\theta_{1 n}}{2\left(t-\gamma_{1 n}\right)^{1 / 2}}+\sqrt{\lambda\left(t-\gamma_{1 n}\right)}\right)\right.}
\end{gathered}
$$

$(2-68 b)$

where functions $\mathrm{E}(\cdot)$ in Eq. (2-68b) are given by Eq. (A.2-3) of Appendix A, and:

2-17 


$$
\begin{aligned}
& { }_{1} Q^{\prime}{ }_{i m n}(x, t)=b_{11}\left\{-\frac{e^{-\lambda t}}{\lambda} \operatorname{erfc}\left[\frac{\theta_{m n}}{2\left(t-\bar{\gamma}_{m n}\right)^{1 / 2}}\right]+\right. \\
& \frac{e^{-\lambda Y_{m}}}{2 \lambda}\left[e^{\theta_{m a} \sqrt{\lambda}} e r f c\left[\frac{\theta_{m n}}{2\left(t-\gamma_{m n}\right)^{1 / 2}}+\sqrt{\lambda\left(t-\gamma_{m n}\right)}\right]+\right. \\
& \left.\left.e^{-\theta_{m} \sqrt{\lambda}} e r f c\left[\frac{\theta_{m n}}{2\left(t-\gamma_{1 n}\right)^{1 / 2}}-\sqrt{\lambda\left(t-\gamma_{m n}\right)}\right]\right]\right\} U\left(t-\gamma_{m n}\right) \\
& +\frac{\left(a_{1 i}-b_{1 i}\right)}{\left(\frac{c_{f}}{R_{i}}\right)^{2}-\lambda}\left\{\exp \left[\frac{c_{f i}}{R_{l}}\left(\theta_{m n}-\frac{c_{f} \gamma_{m n}}{R_{i}}\right)\right] \exp \left[\left(\left(\frac{c_{f i}}{R_{i}}\right)^{2}-\lambda\right) t\right] .\right. \\
& \operatorname{erfc}\left[\frac{\theta_{m n}}{2\left(t-\gamma_{m n}\right)^{1 / 2}}+\frac{c_{f i}}{R_{i}}\left(t-\gamma_{m n}\right)^{1 / 2}\right]- \\
& \frac{\exp \left(-\lambda \gamma_{m n}\right)}{2}\left[e^{\theta_{m n} \sqrt{\lambda}} e r f c\left[\frac{\theta_{m n}}{2\left(t-\gamma_{m n}\right)^{1 / 2}}+\sqrt{\lambda\left(t-\gamma_{m n}\right)}\right]\left(\frac{c_{f i}}{R_{i} \sqrt{\lambda}}+1\right)-\right. \\
& \left.\left.e^{-\theta_{m, 1} \sqrt{\lambda}} \operatorname{erfc}\left[\frac{\theta_{m n}}{2\left(t-\gamma_{m n}\right)^{1 / 2}}-\sqrt{\lambda\left(t-\gamma_{m n}\right)}\right]\left(\frac{c_{f i}}{R_{i} \sqrt{\lambda}}-1\right)\right]\right\} U\left(t-\gamma_{m n}\right)
\end{aligned}
$$

2-18 


$$
\begin{aligned}
& { }_{2} Q_{i m n}^{\prime}(x, t)=\sum_{j=1}^{2}(-1)^{j} a_{2 i} \frac{\beta_{j l}}{q_{i}}\left\{\exp \left[\beta_{j i}\left(\theta_{m n}-\beta_{j i} \gamma_{m n}\right)\right]\right. \\
& \frac{e^{\left(\beta_{A}^{2}-\lambda\right) t}}{\beta_{j i}^{2}-\lambda} \operatorname{erfc}\left[\beta_{j i}\left(t-\gamma_{m n}\right)^{1 / 2}+\frac{\theta_{m n}}{2\left(t-\gamma_{m n}\right)^{1 / 2}}\right] \\
& -\frac{\exp \left(-\lambda \gamma_{m n}\right)}{2\left(\beta_{j i}^{2}-\lambda\right)}\left[e^{\theta_{m i} \sqrt{\lambda}} e r f c\left[\frac{\theta_{m n}}{2\left(t-\gamma_{m n}\right)^{1 / 2}}+\sqrt{\lambda\left(t-\gamma_{m n}\right)}\right]\left(\frac{\beta_{j i}}{\sqrt{\lambda}}+1\right)-\right. \\
& \left.\left.e^{-\theta_{m n} \sqrt{\lambda}} \operatorname{erfc}\left[\frac{\theta_{m n}}{2\left(t-\gamma_{m n}\right)^{1 / 2}}-\sqrt{\lambda\left(t-\gamma_{m n}\right)}\right]\left(\frac{\beta_{j i}}{\sqrt{\lambda}}-1\right)\right]\right\} U\left(t-\gamma_{m n}\right) \\
& Q_{n}(x, t)=\sum_{j=1}^{2}(-1)^{j} \frac{a_{2 n} \beta_{j n}}{q_{n}} e^{-\alpha_{n} x_{n}} \frac{1}{\left(\beta_{j n}^{2}-\lambda\right)}\left[e^{\left(\beta_{j n}^{2}-\lambda\right) t} \operatorname{erfc}\left(\beta_{j n} \sqrt{t}\right)+\right. \\
& \left.\frac{\beta_{j n}}{\sqrt{\lambda}} \operatorname{erf}\left[(\lambda t)^{1 / 2}\right]-1\right] \text {. } \\
& +\frac{b_{1 n}}{\lambda}\left(1-e^{-\lambda t}\right)+\frac{\left(a_{1 n}-b_{1 n}\right)}{\left[\left(\frac{c_{f n}}{R_{n}}\right)^{2}-\lambda\right]}\left\{\exp \left[\left(\left(\frac{c_{f n}}{R_{n}}\right)^{2}-\lambda\right) t\right] .\right. \\
& \left.\left.\operatorname{erfc}\left[\frac{c_{f_{n}}}{R_{n}} t^{1 / 2}\right]+\frac{c_{f n}}{\sqrt{\lambda} R_{n}} \operatorname{erf}\left[(\lambda t)^{1 / 2}\right]-1\right]\right\}
\end{aligned}
$$

Note that when the exponential term in the model describing the initial concentration distribution in the fracture [see Eq. (2-7)] is taken into account, overflow problems are likely to be encountered when the value of the time parameter becomes excessively large. This state of affairs is inherent to the presence of parameter $\beta_{\mathrm{ij}}$ [see, for example, Eq. (2-52)], which by virtue of being negative [i.e., when subscript i corresponds to 1, see Eq. (2-48)], tends to freeze the complementary function at a constant value of approximately 2 (i.e., when its argument becomes less than or equal to -3 ), while the exponential term will increase positively with increasing values of time. To mitigate the inherent overflow problem, the solution is optimized through an iterative process intended to estimate an acceptable upper limit for the 
magnitude of the exponential argument. Consequently, exponential terms with $\beta_{1 j}$ in their list of arguments are ignored (i.e., set automatically to zero) when the preset limit is exceeded. Computationally, this is achieved after assigning the significant absolute limit of the exponential argument, initially to a value corresponding to 30 , the latter affecting exclusively the specific components of the solutions which include parameter $\beta_{i j}$. The computation is reiterated after halving the value of the exponential argument, and the absolute relative error in the computed results is subsequently estimated. This process is continued until, in two successive iterations, the preset convergence criteria (i.e., 1 percent relative error) is said to be satisfied. For the test cases reported herein, a maximum of three iterations were proven sufficient to provide an optimized value of the exponential argument and yield a highly accurate solution.

\subsection{DISCUSSIONS OF RESULTS}

The analytical solutions presented in this section of the report were verified by comparison with three approximate methods of Laplace inversion integral as proposed by Talbot (1979), Durbin (1974), as modified by Piessens and Huysmans (1984) and Stefhest (1970). All three methods apply to the case where the source term corresponds to a continuous exponentially decaying one, in which instance the required inversion of the Laplace transform is strictly confined to the real domain. However, when a periodically fluctuating and decaying source term is adopted, then only the first two of these methods are useful for evaluating the Laplace transform inversion in the complex domain. Note that in the case of Stefhest's algorithm, 36 summation points were found to produce almost oscillation-free solutions.

As far as the calculation of the approximate solution related to the cumulative mass (i.e., the time integrated solution of the concentration at a typical point along the longitudinal axis of the fracture) is concerned, this is performed by numerically integrating solutions of the Laplace-transformed equation of the concentration in the fracture. This integration is performed using a composite Gauss-Legendre quadrature scheme, where 40 integration points were found adequate to yield a convergent quadrature for the investigated test cases.

The two test cases reported subsequently refer to the one-dimensional (1D) transport of two radionuclides: $\mathrm{Np}-237$ (i.e., long half-life) and $\mathrm{Cm}-245$ (short half-life), in a heterogeneous saturated fractured rock system composed of five layers (the last extending to infinity), with piecewise constant parameters. In the first test case, the imposed source term corresponds to an exponentially decaying function [see Eq. (2-14)]. This is substituted by a periodically fluctuating and decaying one [see Eq. (215)] in the second, respectively. In both cases, the steady flow rate of water per unit width of fracture corresponds to $0.1 \mathrm{~m}^{2} / \mathrm{yr}$. Two types of solute release modes at the source were investigated, namely step and band. Note that the flow domain in both fracture and rock layers are assigned nonzero initial concentrations [see Eqs. (2-7) and (2-9)].

\subsubsection{Case 1 Results}

This test case examines the spatial and temporal variation of the concentration of Np-237, as well as the cumulative release of mass from the fracture. In addition, the spatial variation of the concentration in the rock matrix is also investigated. The input data pertaining to this test case is presented in Table 2-1. 
Figure 2-2(a) shows the spatial relative concentration profiles (i.e., $A / A^{\circ}$ ) of $\mathrm{Np}-237$ calculated in the fracture layers at simulation times of $10^{3}, 5 \times 10^{3}$ and $5 \times 10^{4}$ years. A comparison of our results with the ones obtained from the three numerical inversion algorithms [see Tables 2-2(a) through 2-2(c)] shows that these are in excellent agreement. Note that in this test case, the observation times were selected in a manner to allow an evaluation of the accuracy of our solution for both release modes of the radionuclide at the source. It may be added that in the case of the intermediate observation time, the source strength is reduced by half from its original value [see Eq. (2-17)].

Figure 2-2(b) shows the temporal relative concentration of Np-237 observed in the fracture at three different observation points: 100,200 , and 500 meters downstream from the source, located in the second, third, and fifth layer, respectively, for a band release. Up to the leaching time of $5 \times 10^{3}$ years, the shape of the profiles bears a close similarity to those of a step release. Past the leaching time, the relative concentrations profiles show a rapid change of their gradient from positive to negative and concentrations decrease with time to a value close to the initial concentrations of the various fracture layers of interest. A comparison of our results with the three numerical ones [see Tables 2-3(a) through 2-3(c)] shows that with the exception of a portion of the results yielded by Talbot's solution, these are in excellent agreement. Note that in this instance, the adoption of three recommended ${ }^{\dagger}$ values of the constants required by Talbot's algorithm seems to have restricted the accuracy of the latter to simulation times greater than 30, 80, and 100 years. Therefore, it appears that the three constants in Talbot's algorithm are correlated with the independent variables, rendering their selection problem-dependent.

Figure 2-2(c) depicts the time-dependent evolution of the cumulative mass (per unit width of the fracture) profile $\mathrm{Np}-237$ at three different observation points in the fracture, as in the previous example. Because of its computational viability, Stefhest's algorithm is selected from this point on as the benchmark. A comparison of our analytical solution results with those yielded by Stefhest's solution [see Tables 2-4(a) through 2-4(c)] indicates excellent agreement. Note that all three profiles tend to become asymptotic to three specific values of the cumulative mass namely, $4.903 \times 10^{2}, 4.7 \times 10^{2}$, and $4.309 \times 10^{2}(\mathrm{UA} / \mathrm{m})^{\mathrm{H}}$. These values may be easily computed from Eq. (2-62) after setting the value of the independent variable $t$ equal to infinity.

Figure 2-2(d) shows the relative concentration (i.e., $B / A^{\circ}$ ) profiles in the rock matrix at three positions downstream from the source (i.e., $x=100 \mathrm{~m}, 200 \mathrm{~m}$, and $500 \mathrm{~m}$ ) for a step release. Comparison of our analytical results against those yielded by the Stefhest's solution method [see Tables 2-5(a) through 2-5(c)] indicates an excellent agreement. Note that at their downstream end, all three profiles tend to become asymptotic to a concentration value slightly in excess of the residual concentration prevailing in their respective layers.

Figure 2-2(e) shows the relative concentration profiles in the rock matrix at three positions downstream from the source (i.e., $x=100 \mathrm{~m}, 200 \mathrm{~m}$, and $500 \mathrm{~m}$ ) and for a simulation time of $5 \times 10^{4}$ years, for a band release with a leaching time corresponding to $5 \times 10^{3}$ years. Past the leaching time, the contaminant in a typical rock layer close to the source would begin to exhibit a higher concentration than in the fracture, which would then initiate its diffusion back into the fracture. Indeed a reference to Figure 2-2(e) shows that the gradient of the concentration profiles at the fracture/rock

${ }^{\dagger}$ D. Hodgkinson, personal communication.

\# UA: Arbitrary Units of Activity/meter. 
interface tends to decrease with increasing distances from the source. As in the preceding case, results reported in Tables 2-6(a) through 2-6(c) show excellent agreement between the analytical and the numerical solutions. 
Table 2-1. Input parameters for Case 1 exponentially decaying source

\section{SPECIES}

$\mathrm{T}_{1 / 2}$

Release Mode:

Step

Band Leaching Time

$\mathrm{A}^{\circ}$

Q

$\nu_{\mathrm{a}}$

$\nu_{\mathrm{b}}$

$\mathrm{T}_{\mathrm{p}}$
$\underline{N p-237}$

$2.3 \times 10^{6} \mathrm{yr}$

NA

$5 \times 10^{3} \mathrm{yr}$

$1.0^{*}$

$0.1\left(\mathrm{~m}^{2} / \mathrm{yr}\right)$

NA

NA

NA

\begin{tabular}{|c|c|c|c|c|}
\hline \hline Layer & $\mathbf{L}(\mathbf{m})$ & $\mathbf{b}(\mathbf{m})$ & $\mathbf{u}(\mathbf{m} / \mathbf{y r})$ & $\Phi$ \\
\hline \hline 1 & 50.0 & $5.0 \mathrm{E}-03$ & 10.0 & 0.01 \\
\hline 2 & 75.0 & $4.0 \mathrm{E}-03$ & 12.5 & 0.008 \\
\hline 3 & 100.0 & $3.0 \mathrm{E}-03$ & 16.666 & 0.006 \\
\hline 4 & 150.0 & $2.0 \mathrm{E}-03$ & 25.0 & 0.004 \\
\hline 5 & $\infty$ & $1.5 \mathrm{E}-03$ & 33.333 & 0.002 \\
\hline \hline
\end{tabular}

\begin{tabular}{|c|c|c|c|c|}
\hline \hline Layer & $\rho\left(\mathrm{g} / \mathrm{cm}^{3}\right)$ & $\mathbf{D}_{\mathrm{p}}\left(\mathrm{m}^{2} / \mathrm{yr}\right)$ & $\mathbf{K}_{\mathrm{r}}(\mathrm{m})$ & $\mathbf{K}_{\mathbf{r}}\left(\mathrm{cm}^{3} / \mathrm{g}\right)$ \\
\hline \hline 1 & 2.0 & 0.01 & $5.0 \mathrm{E}-03$ & 0.5 \\
\hline 2 & 2.3 & 0.02 & $8.0 \mathrm{E}-03$ & 0.6978 \\
\hline 3 & 2.6 & 0.06 & $2.7 \mathrm{E}-02$ & 1.158 \\
\hline 4 & 2.65 & 0.05 & $1.0 \mathrm{E}-02$ & 1.059 \\
\hline 5 & 2.7 & 0.03 & $3.0 \mathrm{E}-03$ & 0.741 \\
\hline \hline
\end{tabular}


Table 2-1. Input parameters for Case 1 exponentially decaying source (Cont'd)

\begin{tabular}{|c|c|c|c|c|}
\hline \hline Layer & $\mathrm{a}_{\mathbf{1}}{ }^{*}$ & $\mathrm{a}_{\mathbf{2}}{ }^{*}$ & $\alpha\left(\mathrm{m}^{-1}\right)$ & $\mathbf{b}_{\mathbf{1}}{ }^{*}$ \\
\hline \hline 1 & $1.50 \mathrm{E}-04$ & $-0.50 \mathrm{E}-04$ & 0.02 & $1.00 \mathrm{E}-05$ \\
\hline 2 & $2.00 \mathrm{E}-04$ & $-0.25 \mathrm{E}-05$ & 0.02 & $1.75 \mathrm{E}-05$ \\
\hline 3 & $1.75 \mathrm{E}-04$ & $-0.20 \mathrm{E}-05$ & 0.02 & $1.25 \mathrm{E}-05$ \\
\hline 4 & $2.00 \mathrm{E}-04$ & $-0.15 \mathrm{E}-05$ & 0.02 & $1.05 \mathrm{E}-05$ \\
\hline 5 & $1.50 \mathrm{E}-04$ & $-0.20 \mathrm{E}-05$ & 0.02 & $1.05 \mathrm{E}-05$ \\
\hline \hline
\end{tabular}

- (arbitrary units of activity $\left./ \mathrm{L}^{3}\right)$ 


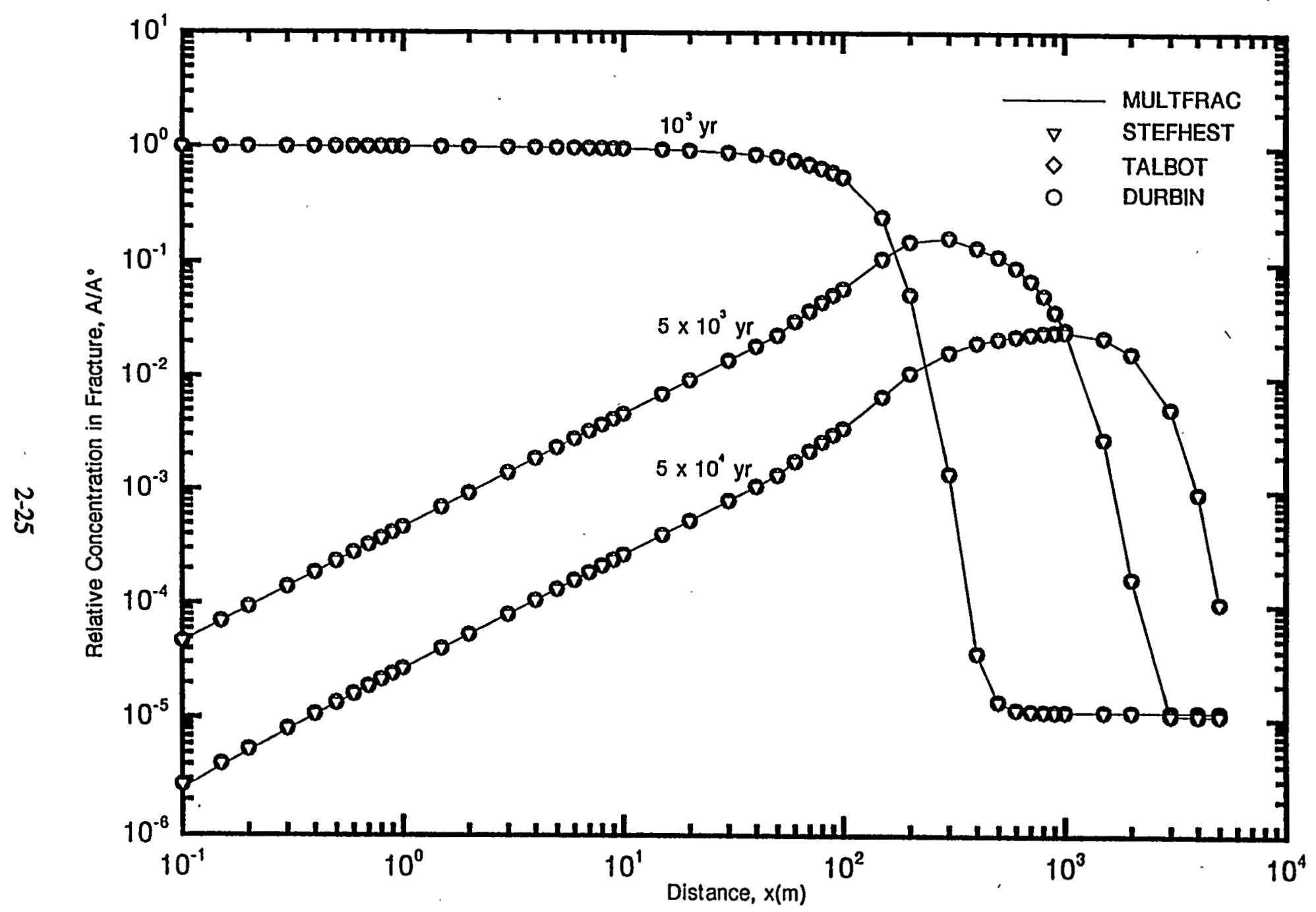

Figure 2-2(a). Relative concentration of $\mathrm{Np}-237$ versus distance in the fracture at different times $t=1,000,5,000$, and 50,000 years (Exponentially decaying source and step and band release mode) 
Table 2-2(a). Case 1 Results: Concentration of $\mathrm{Np}-237$ in the fracture at time $t=1,000$ years (Exponentially decaying source and step release mode)

\begin{tabular}{|c|c|c|c|c|}
\hline DISTANCE (m) & MULTFRAC & STEFHEST & TALBOT & DURBIN \\
\hline $1.000 \mathrm{E}-01$ & 9.993E-01 & $9.993 \mathrm{E}-01$ & 9.993E-01 & $9.993 \mathrm{E}-01$ \\
\hline $1.500 \mathrm{E}-01$ & $9.992 \mathrm{E}-01$ & $9.992 \mathrm{E}-01$ & 9.992E-01 & 9.992E-01 \\
\hline $2.000 \mathrm{E}-01$ & 9.990E-01 & $9.990 \mathrm{E}-01$ & $9.990 \mathrm{E}-01$ & $9.990 \mathrm{E}-01$ \\
\hline $3.000 \mathrm{E}-01$ & $9.986 \mathrm{E}-01$ & $9.986 \mathrm{E}-01$ & $9.986 \mathrm{E}-01$ & $9.986 \mathrm{E}-01$ \\
\hline $4.000 \mathrm{E}-01$ & $9.983 \mathrm{E}-01$ & $9.983 \mathrm{E}-01$ & $9.983 \mathrm{E}-01$ & $9.983 \mathrm{E}-01$ \\
\hline $5.000 \mathrm{E}-01$ & $9.979 \mathrm{E}-01$ & $9.979 \mathrm{E}-01$ & $9.979 \mathrm{E}-01$ & $9.979 \mathrm{E}-01$ \\
\hline
\end{tabular}

Table 2-2(b). Case 1 Results: Concentration of $\mathrm{Np}-237$ in the fracture at time $\mathrm{t}=5,000$ years (Exponentially decaying source and band release mode)

\begin{tabular}{|c|c|c|c|c|}
\hline DISTANCE (m) & MULTFRAC & STEFHEST & TALBOT & DURBIN \\
\hline $1.000 \mathrm{E}-01$ & $4.612 \mathrm{E}-05$ & $4.660 \mathrm{E}-05$ & $4.660 \mathrm{E}-05$ & $4.660 \mathrm{E}-05$ \\
\hline $1.500 \mathrm{E}-01$ & $6.943 \mathrm{E}-05$ & $6.990 \mathrm{E}-05$ & $6.990 \mathrm{E}-05$ & $6.990 \mathrm{E}-05$ \\
\hline $2.000 \mathrm{E}-01$ & 9.273E-05 & $9.320 \mathrm{E}-05$ & $9.320 \mathrm{E}-05$ & $9.320 \mathrm{E}-05$ \\
\hline $3.000 \mathrm{E}-01$ & $1.393 \mathrm{E}-04$ & $1.398 \mathrm{E}-04$ & $1.398 \mathrm{E}-04$ & $1.398 \mathrm{E}-04$ \\
\hline $4.000 \mathrm{E}-01$ & $1.859 \mathrm{E}-04$ & $1.864 \mathrm{E}-04$ & $1.864 \mathrm{E}-04$ & $1.864 \mathrm{E}-04$ \\
\hline $5.000 \mathrm{E}-01$ & $2.325 \mathrm{E}-04$ & $2.330 \mathrm{E}-04$ & $2.330 \mathrm{E}-04$ & 2.330E-04 \\
\hline
\end{tabular}

Table 2-2(c). Case 1 Results: Concentration of $\mathrm{Np}-237$ in the fracture at time $\mathrm{t}=50,000$ years (Exponentially decaying source and step release mode)

\begin{tabular}{|c|c|c|c|c|}
\hline DISTANCE (m) & MULTFRAC & STEFHEST & TALBOT & DURBIN \\
\hline $1.000 \mathrm{E}-01$ & $2.479 \mathrm{E}-06$ & $2.689 \mathrm{E}-06$ & $2.689 \mathrm{E}-06$ & $2.689 \mathrm{E}-06$ \\
\hline $1.500 \mathrm{E}-01$ & $3.824 \mathrm{E}-06$ & $4.034 \mathrm{E}-06$ & $4.034 \mathrm{E}-06$ & $4.034 \mathrm{E}-06$ \\
\hline $2.000 \mathrm{E}-01$ & $5.169 \mathrm{E}-06$ & $5.379 \mathrm{E}-06$ & $5.379 \mathrm{E}-06$ & 5.379E-06 \\
\hline $3.000 \mathrm{E}-01$ & $7.859 \mathrm{E}-06$ & $8.068 \mathrm{E}-06$ & $8.068 \mathrm{E}-06$ & $8.068 \mathrm{E}-06$ \\
\hline $4.000 \mathrm{E}-01$ & $1.055 \mathrm{E}-05$ & $1.076 \mathrm{E}-05$ & $1.076 \mathrm{E}-05$ & $1.076 \mathrm{E}-05$ \\
\hline $5.000 \mathrm{E}-01$ & $1.324 \mathrm{E}-05$ & $1.345 \mathrm{E}-05$ & $1.345 \mathrm{E}-05$ & $1.345 \mathrm{E}-05$ \\
\hline
\end{tabular}

Extracted data; complete data run is provided in microfiche form at the back of this report 


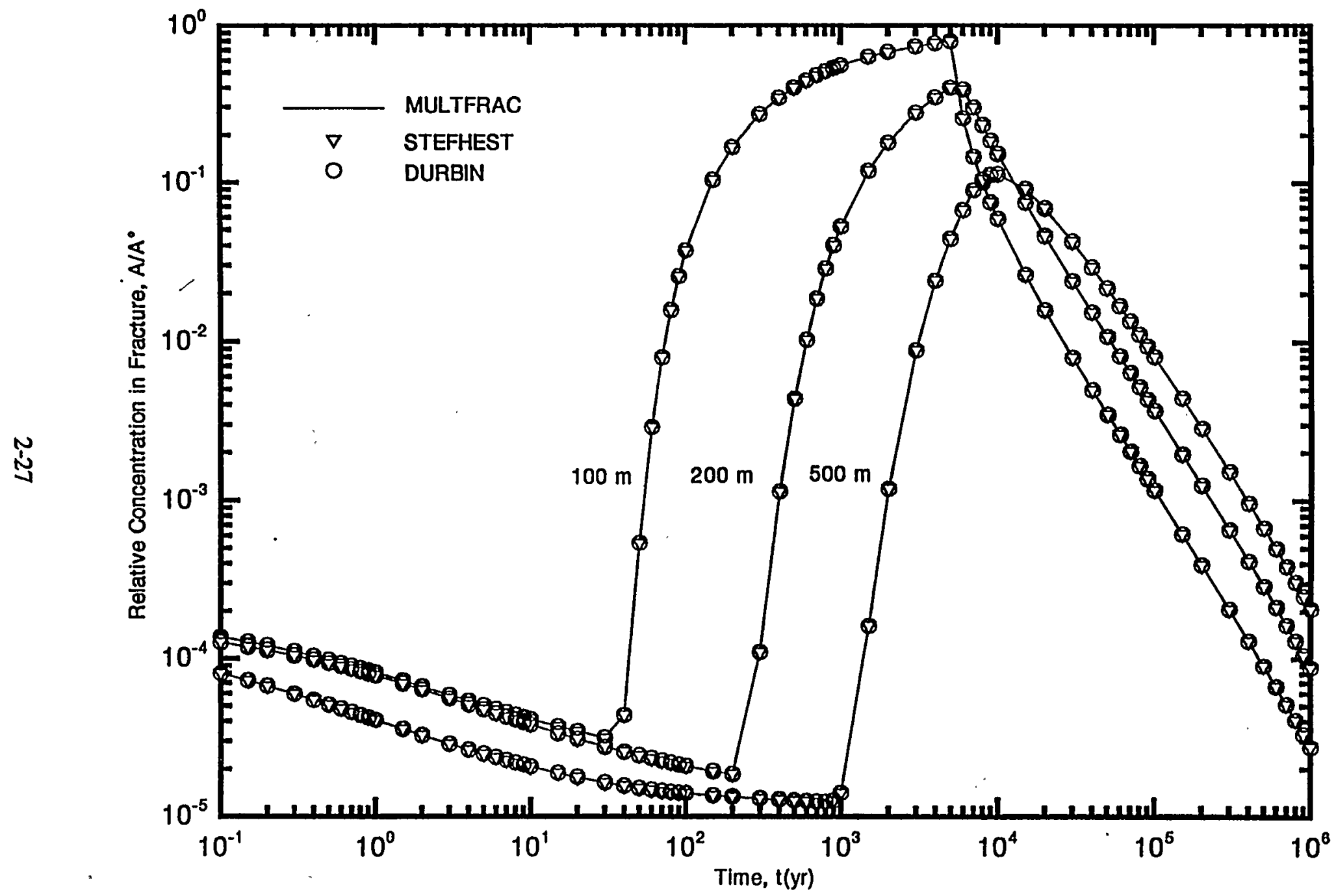

Figure 2-2(b). Relative concentration of $\mathrm{Np}$-237 in the fracture versus time at different positions $\mathrm{x}=100,200$, and 500 meters (Exponentially decaying source and band release mode) 
Table 2-3(a). Case 1 Results: Concentration of $\mathrm{Np}-237$ in the fracture Layer 2, at distance $\mathrm{x}=100$ meters (Exponentially decaying source and step release mode)

\begin{tabular}{|c|c|c|c|c|}
\hline TIME (yr) & MULTFRAC & STEFHEST & TALBOT & DURBIN \\
\hline $1.000 \mathrm{E}-01$ & $1.370 \mathrm{E}-04$ & $1.370 \mathrm{E}-04$ & $3.453+248$ & $1.370 \mathrm{E}-04$ \\
\hline $1.500 \mathrm{E}-01$ & $1.278 \mathrm{E}-04$ & $1.278 \mathrm{E}-04$ & $-1.309+258$ & $1.278 \mathrm{E}-04$ \\
\hline $2.000 \mathrm{E}-01$ & $1.209 \mathrm{E}-04$ & $1.209 \mathrm{E}-04$ & $-1.006+263$ & $1.209 \mathrm{E}-04$ \\
\hline $3.000 \mathrm{E}-01$ & $1.109 \mathrm{E}-04$ & $1.109 \mathrm{E}-04$ & $-1.457+232$ & $1.109 \mathrm{E}-04$ \\
\hline $4.000 \mathrm{E}-01$ & $1.037 \mathrm{E}-04$ & $1.037 \mathrm{E}-04$ & $-3.245+266$ & $1.037 \mathrm{E}-04$ \\
\hline $5.000 \mathrm{E}-01$ & $9.806 \mathrm{E}-05$ & $9.806 \mathrm{E}-05$ & $2.308+235$ & $9.807 \mathrm{E}-05$ \\
\hline
\end{tabular}

Table 2-3(b). Case 1 Results: Concentration of Np-237 in the fracture Layer 3, at distance $\mathrm{x}=\mathbf{2 0 0}$ meters (Exponentially decaying source and band release mode)

\begin{tabular}{|c|c|c|c|c|}
\hline TIME (yr) & MULTFRAC & STEFHEST & TALBOT & DURBIN \\
\hline $1.000 \mathrm{E}-01$ & $1.266 \mathrm{E}-04$ & $1.266 \mathrm{E}-04$ & $3.773+263$ & $1.266 \mathrm{E}-04$ \\
\hline $1.500 \mathrm{E}-01$ & $1.189 \mathrm{E}-04$ & $1.189 \mathrm{E}-04$ & $-2.483+248$ & $1.189 \mathrm{E}-04$ \\
\hline $2.000 \mathrm{E}-01$ & $1.131 \mathrm{E}-04$ & $1.131 \mathrm{E}-04$ & $-6.383+224$ & $1.131 \mathrm{E}-04$ \\
\hline $3.000 \mathrm{E}-01$ & $1.045 \mathrm{E}-04$ & $1.045 \mathrm{E}-04$ & $1.549+232$ & $1.045 \mathrm{E}-04$ \\
\hline $4.000 \mathrm{E}-01$ & $9.819 \mathrm{E}-05$ & $9.819 \mathrm{E}-05$ & $-3.547+269$ & $9.821 \mathrm{E}-05$ \\
\hline $5.000 \mathrm{E}-01$ & $9.321 \mathrm{E}-05$ & $9.321 \mathrm{E}-05$ & $-1.915+271$ & $9.323 \mathrm{E}-05$ \\
\hline
\end{tabular}

Table 2-3(c). Case 1 Results: Concentration of $\mathrm{Np}-237$ in the fracture Layer 5, at distance $\mathbf{x}=\mathbf{5 0 0}$ meters (Exponentially decaying source and band release mode)

\begin{tabular}{|c|c|c|c|c|}
\hline TIME (yr) & MULTFRAC & STEFHEST & TALBOT & DURBIN \\
\hline $1.000 \mathrm{E}-01$ & $8.014 \mathrm{E}-05$ & $8.014 \mathrm{E}-05$ & $1.068+242$ & $8.016 \mathrm{E}-05$ \\
\hline $1.500 \mathrm{E}-01$ & $7.234 \mathrm{E}-05$ & $7.234 \mathrm{E}-05$ & $-5.321+263$ & $7.235 \mathrm{E}-05$ \\
\hline $2.000 \mathrm{E}-01$ & $6.687 \mathrm{E}-05$ & $6.687 \mathrm{E}-05$ & $-7.510+213$ & $6.689 \mathrm{E}-05$ \\
\hline $3.000 \mathrm{E}-01$ & $5.943 E-05$ & $5.943 \mathrm{E}-05$ & $3.313+254$ & $5.942 \mathrm{E}-05$ \\
\hline $4.000 \mathrm{E}-01$ & $5.443 \mathrm{E}-05$ & $5.443 E-05$ & $5.954+235$ & 5.441E-05 \\
\hline $5.000 \mathrm{E}-01$ & $5.074 \mathrm{E}-05$ & $5.074 \mathrm{E}-05$ & $-1.736+248$ & $5.073 E-05$ \\
\hline
\end{tabular}

Extracted data; complete data run is provided in microfiche form at the back of this report 


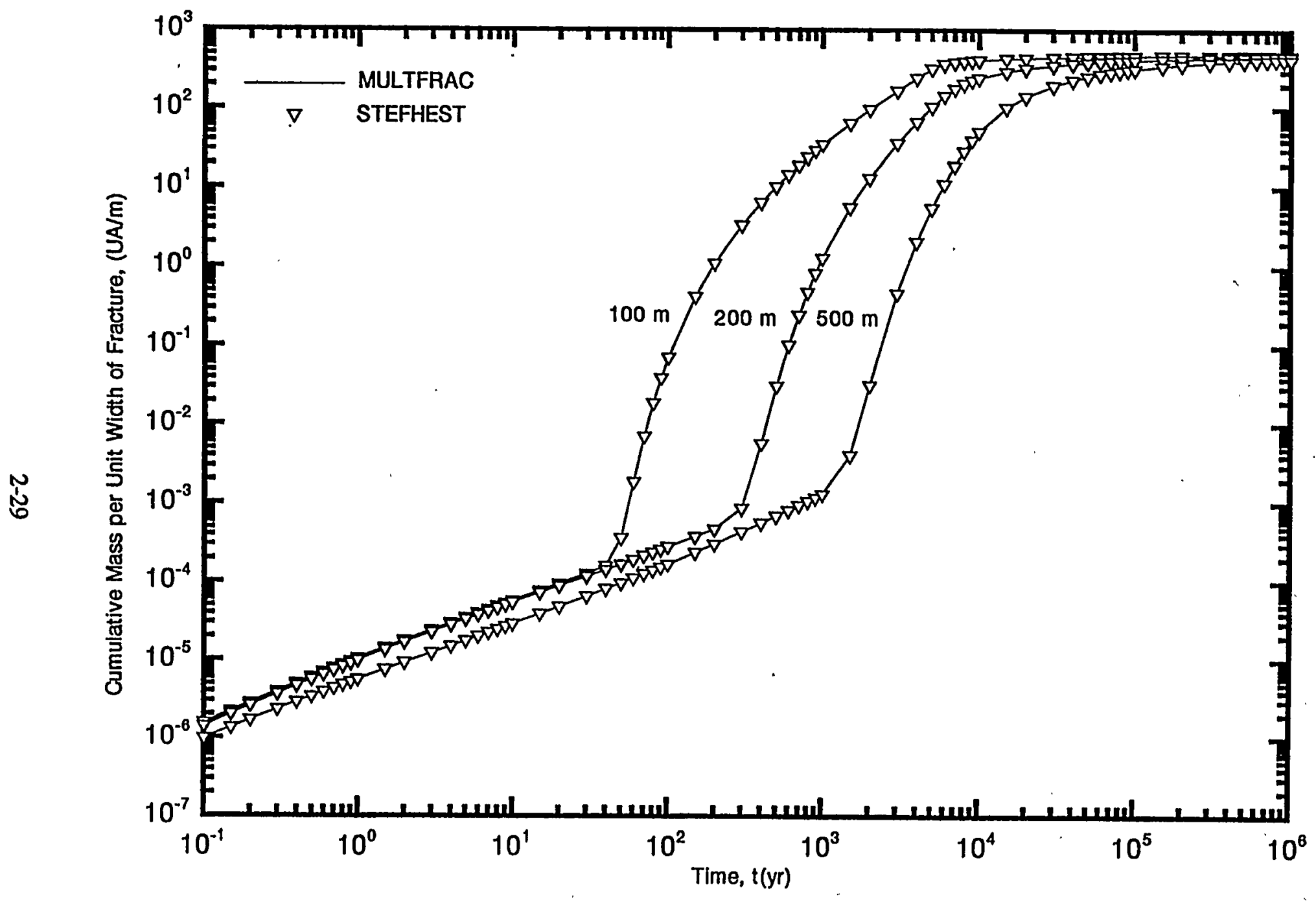

Figure 2-2(c). Cumulative mass of $\mathrm{Np}-237$ per unit in the fracture versus time at different positions $x=100,200$, and 500 meters (Exponentially decaying source and band release mode) 
Table 2-4(a). Case 1 Results: Cumulative mass of $\mathrm{Np}-237$ in the fracture at distance $\mathrm{x}=100$ meters (Exponentially decaying source and band release mode)

\begin{tabular}{|c|c|c|}
\hline TIME (yr) & MULTFRAC & STEFHEST \\
\hline $5.000 \mathrm{E}+05$ & $4.878 E+02$ & $4.879 E+C$ \\
\hline $6.000 \mathrm{E}+05$ & $4.886 \mathrm{E}+02$ & $4.887 \mathrm{E}+\mathrm{C}$ \\
\hline $7.000 \mathrm{E}+05$ & $4.891 \mathrm{E}+02$ & $4.893 E^{\circ}+C$ \\
\hline $8.000 E+05$ & $4.896 \mathrm{E}+02$ & $4.897 \mathrm{E}+\mathrm{C}$ \\
\hline $9.000 \mathrm{E}+05$ & $4.900 E+02$ & $4.901 \mathrm{E}+0$ \\
\hline $1.000 \mathrm{E}+06$ & $4.903 E+02$ & $4.904 E+0$ \\
\hline
\end{tabular}

Table 2-4(b). Case 1 Results: Cumulative mass of $\mathrm{Np}-237$ in the fracture at distance $\mathrm{x}=200$ meters (Exponentially decaying source and band release mode)

$\begin{array}{lll}\text { TIME (yr) } & \text { MULTFRAC } & \text { STEFHEST } \\ 5.000 \mathrm{E}+05 & 4.621 \mathrm{E}+02 & 4.620 \mathrm{E}+02 \\ 6.000 \mathrm{E}+05 & 4.646 \mathrm{E}+02 & 4.645 \mathrm{E}+02 \\ 7.000 \mathrm{E}+05 & 4.664 \mathrm{E}+02 & 4.664 \mathrm{E}+02 \\ 8.000 \mathrm{E}+05 & 4.679 \mathrm{E}+02 & 4.679 \mathrm{E}+02 \\ 9.000 \mathrm{E}+05 & 4.690 \mathrm{E}+02 & 4.690 \mathrm{E}+02 \\ 1.000 \mathrm{E}+06 & 4.700 \mathrm{E}+02 & 4.700 \mathrm{E}+02\end{array}$

Table 2-4(c). Case 1 Results: Cumulative mass of $\mathrm{Np}-237$ in the fracture at distance $\mathrm{x}=500$ meters (Exponentially decaying source and band release mode)

\begin{tabular}{lll} 
TIME (yr) & MULTFRAC & STEFHEST \\
\cline { 2 - 3 } $4.000 \mathrm{E}+05$ & $4.042 \mathrm{E}+02$ & $4.042 \mathrm{E}+02$ \\
$5.000 \mathrm{E}+05$ & $4.122 \mathrm{E}+02$ & $4.123 \mathrm{E}+02$ \\
$6.000 \mathrm{E}+05$ & $4.180 \mathrm{E}+02$ & $4.181 \mathrm{E}+02$ \\
$7.000 \mathrm{E}+05$ & $4.224 \mathrm{E}+02$ & $4.224 \mathrm{E}+02$ \\
$8.000 \mathrm{E}+05$ & $4.258 \mathrm{E}+02$ & $4.259 \mathrm{E}+02$ \\
$9.000 \mathrm{E}+05$ & $4.286 \mathrm{E}+02$ & $4.286 \mathrm{E}+02$ \\
$1.000 \mathrm{E}+06$ & $4.309 \mathrm{E}+02$ & $4.309 \mathrm{E}+02$
\end{tabular}

Extracted data; complete data run is provided in microfiche form at the back of this report 


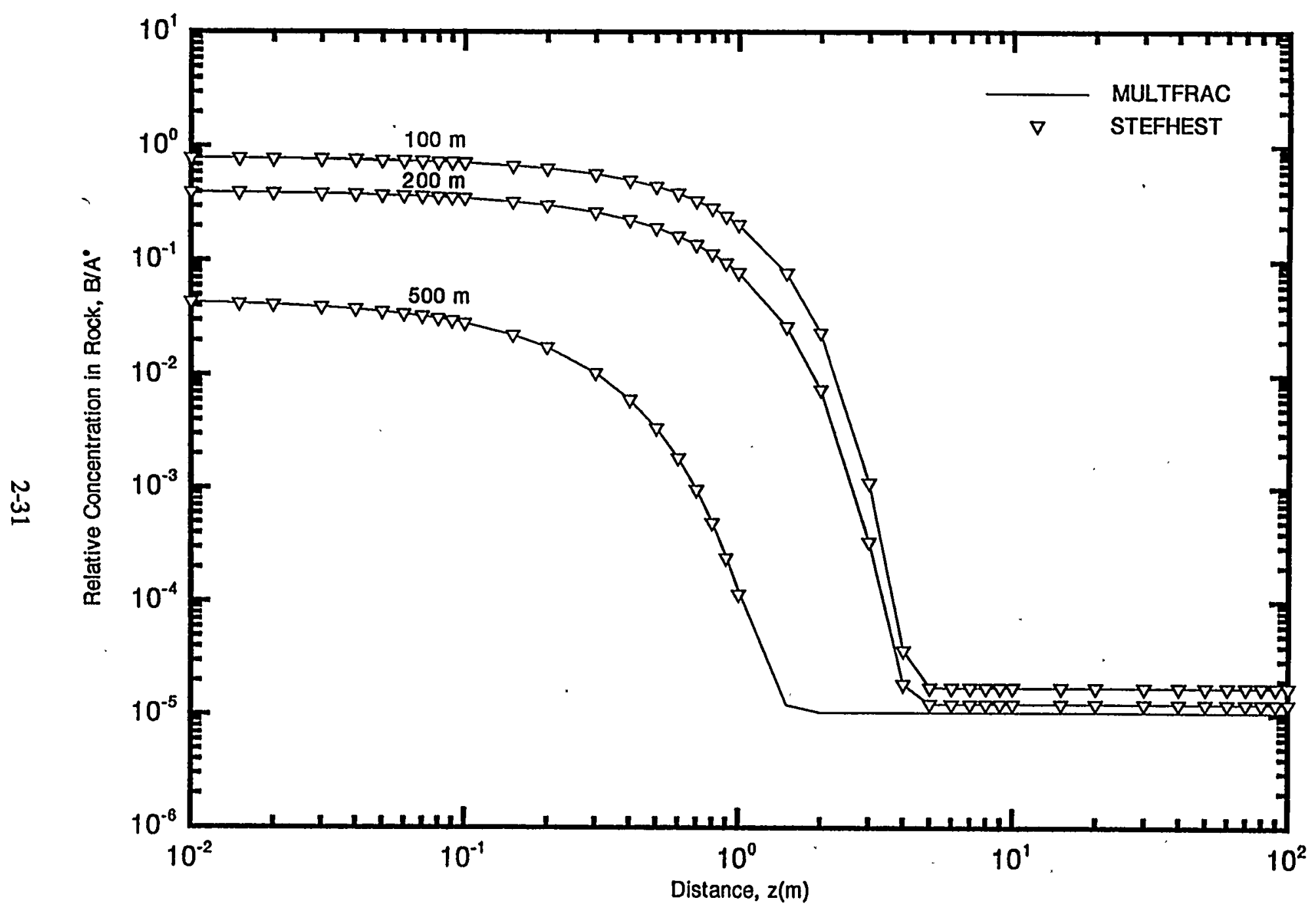

Figure 2-2(d). Relative concentration of $\mathrm{Np}-237$ in rock versus distance $\mathrm{z}$ at time $\mathrm{t}=\mathbf{5 , 0 0 0}$ years and distances from the source $x=100,200$ and 500 meters (Exponentially decaying source and step release mode) 
Table 2-5(a). Case 1 Results: Concentration of $\mathrm{Np-237}$ in the rock matrix Layer 2, at distance $x=100$ meters and time $t=5,000$ years (Exponentially decaying source and step release mode)

$\begin{array}{lll}\text { DISTANCE } z(m) & \text { MULTFRAC } & \text { STEFHEST } \\ 1.000 \mathrm{E}-02 & 7.886 \mathrm{E}-01 & 7.886 \mathrm{E}-01 \\ 1.500 \mathrm{E}-02 & 7.847 \mathrm{E}-01 & 7.847 \mathrm{E}-01 \\ 2.000 \mathrm{E}-02 & 7.809 \mathrm{E}-01 & 7.809 \mathrm{E}-01 \\ 3.000 \mathrm{E}-02 & 7.732 \mathrm{E}-01 & 7.732 \mathrm{E}-01 \\ 4.000 \mathrm{E}-02 & 7.656 \mathrm{E}-01 & 7.656 \mathrm{E}-01 \\ 5.000 \mathrm{E}-02 & 7.579 \mathrm{E}-01 & 7.579 \mathrm{E}-01 \\ & & \\ 9.000 \mathrm{E}+00 & 1.747 \mathrm{E}-05 & 1.747 \mathrm{E}-05 \\ 1.000 \mathrm{E}+01 & 1.747 \mathrm{E}-05 & 1.747 \mathrm{E}-05\end{array}$

Table 2-5(b). Case 1 Results: Concentration of Np-237 in the rock matrix Layer 3, at distance $x=200$ meters and time $t=5,000$ years (Exponentially decaying source and step release mode)

\begin{tabular}{|c|c|c|}
\hline DISTANCE $\mathrm{z}(\mathrm{m})$ & MULTFRAC & STEFHES1 \\
\hline $1.000 \mathrm{E}-02$ & $3.973 E-01$ & 3.973E-01 \\
\hline $1.500 \mathrm{E}-02$ & $3.947 \mathrm{E}-01$ & $3.947 \mathrm{E}-01$ \\
\hline $2.000 \mathrm{E}-02$ & $3.922 \mathrm{E}-01$ & $3.922 \mathrm{E}-01$ \\
\hline $3.000 \mathrm{E}-02$ & $3.871 \mathrm{E}-01$ & $3.871 \mathrm{E}-01$ \\
\hline $4.000 \mathrm{E}-02$ & $3.821 \mathrm{E}-01$ & $3.821 \mathrm{E}-01$ \\
\hline $5.000 \mathrm{E}-02$ & $3.771 \mathrm{E}-01$ & $3.771 \mathrm{E}-01$ \\
\hline $9.000 \mathrm{E}+00$ & $1.248 \mathrm{E}-05$ & $1.248 \mathrm{E}-05$ \\
\hline $1.000 \mathrm{E}+01$ & $1.248 \mathrm{E}-05$ & $1.248 \mathrm{E}-05$ \\
\hline
\end{tabular}

Table 2-5(c). Case 1 Results: Concentration of $\mathrm{Np}-237$ in the rock matrix Layer 5, at distance $x=\mathbf{5 0 0}$ meters and time $t=\mathbf{5 , 0 0 0}$ years (Exponentially decaying source and step release mode)

\begin{tabular}{|c|c|c|}
\hline DISTANCE $\mathrm{z}(\mathrm{m})$ & MULTFRAC & STEFHEST \\
\hline $1.000 \mathrm{E}-02$ & $4.293 E-02$ & $4.294 \mathrm{E}-02$ \\
\hline $1.500 \mathrm{E}-02$ & 4.199E-02 & $4.200 \mathrm{E}-02$ \\
\hline $2.000 \mathrm{E}-02$ & 4.107E-02 & $4.107 \mathrm{E}-02$ \\
\hline $3.000 \mathrm{E}-02$ & $3.927 \mathrm{E}-02$ & $3.927 \mathrm{E}-02$ \\
\hline $4.000 \mathrm{E}-02$ & 3.754E-02 & $3.754 \mathrm{E}-02$ \\
\hline $5.000 \mathrm{E}-02$ & $3.588 \mathrm{E}-02$ & $3.588 \mathrm{E}-02$ \\
\hline $4.000 \mathrm{E}+00$ & $1.048 \mathrm{E}-05$ & $3.047 \mathrm{E}-15$ \\
\hline $5.000 \mathrm{E}+00$ & $1.048 \mathrm{E}-05$ & $-9.383 \mathrm{E}-17$ \\
\hline
\end{tabular}

Extracted data; complete data run is provided in microfiche form at the back of this report 


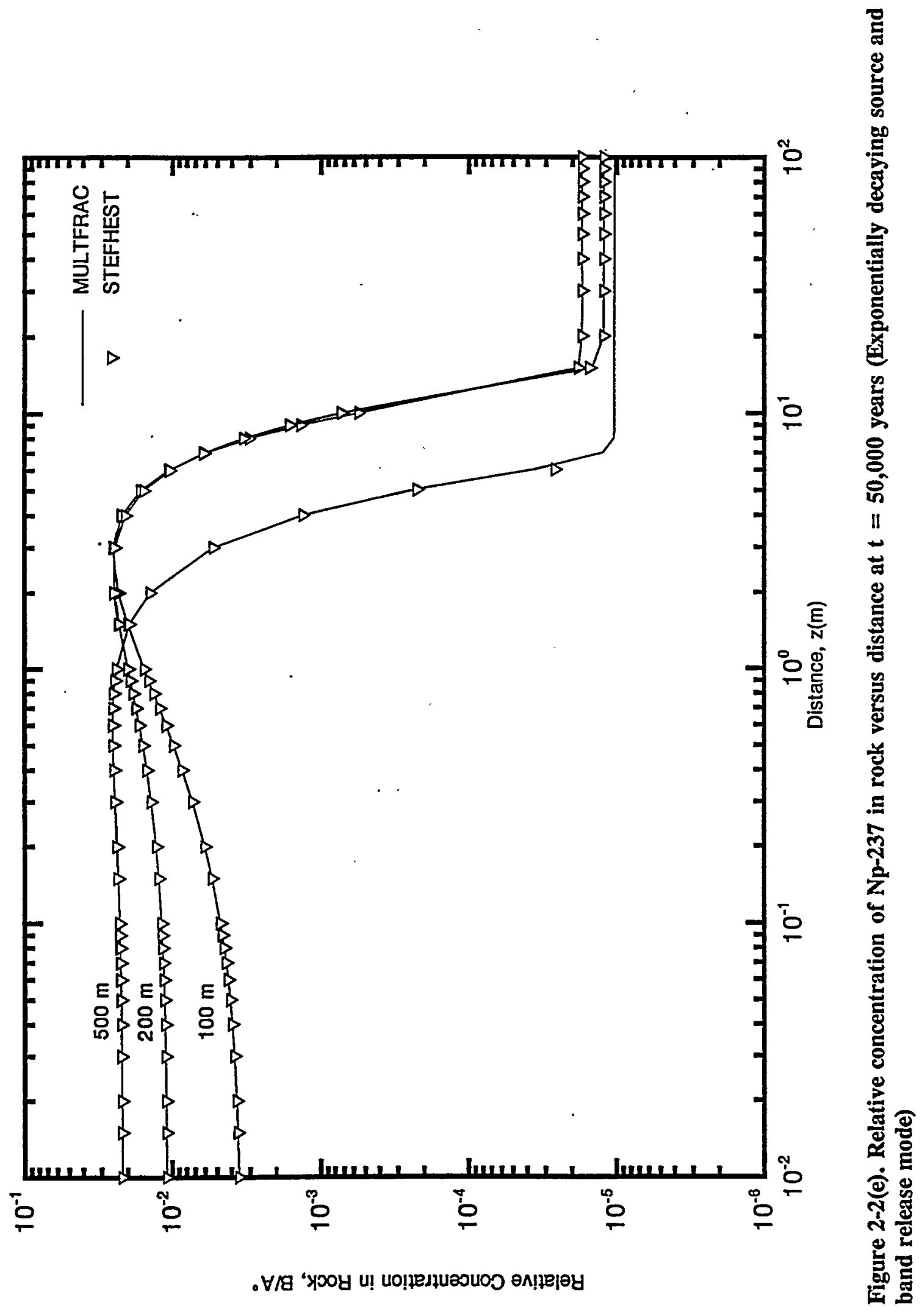


Table 2-6(a). Case 1 Results: Concentration of Np-237 in the rock matrix Layer 2, at distance $x=100$ meters and time $t=50,000$ years (Exponentially decaying source and band release mode)

DISTANCE $\mathrm{z}(\mathrm{m})$ MULTFRAC

$\begin{array}{lll}1.000 \mathrm{E}-02 & 3.566 \mathrm{E}-03 & 3.566 \mathrm{E}-03 \\ 1.500 \mathrm{E}-02 & 3.633 \mathrm{E}-03 & 3.633 \mathrm{E}-03 \\ 2.000 \mathrm{E}-02 & 3.699 \mathrm{E}-03 & 3.699 \mathrm{E}-03 \\ 3.000 \mathrm{E}-02 & 3.832 \mathrm{E}-03 & 3.832 \mathrm{E}-03 \\ 4.000 \mathrm{E}-02 & 3.965 \mathrm{E}-03 & 3.965 \mathrm{E}-03 \\ 5.000 \mathrm{E}-02 & 4.098 \mathrm{E}-03 & 4.098 \mathrm{E}-03\end{array}$

Table 2-6(b). Case 1 Results: Concentration of $\mathrm{Np}-237$ in the rock matrix Layer 3, at distance $x=200$ meters and time $t=\mathbf{5 0 , 0 0 0}$ years (Exponentially decaying source and band release mode)

DISTANCE $\mathrm{z}(\mathrm{m})$ MULTFRAC

$\begin{array}{lll}1.000 \mathrm{E}-02 & 1.090 \mathrm{E}-02 & 1.090 \mathrm{E}-02 \\ 1.500 \mathrm{E}-02 & 1.095 \mathrm{E}-02 & 1.095 \mathrm{E}-02 \\ 2.000 \mathrm{E}-02 & 1.101 \mathrm{E}-02 & 1.101 \mathrm{E}-02 \\ 3.000 \mathrm{E}-02 & 1.112 \mathrm{E}-02 & 1.112 \mathrm{E}-02 \\ 4.000 \mathrm{E}-02 & 1.123 \mathrm{E}-02 & 1.123 \mathrm{E}-02 \\ 5.000 \mathrm{E}-02 & 1.134 \mathrm{E}-02 & 1.134 \mathrm{E}-02\end{array}$

Table 2-6(c). Case 1 Results: Concentration of $\mathrm{Np}-237$ in the rock matrix Layer 3, at distance $x=500$ meters and time $t=\mathbf{5 0 , 0 0 0}$ years (Exponentially decaying source and band release mode)

\begin{tabular}{llll} 
DISTANCE $\mathrm{z}(\mathrm{m})$ & \multicolumn{1}{l}{ MULTFRAC } & & STEFHEST \\
$1.000 \mathrm{E}-02$ & $2.184 \mathrm{E}-02$ & & $2.184 \mathrm{E}-02$ \\
$1.500 \mathrm{E}-02$ & $2.189 \mathrm{E}-02$ & $2.189 \mathrm{E}-02$ \\
$2.000 \mathrm{E}-02$ & $2.195 \mathrm{E}-02$ & $2.195 \mathrm{E}-02$ \\
$3.000 \mathrm{E}-02$ & $2.206 \mathrm{E}-02$ & $2.206 \mathrm{E}-02$ \\
$4.000 \mathrm{E}-02$ & $2.217 \mathrm{E}-02$ & $2.217 \mathrm{E}-02$ \\
$5.000 \mathrm{E}-02$ & $2.228 \mathrm{E}-02$ & $2.228 \mathrm{E}-02$
\end{tabular}

Extracted data; complete data run is provided in microfiche form at the back of this report 


\subsubsection{Case 2 Results}

This test case examines, as before, the spatial and temporal variation of the concentration of $\mathrm{Cm}$ 245 , as well as its cumulative mass flux in the fracture. In addition, the spatial variations of the concentration in the rock matrix are also investigated. The source terms correspond now to a periodically fluctuating one with exponential decay, and the assigned residual concentrations are almost one order of magnitude less than their counterparts in the case of Np-237. The input data pertaining to this test case is presented in Table 2-7. Note that the implementation of a periodically decaying source restricts the use of benchmarking algorithms other than Talbot's and Durbin's for reasons presented earlier.

Figure 2-3(a) shows the spatial relative concentration profiles of $\mathrm{Cm}-245$ observed in the fracture layers for simulation times corresponding to $10^{3}, 5 \times 10^{3}$, and $5 \times 10^{4}$ years. A comparison of our results with the ones obtained from the two numerical inversion algorithms [Tables 2-8(a) through 2-8(c)] shows that these are in excellent agreement.

Figure 2-3(b) shows the temporal relative concentration of $\mathrm{Cm}-245$ observed in the fracture at three different observation points: 100,200, and 500 meters downstream from the source, located in the second, third, and fifth layer respectively, for a band release mode. The observations here are similar to the ones reported for Np-237 except that in the present case the upper tail of the concentration profiles is akin to the assigned initial concentrations of the various fracture layers of interest. A comparison of our results with those yielded by Talbot's and Durbin's algorithms lying within the acceptable range of concentrations [see Tables 2-9(a) through 2-9(c)] seems to indicate good agreement. Note that Talbot's algorithm performance is further reduced in this case, where correct predictions.of the concentrations at the three monitoring points seem to be registered only for times greater than 40,80 , and 300 years, respectively.

Figure 2-3(c) depicts the time-dependent evolution of the cumulative mass release (per unit width of the fracture) profile of $\mathrm{Cm}-245$ at three different observation points in the fracture as in the previous example. Because of its robustness, Durbin's algorithm is selected as the benchmark. A comparison of our analytical solution results with those yielded by Durbin's solution [see Tables 2-10(a) through 2-10(c)] indicates excellent agreement. Note that all three profiles will tend to become asymptotic to three specific values of the cumulative mass namely: $2.175 \times 10^{2}, 1.237 \times 10^{2}$, and $40.9(\mathrm{UA} / \mathrm{m})^{\dagger}$.

Figures 2-3(d) and 2-3(e) show the relative concentration profiles in the rock matrix at three positions downstream from the source (i.e., $x=100 \mathrm{~m}, 200 \mathrm{~m}$, and $500 \mathrm{~m}$ ) for a step release and band release, respectively. Comparison of our analytical results against those yielded by the two approximate solution methods [see Tables 2-11(a) through 2-12(c)] indicates excellent agreement.

The assumption of zero dispersive flux in the fracture raises the question of the range of validity of the analytical solutions presented in this report. This matter depends very much on the importance of the hydrodynamic dispersion effects prevailing in the fracture. This matter has been investigated and quantified numerically by Ahn et al., (1985) (i.e., for the case of zero initial concentrations in both fracture and rock) who suggested that hydrodynamic dispersion D (see Bear, 1972) should meet the following criterion

${ }^{\dagger}$ UA: Arbitrary Units of Activity/meter. 


$$
D_{i} \leq \frac{10 u_{i}^{2} b_{i}}{\Phi\left(D_{p i} R_{i}^{\prime}\right)^{1 / 2}}
$$

in order to validate the use of the zero fracture dispersion solution. The maximum permissible value of $D_{i}$ for any layer $i$ would correspond to a minimum of $254.0 \mathrm{~m}^{2} / \mathrm{yr}$ for Test Case 1 , and $245.0 \mathrm{~m}^{2} / \mathrm{yr}$ for Test Case 2. Expressed in terms of dispersivity (i.e., $D_{\mathrm{i}} / \mathrm{u}_{\mathrm{i}}$ ), these would correspond approximately to a value of $16 \mathrm{~m}$ in both cases.

Table 2-7. Input parameters for Case 2 periodically fluctuating source with exponential decay

\section{SPECIES}

$\mathrm{T}_{1 / 2}$

Release Mode:

Step

Band Leaching Time

$\mathrm{A}^{\circ}$

Q

$\nu_{2}$

$\nu_{\mathrm{b}}$

$T_{p}$
Cm-245

$8.5 \times 10^{3} \mathrm{yr}$

NA

$5 \times 10^{3}$ yr

$1.0^{*}$

$0.1\left(\mathrm{~m}^{3} / \mathrm{yr}\right)$

0.75

0.25

$5.0 \mathrm{yr}$ 
Table 2-7. Input parameters for Case 2 periodically fluctuating source with exponential decay (Cont'd)

\begin{tabular}{|c|c|c|c|c|}
\hline \hline Layer & $\mathbf{L}(\mathrm{m})$ & $\mathbf{b}(\mathrm{m})$ & $\mathbf{u}(\mathrm{m} / \mathbf{y r})$ & $\Phi$ \\
\hline \hline 1 & 50.0 & $5.0 \mathrm{E}-03$ & 10.0 & 0.01 \\
\hline 2 & 75.0 & $4.0 \mathrm{E}-03$ & 12.5 & 0.008 \\
\hline 3 & 100.0 & $3.0 \mathrm{E}-03$ & 16.666 & 0.006 \\
\hline 4 & 150.0 & $2.0 \mathrm{E}-03$ & 25.0 & 0.004 \\
\hline 5 & $\infty$ & $1.5 \mathrm{E}-03$ & 33.333 & 0.002 \\
\hline \hline
\end{tabular}

\begin{tabular}{|c|c|c|c|c|}
\hline \hline Layer & $\rho\left(\mathrm{g} / \mathrm{cm}^{3}\right)$ & $\mathbf{D}_{\mathrm{p}}\left(\mathrm{m}^{2} / \mathrm{yr}\right)$ & $\mathrm{K}_{\mathrm{r}}(\mathrm{m})$ & $\mathbf{K}_{\mathbf{r}}\left(\mathrm{cm}^{3} / \mathrm{g}\right)$ \\
\hline \hline 1 & 2.0 & 0.01 & $1.5 \mathrm{E}-02$ & 1.5 \\
\hline 2 & 2.3 & 0.02 & $8.0 \mathrm{E}-03$ & 1.2 \\
\hline 3 & 2.6 & 0.06 & $5.4 \mathrm{E}-02$ & 1.25 \\
\hline 4 & 2.65 & 0.05 & $1.0 \mathrm{E}-02$ & 0.75 \\
\hline 5 & 2.7 & 0.03 & $4.5 \mathrm{E}-03$ & 2.0 \\
\hline \hline
\end{tabular}

\begin{tabular}{|c|c|c|c|c|}
\hline \hline Layer & $\mathbf{a}_{1}^{*}$ & $\mathbf{a}_{2}^{*}$ & $\alpha\left(\mathrm{m}^{-1}\right)$ & $\mathbf{b}_{\mathbf{1}}{ }^{*}$ \\
\hline \hline 1 & $1.50 \mathrm{E}-05$ & $-0.50 \mathrm{E}-05$ & 0.05 & $1.00 \mathrm{E}-06$ \\
\hline 2 & $2.00 \mathrm{E}-05$ & $-0.25 \mathrm{E}-06$ & 0.05 & $1.75 \mathrm{E}-06$ \\
\hline 3 & $1.75 \mathrm{E}-05$ & $-0.20 \mathrm{E}-06$ & 0.05 & $1.25 \mathrm{E}-06$ \\
\hline 4 & $2.00 \mathrm{E}-05$ & $-0.15 \mathrm{E}-06$ & 0.05 & $1.05 \mathrm{E}-06$ \\
\hline 5 & $1.50 \mathrm{E}-05$ & $-0.20 \mathrm{E}-06$ & 0.05 & $1.05 \mathrm{E}-06$ \\
\hline
\end{tabular}

(arbitrary units of activity/L $\mathrm{L}^{3}$ ) 


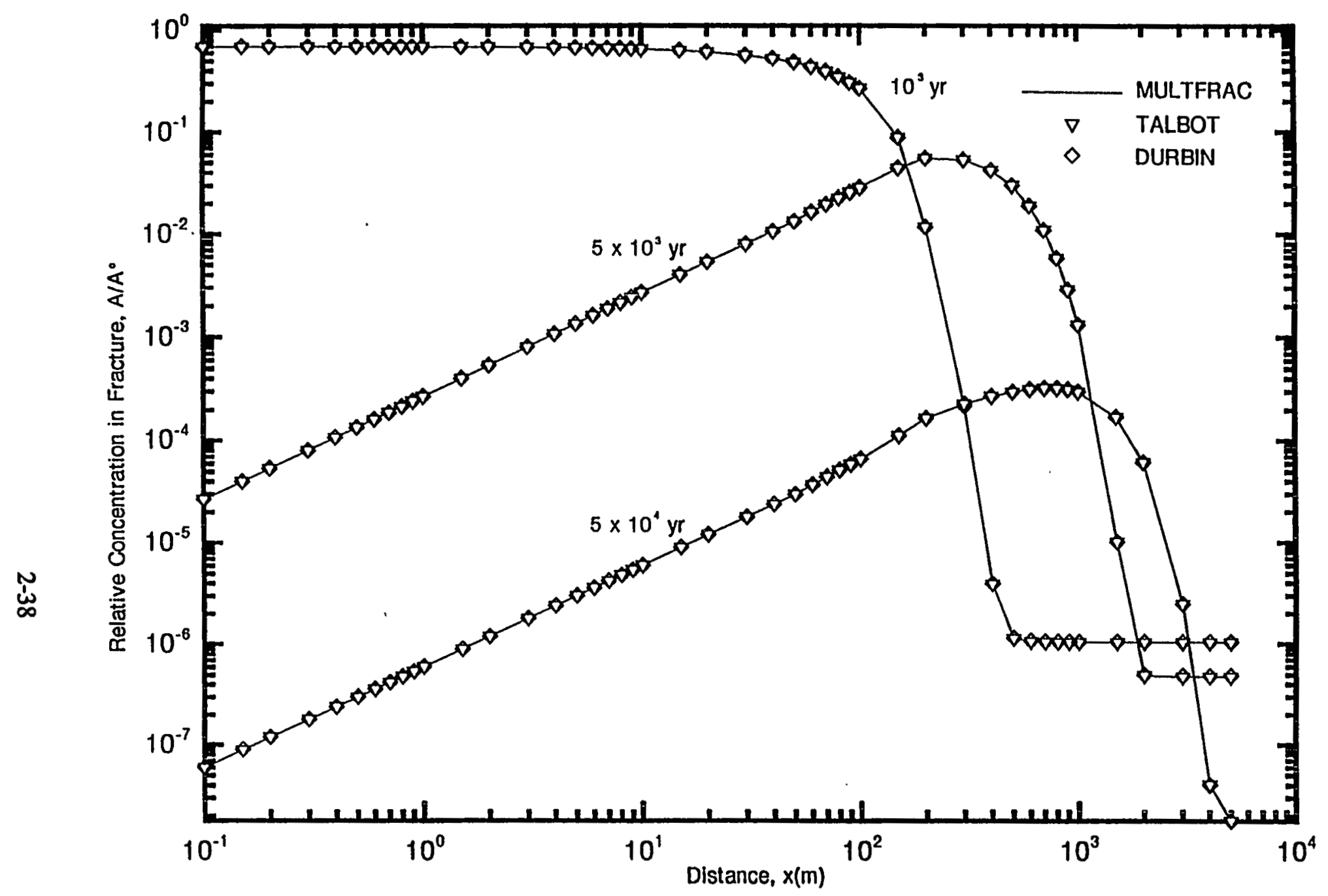

Figure 2-3(a). Relative concentration of $\mathrm{Cm}-245$ versus distance in the fracture at different times $t=1,000,5,000$, and 50,000 years (Periodically fluctuating source with exponential decay, step and band release mode) 
Table 2-8(a). Case 2 Results: Concentration of $\mathrm{Cm}-245$ in the fracture at time $t=1,000$ years (Periodically fluctuating source with exponential decay and step release mode)

\begin{tabular}{lllll} 
DISTANCE $x(m)$ & MULTFRAC & TALBOT & DURBIN \\
\cline { 1 - 2 } $1.000 \mathrm{E}-01$ & $6.908 \mathrm{E}-01$ & & $6.908 \mathrm{E}-01$ & \\
$1.500 \mathrm{E}-01$ & $6.906 \mathrm{E}-01$ & & $6.906 \mathrm{E}-01$ & \\
$2.000 \mathrm{E}-01$ & $6.904 \mathrm{E}-01$ & $6.906 \mathrm{E}-01$ \\
$3.000 \mathrm{E}-01$ & $6.900 \mathrm{E}-01$ & $6.900 \mathrm{E}-01$ & $6.904 \mathrm{E}-01$ \\
$4.000 \mathrm{E}-01$ & $6.896 \mathrm{E}-01$ & $6.896 \mathrm{E}-01$ & $6.896 \mathrm{E}-01$ \\
$5.000 \mathrm{E}-01$ & $6.891 \mathrm{E}-01$ & $6.891 \mathrm{E}-01$ & $6.891 \mathrm{E}-01$
\end{tabular}

Table 2-8(b). Case 2 Results: Concentration of $\mathrm{Cm}-245$ in the fracture at time $t=5,000$ years (Periodically fluctuating source with exponential decay and band release mode)

$\begin{array}{lllll}\text { DISTANCE } \times(m) & \text { MULTFRAC } & \text { TALBOT } & \text { DURBIN } \\ 1.000 \mathrm{E}-01 & 2.675 \mathrm{E}-05 & & \\ 1.500 \mathrm{E}-01 & 4.014 \mathrm{E}-05 & & 4.016 \mathrm{E}-05 & \\ 2.000 \mathrm{E}-01 & 5.352 \mathrm{E}-05 & 5.355 \mathrm{E}-05 & 5.357 \mathrm{E}-05 \\ 3.000 \mathrm{E}-01 & 8.030 \mathrm{E}-05 & 8.033 \mathrm{E}-05 & 8.035 \mathrm{E}-05 \\ 4.000 \mathrm{E}-01 & 1.071 \mathrm{E}-04 & 1.071 \mathrm{E}-04 & 1.071 \mathrm{E}-04 \\ 5.000 \mathrm{E}-01 & 1.338 \mathrm{E}-04 & 1.339 \mathrm{E}-04 & 1.339 \mathrm{E}-04\end{array}$

Table 2-8(c). Case 2 Results: Concentration of $\mathrm{Cm}-245$ in the fracture at time $\mathrm{t}=50,000$ years (Periodically fluctuating source with exponential decay and band release mode)

\begin{tabular}{lllll} 
DISTANCE x(m) & MULTFRAC & TALBOT & DURBIN \\
\cline { 2 - 3 } $1.000 \mathrm{E}-01$ & $5.953 \mathrm{E}-08$ & & $5.991 \mathrm{E}-08$ & $5.991 \mathrm{E}-08$ \\
$1.500 \mathrm{E}-01$ & $8.949 \mathrm{E}-08$ & & $8.987 \mathrm{E}-08$ & $8.987 \mathrm{E}-08$ \\
$2.000 \mathrm{E}-01$ & $1.194 \mathrm{E}-07$ & & $1.198 \mathrm{E}-07$ & $1.198 \mathrm{E}-07$ \\
$3.000 \mathrm{E}-01$ & $1.794 \mathrm{E}-07$ & & $1.797 \mathrm{E}-07$ & $1.797 \mathrm{E}-07$ \\
$4.000 \mathrm{E}-01$ & $2.393 \mathrm{E}-07$ & & $2.397 \mathrm{E}-07$ & $2.397 \mathrm{E}-07$ \\
$5.000 \mathrm{E}-01$ & $2.992 \mathrm{E}-07$ & $2.996 \mathrm{E}-07$ & $2.996 \mathrm{E}-07$
\end{tabular}

Extracted data; complete data run is provided in microfiche form at the back of this report 


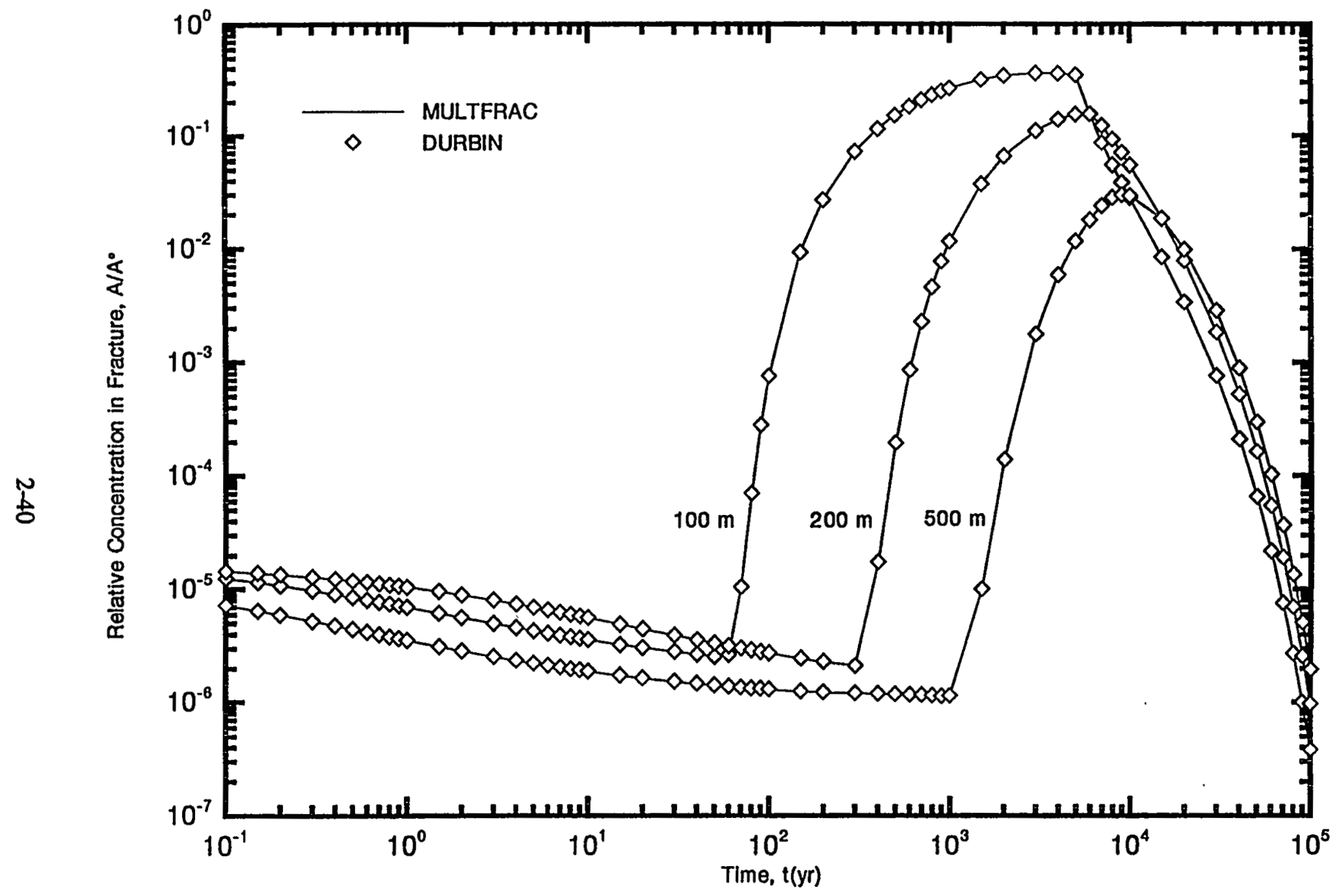

Figure 2-3(b). Relative concentration of $\mathrm{Cm}-245$ in the fracture versus time at different positions $\mathrm{x}=100,200$, and 500 meters (Periodically fluctuating source with exponential decay, step and band release mode) 
Table 2-9(a). Case 2 Results: Concentration of Cm-245 in the fracture in Layer 2, at distance $x=100$ meters (Periodically fluctuating source with exponential decay and step release mode)

$\begin{array}{lllll}\text { TIME (yr) } & \text { MULTFRAC } & \text { TALBOT } & \text { DURBIN } \\ 2.000 \mathrm{E}+01 & & 3.049 \mathrm{E}-06 & -1.702 \mathrm{E}+45 & 3.058 \mathrm{E}-06 \\ 3.000 \mathrm{E}+01 & 2.810 \mathrm{E}=06 & -5.177 \mathrm{E}+02 & 2.837 \mathrm{E}-06 \\ 4.000 \mathrm{E}+01 & 2.667 \mathrm{E}-06 & 2.680 \mathrm{E}-06 & 2.673 \mathrm{E}-06 \\ 5.000 \mathrm{E}+01 & 2.570 \mathrm{E}-06 & 2.568 \mathrm{E}-06 & 2.544 \mathrm{E}-06 \\ 6.000 \mathrm{E}+01 & 2.703 \mathrm{E}-06 & 2.708 \mathrm{E}-06 & 2.669 \mathrm{E}-06 \\ 7.000 \mathrm{E}+01 & 1.027 \mathrm{E}-05 & 1.050 \mathrm{E}-05 & 1.054 \mathrm{E}-05 \\ 8.000 \mathrm{E}+01 & 6.893 \mathrm{E}-05 & 7.056 \mathrm{E}-05 & 7.053 \mathrm{E}-05 \\ 9.000 \mathrm{E}+01 & 2.757 \mathrm{E}-04 & 2.814 \mathrm{E}-04 & 2.813 \mathrm{E}-04\end{array}$

Table 2-9(b). Case 2 Results: Concentration of $\mathrm{Cm}-245$ in the fracture in Layer 3, at distance $x=200$ meters (Periodically fluctuating source with exponential decay and band release mode)

\begin{tabular}{lllll} 
TIME (yr) & MULTFRAC & TALBOT & DURBIN \\
\cline { 1 - 2 } & & & \\
$8.000 \mathrm{E}+01$ & $2.913 \mathrm{E}-06$ & & $9.066 \mathrm{E}+39$ & $2.923 \mathrm{E}-06$ \\
$9.000 \mathrm{E}+01$ & $2.818 \mathrm{E}-06$ & & $1.164 \mathrm{E}+06$ & $2.827 \mathrm{E}-06$ \\
$1.000 \mathrm{E}+02$ & $2.737 \mathrm{E}-06$ & $-2.442 \mathrm{E}+15$ & $2.746 \mathrm{E}-06$ \\
$1.500 \mathrm{E}+02$ & $2.457 \mathrm{E}-06$ & $2.460 \mathrm{E}-06$ & $2.482 \mathrm{E}-06$ \\
$2.000 \mathrm{E}+02$ & $2.284 \mathrm{E}-06$ & $2.284 \mathrm{E}-06$ & $2.312 \mathrm{E}-06$ \\
$3.000 \mathrm{E}+02$ & $2.133 \mathrm{E}-06$ & $2.135 \mathrm{E}-06$ & $2.127 \mathrm{E}-06$ \\
$4.000 \mathrm{E}+02$ & $1.718 \mathrm{E}-05$ & $1.740 \mathrm{E}-05$ & $1.756 \mathrm{E}-05$ \\
$5.000 \mathrm{E}+02$ & $1.944 \mathrm{E}-04$ & $1.966 \mathrm{E}-04$ & $1.963 \mathrm{E}-04$
\end{tabular}

Table 2-9(c). Case 2 Results: Concentration of $\mathrm{Cm}-245$ in the fracture in Layer 5, at distance . $\mathbf{x}=\mathbf{5 0 0}$ meters (Periodically fluctuating source with exponential decay and band release mode)

\begin{tabular}{|c|c|c|c|}
\hline \multirow[b]{2}{*}{ TIME (yr) } & \multirow[b]{2}{*}{ MULTFRAC } & \\
\hline & & TALBOT & DURBIN \\
\hline $9.000 \mathrm{E}+01$ & 1.317E-06 & $-4.803 E+93$ & $1.331 E-06$ \\
\hline $1.000 \mathrm{E}+02$ & $1.302 \mathrm{E}-06$ & $-3.967 E+75$ & $1.316 \mathrm{E}-06$ \\
\hline $1.500 \mathrm{E}+02$ & $1.255 \mathrm{E}-06$ & $-4.242 \mathrm{E}+22$ & $1.269 \mathrm{E}-06$ \\
\hline $2.000 \mathrm{E} 02$ & $1.231 \mathrm{E}-06$ & $-2.924 \mathrm{E}-05$ & $1.245 \mathrm{E}-06$ \\
\hline $3.000 \mathrm{E}+02$ & $1.207 \mathrm{E}-06$ & $1.207 \mathrm{E}-06$ & $1.220 \mathrm{E}-06$ \\
\hline $4.000 \mathrm{E}+02$ & $1.191 \mathrm{E}-06$ & $1.192 \mathrm{E}-06$ & $1.205 \mathrm{E}-06$ \\
\hline $5.000 \mathrm{E}+02$ & $1.177 \mathrm{E}-06$ & $1.178 \mathrm{E}-06$ & $1.192 \mathrm{E}-06$ \\
\hline $6.000 \mathrm{E}+02$ & $1.164 \mathrm{E}-06$ & $1.165 E-06$ & $1.181 \mathrm{E}-06$ \\
\hline
\end{tabular}

Extracted data; complete data run is provided in microfiche form at the back of this report 


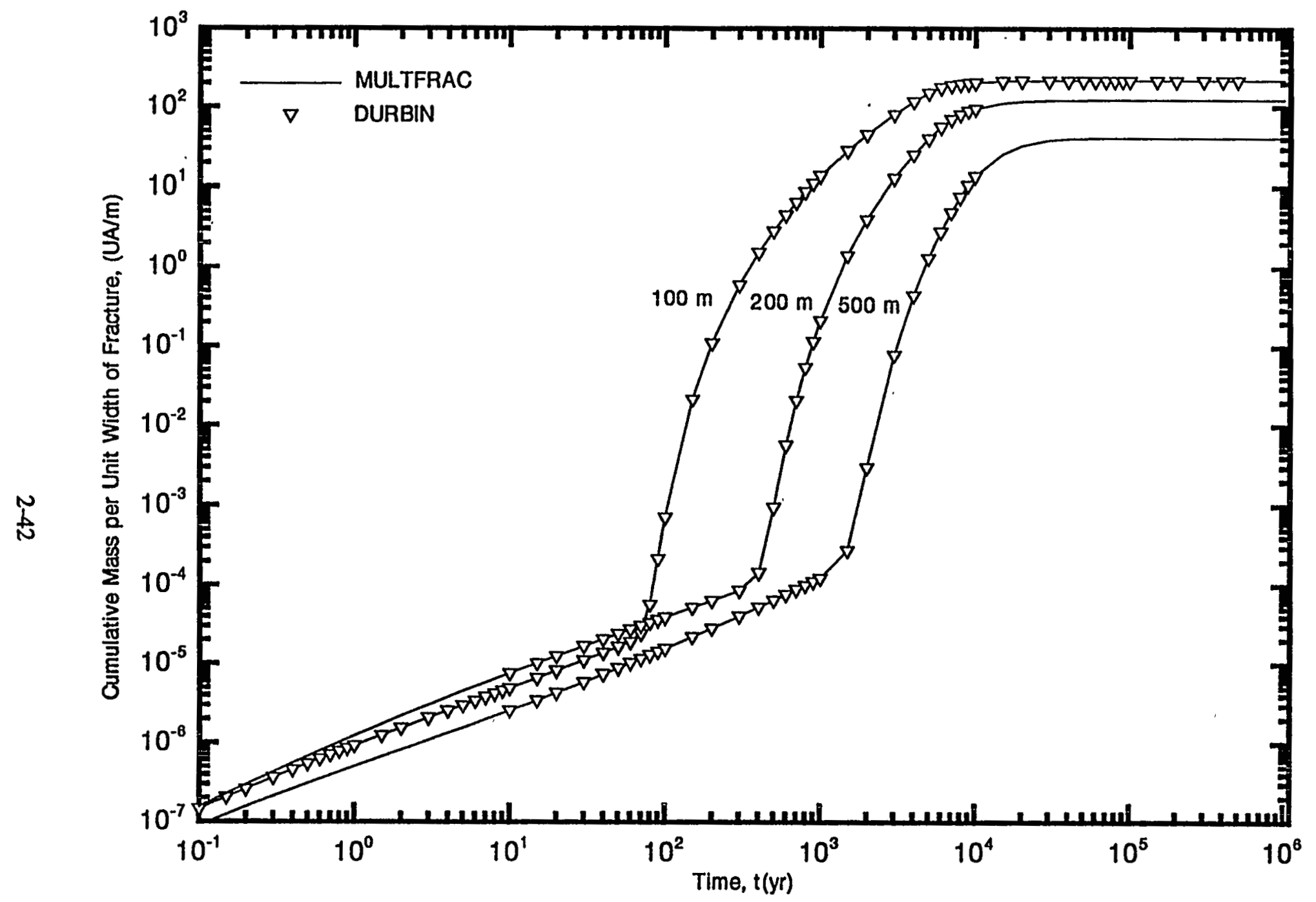

Figure 2-3(c). Cumulative mass of $\mathrm{Cm}-245$ per unit in the fracture versus time at different positions $\mathrm{x}=100,200$, and 500 meters (Periodically fluctuating source with exponential decay) 
Table 2-10(a). Case 2 Results: Cumulative mass of $\mathrm{Cm}-245$ in the fracture at distance $x=100$ meters (Periodically fluctuating source with exponential decay and band release mode)

$\begin{array}{lll}\text { TIME (yr) } & \text { MULTFRAC } & \text { DURBIN } \\ 3.000 \mathrm{E}+05 & 2.175 \mathrm{E}+02 & 2.174 \mathrm{E}+02 \\ 4.000 \mathrm{E}+05 & 2.175 \mathrm{E}+02 & 2.179 \mathrm{E}+02 \\ 5.000 \mathrm{E}+05 & 2.175 \mathrm{E}+02 & 2.184 \mathrm{E}+02 \\ 6.000 \mathrm{E}+05 & 2.175 \mathrm{E}+02 & \text { NA } \\ 7.000 \mathrm{E}+05 & 2.175 \mathrm{E}+02 & \text { NA } \\ 8.000 \mathrm{E}+05 & 2.175 \mathrm{E}+02 & \text { NA } \\ 9.000 \mathrm{E}+05 & 2.175 \mathrm{E}+02 & \text { NA } \\ 1.000 \mathrm{E}+06 & 2.175 \mathrm{E}+02 & \text { NA }\end{array}$

Table 2-10(b). Case 2 Results: Cumulative mass of $\mathrm{Cm}-245$ in the fracture at distance $x=200$ meters (Periodically fluctuating source with exponential decay and band release mode)

TIME (yr) MULTFRAC DURBIN

$\begin{array}{lll}5.000 \mathrm{E}+05 & 1.237 \mathrm{E}+02 & \text { NA } \\ 6.000 \mathrm{E}+05 & 1.237 \mathrm{E}+02 & \text { NA } \\ 7.000 \mathrm{E}+05 & 1.237 \mathrm{E}+02 & \text { NA } \\ 8.000 \mathrm{E}+05 & 1.237 \mathrm{E}+02 & \text { NA } \\ 9.000 \mathrm{E}+05 & 1.237 \mathrm{E}+02 & \text { NA } \\ 1.000 \mathrm{E}+06 & 1.237 \mathrm{E}+02 & \text { NA }\end{array}$

Table 2-10(c). Case 2 Results: Cumulative mass of $\mathrm{Cm}-245$ in the fracture at distance $x=500$ meters (Periodically fluctuating source with exponential decay and band release mode)

$\begin{array}{lll}\text { TIME (yr) } & \text { MULTFRAC } & \text { DUR } \\ 5.000 \mathrm{E}+05 & 4.092 \mathrm{E}+01 & \text { NA } \\ 6.000 \mathrm{E}+05 & 4.092 \mathrm{E}+01 & \text { NA } \\ 7.000 \mathrm{E}+05 & 4.092 \mathrm{E}+01 & \text { NA } \\ 8.000 \mathrm{E}+05 & 4.092 \mathrm{E}+01 & \text { NA } \\ 9.000 \mathrm{E}+05 & 4.092 \mathrm{E}+01 & \text { NA } \\ 1.000 \mathrm{E}+06 & 4.092 \mathrm{E}+01 & \text { NA }\end{array}$

Extracted data; complete data run is provided in microfiche form at the back of this report 


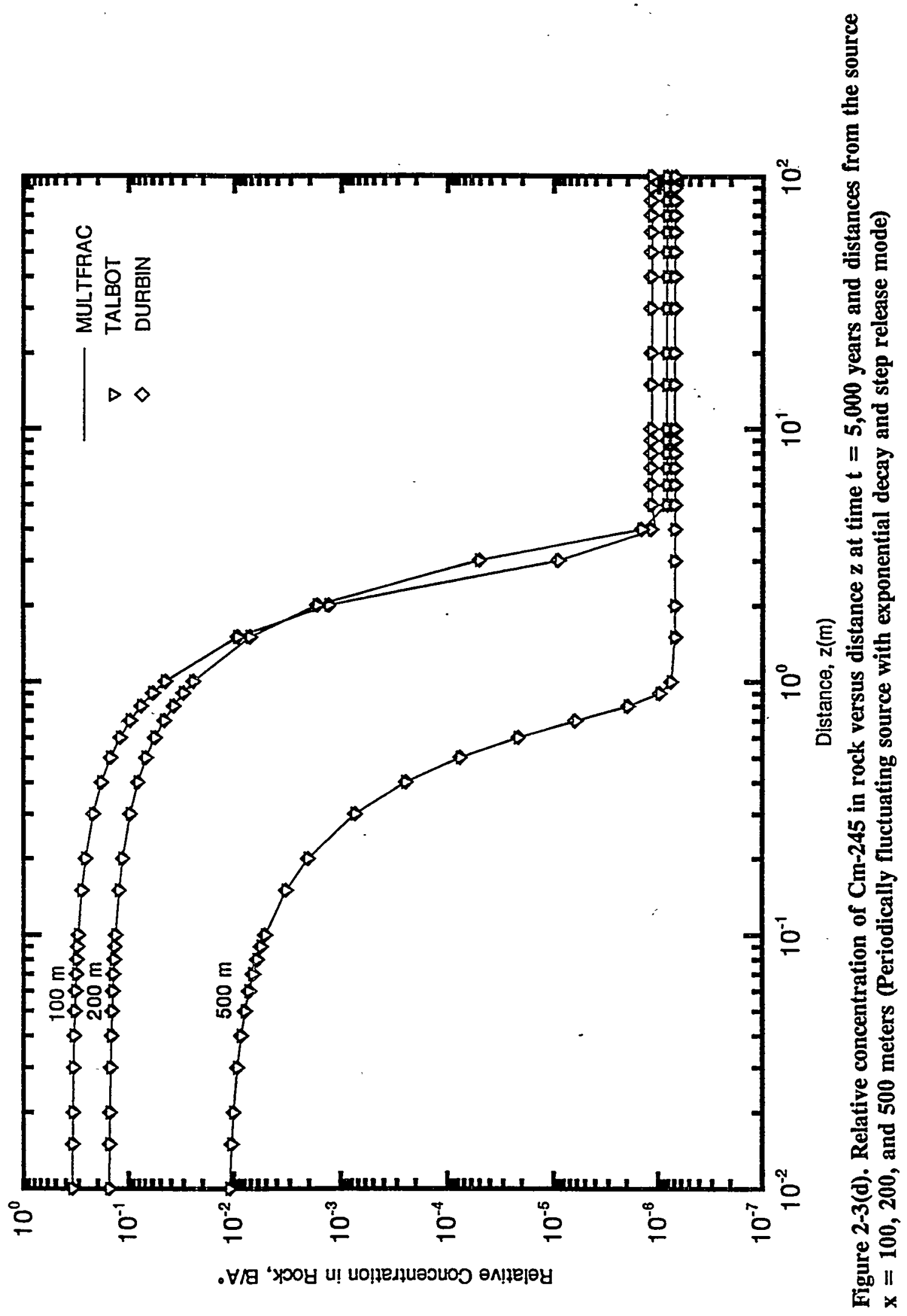


Table 2-11(a). Case 2 Results: Concentration of Cm-245 in the rock matrix Layer 2, at distance $x=100$ meters and time $t=5,000$ years (Periodically fluctuating source with exponential decay and step release mode)

\begin{tabular}{|c|c|c|c|}
\hline DISTANCE $\mathrm{z}(\mathrm{m})$ & MULTFRAC & TALBOT & DURBIN \\
\hline $1.500 \mathrm{E}-02$ & $3.446 \mathrm{E}-01$ & $3.446 \mathrm{E}-01$ & $3.446 \mathrm{E}-01$ \\
\hline $2.000 \mathrm{E}-02$ & $3.421 \mathrm{E}-01$ & $3.421 \mathrm{E}-01$ & $3.421 \mathrm{E}-01$ \\
\hline $3.000 \mathrm{E}-02$ & 3.373E-01 & $3.373 \mathrm{E}-01$ & $3.373 \mathrm{E}-01$ \\
\hline $4.000 \mathrm{E}-02$ & $3.326 \mathrm{E}-01$ & $3.326 \mathrm{E}-01$ & $3.326 \mathrm{E}-01$ \\
\hline $5.000 \mathrm{E}-02$ & $3.278 \mathrm{E}-01$ & $3.278 \mathrm{E}-01$ & $3.278 \mathrm{E}-01$ \\
\hline
\end{tabular}

Table 2-11(b). Case 2 Results: Concentration of $\mathrm{Cm}-245$ in the rock matrix Layer 3, at distance $x=200$ meters and time $t=5,000$ years (Periodically fluctuating source with exponential decay and step release mode)

\begin{tabular}{|c|c|c|c|}
\hline DISTANCE z(m) & MULTFRAC & TALBOT & DURBIN \\
\hline $1.000 \mathrm{E}-02$ & $1.539 \mathrm{E}-01$ & $1.539 \mathrm{E}-01$ & $1.539 \mathrm{E}-01$ \\
\hline $1.500 \mathrm{E}-02$ & $1.528 \mathrm{E}-01$ & $1.528 \mathrm{E}-01$ & $1.528 \mathrm{E}-01$ \\
\hline $2.000 \mathrm{E}-02$ & $1.516 \mathrm{E}-01$ & $1.516 \mathrm{E}-01$ & $1.516 \mathrm{E}-01$ \\
\hline $3.000 E-02$ & $1.494 \mathrm{E}-01$ & $1.494 \mathrm{E}-01$ & $1.494 \mathrm{E}-01$ \\
\hline $4.000 \mathrm{E}-02$ & $1.472 \mathrm{E}-01$ & $1.472 \mathrm{E}-01$ & $1.472 \mathrm{E}-01$ \\
\hline $5.000 \mathrm{E}-02$ & $1.450 \mathrm{E}-01$ & $1.450 \mathrm{E}-01$ & $1.450 \mathrm{E}-01$ \\
\hline
\end{tabular}

Table 2-11(c). Case 2 Results: Concentration of $\mathrm{Cm}-245$ in the rock matrix Layer 5, at distance $x=500$ meters and time $t=5,000$ years (Periodically fluctuating source with exponential decay and step release mode)

\begin{tabular}{|c|c|c|c|}
\hline DISTANCE z(m) & MULTFRAC & TALBOT & DURBIN \\
\hline $1.000 \mathrm{E}-02$ & $1.101 \mathrm{E}-02$ & $1.100 \mathrm{E}-02$ & $1.100 \mathrm{E}-02$ \\
\hline $1.500 \mathrm{E}-02$ & $1.057 \mathrm{E}-02$ & $1.057 \mathrm{E}-02$ & $1.057 \mathrm{E}-02$ \\
\hline $2.000 \mathrm{E}-02$ & $1.015 \mathrm{E}-02$ & $1.015 \mathrm{E}-02$ & $1.015 \mathrm{E}-02$ \\
\hline $3.000 \mathrm{E}-02$ & $9.353 \mathrm{E}-03$ & $9.352 \mathrm{E}-03$ & $9.352 \mathrm{E}-03$ \\
\hline $4.000 \mathrm{E}-02$ & $8.611 \mathrm{E}-03$ & $8.610 \mathrm{E}-03$ & 8.610E-03 \\
\hline $5.000 \mathrm{E}-02$ & $7.921 \mathrm{E}-03$ & $7.920 \mathrm{E}-03$ & $\cdot 7.920 \mathrm{E}-03$ \\
\hline
\end{tabular}

Extracted data; complete data run is provided in microfiche form at the back of this report 


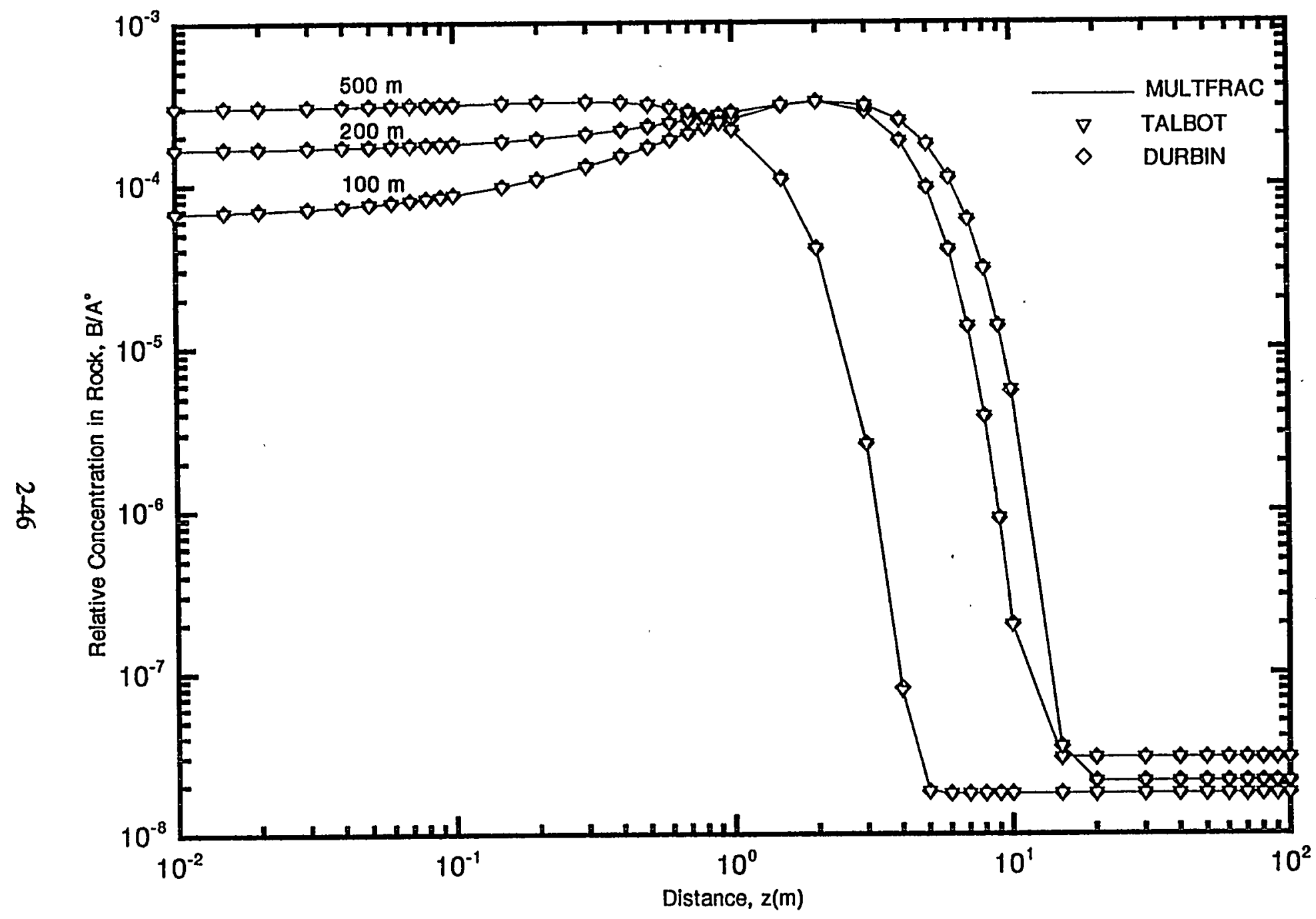

Figure 2-3(e). Relative concentration of $\mathrm{Cm}-245$ in rock versus distance at $t=50,000$ years (Periodically fluctuating source with exponential decay and band release mode) 
Table 2-12(a). Case 2 Results: Concentration of $\mathrm{Cm}-245$ in the rock matrix Layer 2, at distance $x=100$ meters and time $t=50,000$ years (Periodically fluctuating source with exponential decay and band release mode)

\begin{tabular}{lllll} 
DISTANCE $z(m)$ & MULTFRAC & TALBOT & DURBIN \\
\cline { 2 - 3 } & & & \\
$1.000 \mathrm{E}-02$ & $6.722 \mathrm{E}-05$ & $6.722 \mathrm{E}-05$ & $6.723 \mathrm{E}-05$ \\
$1.500 \mathrm{E}-02$ & $6.833 \mathrm{E}-05$ & $6.833 \mathrm{E}-05$ & $6.834 \mathrm{E}-05$ \\
$2.000 \mathrm{E}-02$ & $6.944 \mathrm{E}-05$ & $6.944 \mathrm{E}-05$ & $6.944 \mathrm{E}-05$ \\
$3.000 \mathrm{E}-02$ & $7.166 \mathrm{E}-05$ & $7.166 \mathrm{E}-05$ & $7.165 \mathrm{E}-05$ \\
$4.000 \mathrm{E}-02$ & $7.387 \mathrm{E}-05$ & $7.387 \mathrm{E}-05$ & $7.387 \mathrm{E}-05$ \\
$5.000 \mathrm{E}-02$ & $7.608 \mathrm{E}-05$ & $7.608 \mathrm{E}-05$ & $7.607 \mathrm{E}-05$
\end{tabular}

Table 2-12(b). Case 2 Results: Concentration of $\mathrm{Cm}-245$ in the rock matrix Layer 3, at distance $x=200$ meters and time $t=50,000$ years (Periodically fluctuating source with exponential decay and band release mode)

\begin{tabular}{|c|c|c|c|}
\hline DISTANCE $\mathrm{z}(\mathrm{m})$ & MULTERAC & TALBOT & DURBIN \\
\hline $1.000 \mathrm{E}-02$ & $1.661 \mathrm{E}-04$ & $1.661 \mathrm{E}-04$ & $1.660 \mathrm{E}-04$ \\
\hline $1.500 \mathrm{E}-02$ & $1.668 \mathrm{E}-04$ & $1.668 \mathrm{E}-04$ & $1.667 \mathrm{E}-04$ \\
\hline $2.000 \mathrm{E}-02$ & $1.675 \mathrm{E}-04$ & $1.675 \mathrm{E}-04$ & $1.674 \mathrm{E}-04$ \\
\hline $3.000 \mathrm{E}-02$ & $1.689 \mathrm{E}-04$ & $1.689 \mathrm{E}-04$ & $1.688 \mathrm{E}-04$ \\
\hline $4.000 \mathrm{E}-02$ & $1.703 \mathrm{E}-04$ & $1.703 E-04$ & $1.702 \mathrm{E}-04$ \\
\hline $5.000 \mathrm{E}-02$ & $1.716 \mathrm{E}-04$ & $1.716 \mathrm{E}-04$ & $1.716 \mathrm{E}-04$ \\
\hline
\end{tabular}

Table 2-12(c). Case 2 Results: Concentration of $\mathrm{Cm}-245$ in the rock matrix Layer 5, at distance $x=500$ meters and time $t=\mathbf{5 0 , 0 0 0}$ years (Periodically fluctuating source with exponential decay and band release mode)

\begin{tabular}{|c|c|c|c|}
\hline DISTANCE $\mathrm{z}(\mathrm{m})$ & MULTFRAC & TALBOT & DURBIN \\
\hline $1.000 \mathrm{E}-02$ & $3.001 E-04$ & $3.001 \mathrm{E}-04$ & $3.001 E-04$ \\
\hline $1.500 \mathrm{E}-02$ & $3.010 \mathrm{E}-04$ & $3.010 \mathrm{E}-04$ & $3.010 \mathrm{E}-04$ \\
\hline $2.000 \mathrm{E}-02$ & $3.019 \mathrm{E}-04$ & $3.019 E-04$ & $3.019 \mathrm{E}-04$ \\
\hline $3.000 \mathrm{E}-02$ & 3.037E-04 & $3.037 E-04$ & $3.037 \mathrm{E}-04$ \\
\hline $4.000 \mathrm{E}-02$ & 3.054E-04 & $3.054 \mathrm{E}-04$ & $3.054 \mathrm{E}-04$ \\
\hline $5.000 \mathrm{E}-02$ & $3.070 \mathrm{E}-04$ & $3.070 \mathrm{E}-04$ & $3.070 \mathrm{E}-04$ \\
\hline
\end{tabular}

Extracted data; complete data run is provided in microfiche form at the back of this report 


\section{ANALYTICALLY DERIVED SENSITIVITIES IN THE FRACTURE}

\subsection{LOCAL SENSITTVITIES}

Local sensitivities or first-order derivatives of the concentration and cumulative mass in the fracture, with respect to a typical parameter $\alpha$ (i.e., $\partial \mathrm{A}_{\mathrm{i}} / \partial \alpha_{\mathrm{i}}$ and $\partial \mathrm{M}_{\mathrm{i}} / \partial \alpha_{\mathrm{i}}$ ), are required in parameter estimation or sampling design studies (sensitivity of concentration), and in predicting the sensitivity and uncertainty of the performance of a system (sensitivity of cumulative mass). There are two classical methods for evaluating the local sensitivities. The first, and the most accurate, is the analytically derived solution, which is estimated after a direct differentiation of the closed form solution with respect to the parameters of interest. The second uses numerical derivatives obtained from finite-difference approximations. In the following, the analytically derived sensitivities are related to the concentration in the fracture, where the initial concentration in both fracture and rock matrix are assumed to correspond to some constant values. In addition, the sensitivities are verified through a comparison of the results with those derived through finite-difference approximations (i.e., forward-difference and centraldifference).

\subsection{ANALYTICAL DERIVATIVES}

This section presents the analytically derived local sensitivities of the concentrations and cumulative mass flux in the fracture with respect to the entire range of parameters governing the nondispersive transport process in the fractured rock system of interest described by the equations reported in the previous chapter of this report.

\subsubsection{Total Differentials}

In order to evaluate the first-order derivatives of the concentration and cumulative mass in the fracture reported in the preceding sections, the total differentials of $R_{i}, R_{i}^{\prime}, c_{i j}, p_{i}, \theta_{m n}, \gamma_{m m}, q_{i}$, and $\beta_{j i}$, given by Eqs. (2-5), (2-6), (2-29), (2-35b), (2-39), (2-40), (2-47) and (2-48), (see also Appendix F), have to be defined. Applying the chain rule of differentiation, these may be written as

$$
\begin{gathered}
d R_{i}=\frac{\partial R_{i}}{\partial K_{f i}} d K_{f i}+\frac{\partial R_{i}}{\partial b_{i}} d b_{i} \\
d{R^{\prime}}_{i}^{\prime}=\frac{\partial R_{i}^{\prime}}{\partial \Phi_{i}} d \phi_{i}+\frac{\partial R_{i}^{\prime}}{\partial \rho_{r i}} d \rho_{r i}+\frac{\partial R_{i}^{\prime}}{\partial K_{r i}} d K_{r i} \\
d c_{f i}=\frac{\partial c_{f i}}{\partial \phi_{i}} d \phi_{i}+\frac{\partial c_{f i}}{\partial b_{i}} d b_{i}+\frac{\partial c_{f i}}{\partial R_{i}^{\prime}} d R_{i}^{\prime}+\frac{\partial c_{f i}}{\partial D_{p_{t}}} d D_{p_{t}} \\
d p_{i}=\frac{\partial p_{i}}{\partial u_{i}} d u_{i}+\frac{\partial p_{i}}{\partial \alpha_{i}} d \alpha_{i}
\end{gathered}
$$




$$
\begin{gathered}
d \theta_{m n}=\frac{\partial \theta_{m n}}{\partial c_{f i}} d c_{f i}+\frac{\partial \theta_{m n}}{\partial \Gamma_{i}} d \Gamma_{i} \\
d \gamma_{m n}=\frac{\partial \gamma_{m n}}{\partial R_{i}} d R_{i}+\frac{\partial \gamma_{m n}}{\partial \Gamma_{i}} d \Gamma_{i} \\
d q_{i}=\frac{\partial q_{i}}{\partial c_{f i}} d c_{f i}+\frac{\partial q_{i}}{\partial R_{i}} d R_{i}+\frac{\partial q_{i}}{\partial p_{i}} d p_{i} \\
d \beta_{j i}=\frac{\partial \beta_{j i}}{\partial c_{f i}} d c_{f i}+\frac{\partial \beta_{j i}}{\partial R_{i}} d R_{i}+\frac{\partial \beta_{j i}}{\partial p_{i}} d p_{i} \\
d \Gamma_{i}=\frac{\partial \Gamma_{i}}{\partial L_{i}} d L_{i}+\frac{\partial \Gamma_{i}}{\partial u_{i}} d u_{i} \\
\Gamma_{i}=\bar{\eta}_{i}, i<n \\
\Gamma_{i}=\eta_{i}, i=n
\end{gathered}
$$

Substitution of Eqs. (3-3) and (3-9) in Eq. (3-5) gives

$$
\begin{gathered}
d \theta_{m n}=\frac{\partial \theta_{m n}}{\partial c_{f i}}\left[\frac{\partial c_{f i}}{\partial \Phi_{i}} d \Phi_{i}+\frac{\partial c_{f i}}{\partial b_{i}} d b_{i}+\frac{\partial c_{f i}}{\partial R_{i}^{\prime}} d R_{i}^{\prime}+\frac{\partial c_{f i}}{\partial D_{p i}} d D_{p i}\right] \\
+\frac{\partial \theta_{m}}{\partial \Gamma_{i}}\left[\frac{\partial \Gamma_{i}}{\partial L_{i}} d L_{i}+\frac{\partial \Gamma_{i}}{\partial u_{i}} d u_{i}\right]
\end{gathered}
$$

Similarly, substituting Eqs. (3-1) and (3-9) in Eq. (3-6) yields

$$
d \gamma_{m n}=\frac{\partial \gamma_{m u r}}{\partial R_{i}} d R_{i}+\frac{\partial \gamma_{m n}}{\partial \Gamma_{i}}\left[\frac{\partial \Gamma_{i}}{\partial L_{i}} d L_{i}+\frac{\partial \Gamma_{i}}{\partial u_{i}} d u_{i}\right]
$$

where

$$
d u_{i}=\frac{\partial u_{i}}{\partial b_{i}} d b_{i}
$$

Note that the total differentials of $R_{i}$ and $R_{i}^{\prime}$, as given by Eqs. (3-1) and (3-2), are used whenever appropriate (i.e., if either $R_{i}$ or $R_{i}^{\prime}$ is expressed in terms of their respective components). 
Using the following partial derivatives

$$
\begin{aligned}
& \frac{\partial \Gamma_{i}}{\partial \tilde{L}_{i}}=\frac{1}{u_{i}} \\
& \tilde{L}_{i}= \begin{cases}L_{i}, & i<n \\
x-x_{i-1}, & i=n\end{cases} \\
& \frac{\partial \Gamma_{i}}{\partial u_{i}}=-\frac{\tilde{L}_{i}}{u_{i}^{2}} \\
& \frac{\partial \theta_{m}}{\partial c_{f i}}=\Gamma_{i} \\
& \frac{\partial \theta_{m}}{\partial \Gamma_{i}}=c_{f i} \\
& \frac{\partial \gamma_{m n}}{\partial \Gamma_{i}}=R_{i} \\
& \frac{\partial \gamma_{m n}}{\partial R_{i}}=\Gamma_{i} \\
& \frac{\partial q_{i}}{\partial c_{f i}}=\frac{c_{f i}}{q_{i} R_{i}^{2}} \\
& \frac{\partial q_{i}}{\partial R_{i}}=-\frac{2}{q_{i}}\left[\frac{c_{f i}^{2}}{2 R_{i}^{3}}+\frac{p_{i}}{R_{i}^{2}}\right] \\
& \frac{\partial q_{i}}{\partial p_{i}}=\frac{2}{q_{i} R_{i}} \\
& \frac{\partial \beta_{j i}}{\partial c_{f i}}=\frac{1}{2 R_{i}}+(-1)^{j} \frac{c_{f i}}{2 q_{i} R_{l}^{2}}, j=1,2
\end{aligned}
$$




$$
\begin{gathered}
\frac{\partial \beta_{j i}}{\partial R_{i}}=-\frac{c_{f_{i}}}{2 R_{i}^{2}}-(-1)^{j} \frac{1}{R_{i}^{2}}\left[\frac{c_{f i}^{2}}{2 R_{i}}+p_{i}\right], j=1,2 \\
\frac{\partial \beta_{j i}}{\partial q_{i}}=(-1)^{\prime} \frac{1}{2}, j=1,2 \\
\frac{\partial \beta_{j i}}{\partial p_{i}}=\frac{\partial \beta_{j i}}{\partial q_{i}} \frac{\partial q_{i}}{\partial p_{i}}=(-1)^{j} \frac{1}{q_{i} R_{i}} \\
\frac{\partial p_{i}}{\partial u_{i}}=\alpha_{i} \\
\frac{\partial p_{i}}{\partial \alpha_{i}}=u_{i} \\
\frac{\partial u_{i}}{\partial b_{i}}=-\frac{Q}{2 b_{i}^{2}}
\end{gathered}
$$

the first-order derivatives of $\theta_{\operatorname{ma}}, \gamma_{\mathrm{ma}}, \mathrm{c}_{\mathrm{in}}, \mathrm{R}_{\mathrm{i}}$, and $\mathrm{R}_{\mathrm{i}}^{\prime}$, with respect to a typical parameter $\alpha_{\mathrm{i}}$, are reported in Tables 3-1 through 3-5, respectively. The total differential of $\beta_{\mathrm{ji}}$, given by Eq. (3-8), may be evaluated based on the latter tables, and the various derivatives given in Eqs. (3-14) through (3-20). Note that $Q$ in Eq. (3-20) corresponds to the steady flow rate of water $\left(Q=2 u_{i} b_{i}\right)$ through the fracture.

\subsubsection{First-Order Derivatives of the Concentrations} written as

Using the notations reported in Appendix D, the various components of Eq. (2-42) may now be

$$
F_{o_{1 n}}(x, t)=A^{0} e^{-\lambda t 1} P_{1 n} U\left(t-\gamma_{1 n}\right)
$$


for a continuously decaying source

$$
\begin{gathered}
{ }_{1} H_{i m n}(x, t)=e^{-\lambda t}\left[b_{1 i}{ }^{1} P_{m n}+\left(a_{1 i}-b_{1 i}\right){ }^{3} P_{i m n}{ }^{4} P_{i m n}{ }^{2} P_{m n}\right] U\left(t-\gamma_{m n}\right) \\
{ }_{2} H_{i m n}(x, t)=e^{-\lambda t} a_{2 i} \sum_{j=1}^{2}(-1)^{j}{ }^{9} P_{j i}{ }^{8} P_{j i m n}{ }^{7} P_{j i m n} U\left(t-\gamma_{m n}\right) \\
F_{n}(x, t)=e^{-\lambda t} a_{2 n} \sum_{i=1}^{2}(-1)^{j}{ }^{9} P_{\epsilon}{ }^{10} P_{\epsilon}{ }^{11} P_{\epsilon} \\
+e^{-\lambda t}\left[b_{1 n}+\left(a_{1 n}-b_{1 n}\right){ }^{5} P_{n}{ }^{6} P_{n}\right]
\end{gathered}
$$


Table 3-1. First-order partial derivatives of $\theta_{\operatorname{mn}}$ with respect to input parameters $\alpha_{i}$ (i.e., $\mathbf{L}_{i}, \mathbf{u}_{\mathrm{i}}, \phi_{\mathrm{i}}, \rho_{\mathrm{i}}, \mathbf{D}_{\mathrm{p} i}, \mathbf{R}_{\mathrm{i}}, \mathbf{K}_{\mathrm{in}}, \mathbf{R}_{\mathrm{i}}^{\prime}$, and $\mathrm{K}_{\mathrm{ri}}$ )

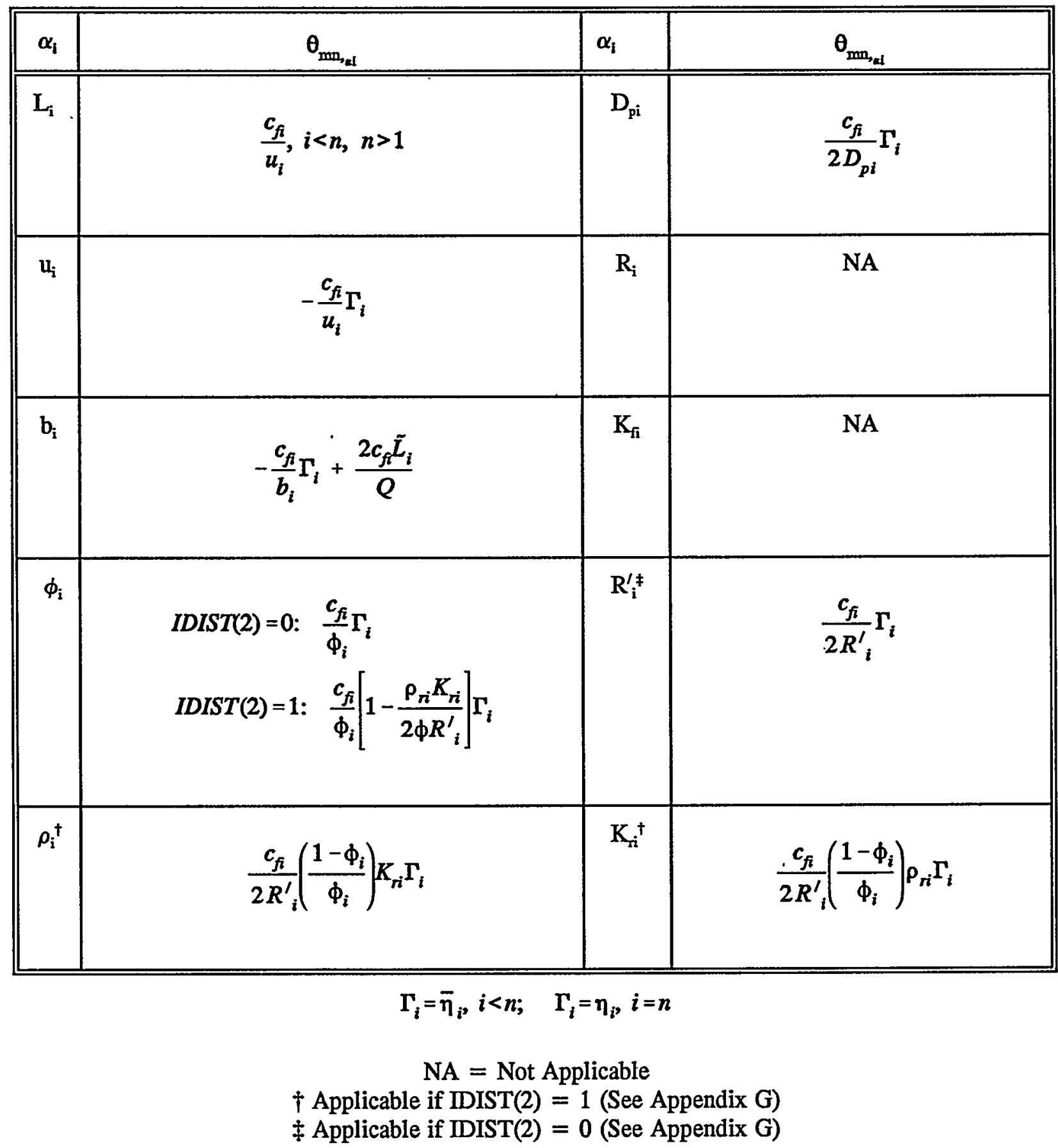


Table 3-2. First-order partial derivatives of $\gamma_{\mathrm{mn}}$ with respect to input parameters $\alpha_{1}$ (i.e., $L_{i}, u_{i}, b_{i}, R_{i}$, and $K_{n}$ )

\begin{tabular}{|c|c|}
\hline$\alpha_{, 1}$ & $\gamma_{\text {min, }}$ \\
\hline $\mathrm{L}_{\mathrm{i}}$ & $\frac{R_{i}}{u_{i}}, i<n, n>1$ \\
\hline $\mathbf{u}_{\mathbf{i}}$ & $-\frac{\boldsymbol{R}_{i} \boldsymbol{\Gamma}_{\boldsymbol{i}}}{\boldsymbol{u}_{\boldsymbol{i}}}$ \\
\hline$b_{i}^{\dagger}$ & $\begin{array}{l}I D I S T(1)=0: \quad \frac{2 R_{i} \tilde{L}_{i}}{Q} \\
I D I S T(1)=1:-\frac{K_{f} \Gamma_{i}}{b_{i}^{2}}+\frac{2 R_{i} \tilde{L}_{i}}{Q}\end{array}$ \\
\hline$R_{i}^{\ddagger}$ & $\Gamma_{i}$ \\
\hline $\mathrm{K}_{\mathrm{ni}}{ }^{\dagger}$ & $\frac{\Gamma_{i}}{b_{i}}$ \\
\hline
\end{tabular}

$\dagger$ Applicable only if IDIST(1) $=1$ (See Appendix G)

$\doteqdot$ Applicable only if IDIST(1) $=0$ (See Appendix G) 
Table 3-3. First-order partial derivatives of $c_{n}$ with respect to input parameters $\alpha_{i}$ (i.e., $L_{i}, u_{i}, \phi_{i}, \rho_{i}, D_{p i}, R_{i}, K_{n}, R_{i}^{\prime}$, and $K_{r i}$ )

\begin{tabular}{|c|c|c|c|}
\hline$\alpha_{\mathrm{i}}$ & $c_{f_{i_{\text {el }}}}$ & $\alpha_{i}$ & $c_{f_{i_{u t}}}$ \\
\hline $\mathrm{L}_{\mathbf{i}}$ & NA & $D_{p i}$ & $\frac{c_{f i}}{2 D_{p i}}$ \\
\hline $\mathbf{u}_{\mathbf{i}}$ & NA & $\mathrm{R}_{\mathrm{i}}$ & NA \\
\hline$b_{i}$ & $-\frac{c_{f i}}{b_{i}}$ & $K_{\mathrm{fi}}$ & NA \\
\hline$\phi_{\mathrm{i}}$ & $\begin{array}{ll}\operatorname{IDIST}(2)=0: & \frac{c_{f i}}{\phi_{i}} \\
\operatorname{IDIST}(2)=1: & \frac{c_{f i}}{\phi_{i}}\left[1-\frac{\rho_{r} K_{r i}}{2 \phi R_{i}^{\prime}}\right]\end{array}$ & $\mathbf{R}_{\dot{i}}^{\prime \neq}$ & $\frac{c_{f i}}{2 R^{\prime}}$ \\
\hline$\rho_{i}^{\dagger}$ & $\frac{c_{f i}}{2 R_{i}^{\prime}}\left(\frac{1-\phi_{i}}{\phi_{i}}\right) K_{r i}^{\prime}$ & $\mathrm{K}_{r i}^{\dagger}$ & $\frac{c_{f_{i}}}{2 R_{i}^{\prime}}\left(\frac{1-\phi_{i}}{\phi_{i}}\right) \rho_{r i}$ \\
\hline
\end{tabular}

$$
\text { NA }=\text { Not Applicable }
$$

$\uparrow$ Applicable only if IDIST(2) $=1$ (See Appendix G)

$\ddagger$ Applicable only if IDIST(2) $=0$ (See Appendix G) 
Table 3-4. First-order partial derivatives of $R_{i}$ with respect to input parameters $\alpha_{i}$ (i.e., $b_{i}, R_{b}$ and $K_{n}$ )

\begin{tabular}{|c|c|c|c|c|c|}
\hline$\alpha_{1}$ & $\mathbf{R}_{\mathrm{i}_{\mathrm{ad}}}$ & $\alpha_{i}$ & $R_{i_{\text {ded }}}$ & $\alpha_{i}$ & $R_{i, g}$ \\
\hline$b_{i}^{\dagger}$ & $-\frac{K_{f i}}{b_{i}^{2}}$ & $\mathbf{R}_{\mathbf{i}}^{*}$ & 1.0 & $\mathrm{~K}_{\mathrm{fi}}^{\dagger}$ & $\frac{1}{b_{i}}$ \\
\hline
\end{tabular}

$\dagger$ Applicable only if IDIST(1) $=1$ (See Appendix G)

$\ddagger$ Applicable only if IDIST(1) $=0$ (See Appendix G)

Table 3-5. First-order partial derivatives of $\mathbf{R}_{i}^{\prime}$ with respect to input parameters $\alpha_{i}$ (i.e., $\Phi_{i}, \rho_{i}, K_{r i}$, and $R_{i}^{\prime}$ )

\begin{tabular}{|c|c|c|c|c|c|c|c|}
\hline$\alpha_{1}$ & $\mathbf{R}_{i_{\text {ald }}^{\prime}}^{\prime}$ & $\alpha_{1}$ & $\mathbf{R}_{\mathbf{i}_{\text {a }}}^{\prime}$ & $\alpha_{1}$ & $R_{i_{\text {da }}}^{\prime}$ & $\alpha_{1}$ & $\mathrm{R}_{\mathbf{i}_{\mathrm{ed}}}^{\prime}$ \\
\hline$\Phi_{i}^{\dagger}$ & $-\frac{1}{\phi_{i}^{2}}$ & $\rho_{i}^{\dagger}$ & $\frac{\left(1-\Phi_{i}\right)}{\Phi_{i}} K_{n i}$ & $\mathrm{~K}_{\mathrm{i}}^{\dagger}$ & $\frac{\left(1-\Phi_{i}\right)}{\Phi_{i}} \rho_{n}$ & $\mathbf{R}_{i}^{\prime \neq}$ & 1.0 \\
\hline
\end{tabular}

$\dagger$ Applicable only if IDIST(1) $=1$ (See Appendix G)

$\ddagger$ Applicable only if IDIST(1) $=0$ (See Appendix G)

The partial derivatives of the above equations, with respect to a typical parameter $\alpha$ at the exclusion of $\mathrm{A}^{0}$, $\lambda, \alpha, a_{1 i}, a_{2 i}$, and $b_{1 i}$, may now be written as

$$
\begin{aligned}
& F_{0_{1 n_{g}}}(x, t)=A^{0} e^{-\lambda t}{ }^{1} P_{1 n_{g}} U\left(t-\gamma_{1 n}\right)
\end{aligned}
$$

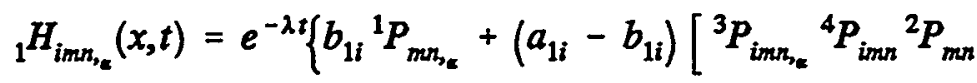

$$
\begin{aligned}
& \left.\left.+{ }^{3} P_{i m n}\left({ }^{4} P_{i m n n_{\mathrm{se}}}{ }^{2} P_{m n}+{ }^{4} P_{i m n}{ }^{2} P_{m n_{\mathrm{s}}}\right)\right]\right\} U\left(t-\gamma_{m n}\right)
\end{aligned}
$$




$$
\begin{aligned}
& { }_{2} H_{i m n_{a}}(x, t)=e^{-\lambda t} a_{2 i}\left[\sum_{j=1}^{2}(-1)^{j}{ }^{9} P_{j i_{\alpha}}{ }^{8} P_{j i m n}{ }^{7} P_{j i m n}\right.
\end{aligned}
$$

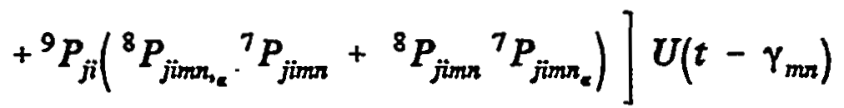

$$
\begin{aligned}
& F_{m_{m}}(x, t)=e^{-\lambda t} a_{2 n} \sum_{j=1}^{2}(-1)^{j}\left[{ }^{9} P_{j n}\left({ }^{10} P_{j n_{m}}{ }^{11} P_{j m_{3}}+{ }^{10} P_{j n}{ }^{11} P_{j m_{m}}\right)\right. \\
& \left.+{ }^{9} P_{j n_{k}}{ }^{10} P_{j n}{ }^{11} P_{j n}\right] \\
& +e^{-\lambda t}\left[b_{1 n}+\left(a_{1 n}-b_{1 n}\right)\left({ }^{5} P_{n_{1,}}{ }^{6} P_{n}+{ }^{5} P_{n}{ }^{6} P_{n n_{e}}\right)\right]
\end{aligned}
$$

the first-order partial derivatives of the functions given by Eq. (3-21), with respect to $A^{0}, \lambda, a_{1 i}, a_{2 i}$, and $b_{1 i}$, may now be written as

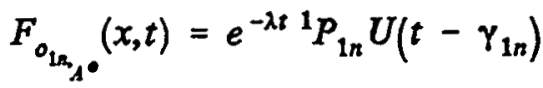

$$
\begin{aligned}
& F_{o_{1 n_{2}}}(x, t)=-t F_{o_{1 n}}(x, t) U\left(t-\gamma_{1 n}\right) \\
& { }_{1} H_{i m n n_{a_{1}}}(x, t)=e^{-\lambda s}\left[{ }^{3} P_{i m n}{ }^{4} P_{i m n}{ }^{2} P_{m n}\right] U\left(t-\gamma_{m n}\right) \\
& { }_{1} H_{i m n, 2}(x, t)=-t_{1} H_{i m n}(x, t) U\left(t-\gamma_{m n}\right) \\
& { }_{1} H_{i m m b_{b n}}(x, t)=e^{-\lambda t}\left[{ }^{1} P_{m n}-{ }^{3} P_{i m n}{ }^{4} P_{i m n}{ }^{2} P_{m n}\right] U\left(t-\gamma_{m n}\right) \\
& { }_{2} H_{i m r_{a_{2} t}}(x, t)=\frac{1}{a_{2 i}}{ }_{2} H_{i m n}(x, t) U\left(t-\gamma_{m n}\right) \\
& { }_{2} H_{i m n_{2}}(x, t)=-t{ }_{2} H_{i m n}(x, t) U\left(t-\gamma_{m n}\right) \\
& F_{n_{a_{1 n}}}(x, t)=e^{-\lambda t{ }^{5} P_{n}{ }^{6} P_{n}} \\
& F_{n_{i 2 n}}=e^{-\lambda t}\left[\sum_{i=1}^{2}(-1)^{j}{ }^{10} P_{i n}{ }^{11} P_{i n}\right]
\end{aligned}
$$




$$
\begin{gathered}
F_{n, b_{1 n}}(x, t)=1-e^{-\lambda t}\left[{ }^{5} P_{n}{ }^{6} P_{n}\right] \\
F_{n_{2,}}(x, t)=-t F_{n}(x, t)
\end{gathered}
$$

\subsubsection{First-Order Derivatives of the Cumulative Mass} be written as

Using the notations reported in Appendix E, the various components of Eq. (2-62) may now

$$
Q_{0_{2 n}}(x, t)=A^{0}\left\{-{ }^{0} G^{1} G_{1 n}+\left[{ }^{3} G_{1 n}^{+}{ }^{2} G_{1 n}^{+}+{ }^{3} G_{1 n}^{-2} G_{1 n}^{-}\right]\right\} U\left(t-\gamma_{m n}\right)
$$

for a continuously decaying source

$$
\begin{aligned}
& { }_{1} Q_{i m n}^{\prime}(x, t)=b_{11}\left\{-{ }^{0} G^{1} G_{m n}+{ }^{2} G_{m n}^{+}{ }^{3} G_{m n}^{+}+{ }^{2} G_{m n}^{-}{ }^{3} G_{m n}^{-}\right\} U\left(t-\gamma_{m n}\right) \\
& +\left(a_{1 i}-b_{1 i}\right)\left\{{ }^{7} G_{i}{ }^{6} G_{i m n}{ }^{5} G_{i m n}-{ }^{3} G_{m n}^{+}{ }^{2} G_{m n}^{+}{ }^{4} G_{i}^{-}\right. \\
& \left.+{ }^{3} G_{m n}^{-} G_{m n}^{-}{ }^{4} G_{i}^{+}\right\} U\left(t-\gamma_{m n}\right) . \\
& \left.{ }_{2} Q_{i m n}^{\prime}(x, t)=a_{2 i} \sum_{j=1}^{2}(-1)\right\}\left\{{ }^{10} G_{j i}^{9} G_{j i m n}{ }^{14} G_{j i}{ }^{8} G_{j i m n}+\right. \\
& \left.{ }^{10} G_{H i}\left(-{ }^{3} G_{m n}^{+2} G_{m n}^{+11} G_{i}^{-}+{ }^{3} G_{m n}^{-2} G_{m n}^{-11} G_{i}^{+}\right)\right\} U\left(t-\gamma_{m n}\right) \\
& Q_{n}(x, t)=a_{2 n} \sum_{j=1}^{2}(-1)^{j}\left\{{ }^{10} G_{j n}{ }^{14} G_{j n}\left[{ }^{12} G_{j n}{ }^{13} G_{j n}+{ }^{15} G_{j n}\left({ }^{16} G_{j n}-1\right)\right]\right\} \\
& +b_{1 n}\left(\frac{1}{\lambda}-{ }^{0} G\right)+\left(a_{1 n}-b_{1 n}\right){ }^{7} G_{n}\left[{ }^{17} G_{n}{ }^{18} G_{n}+{ }^{19} G_{n}-1\right]
\end{aligned}
$$

The partial derivatives of Eq. (3-27d), with respect to a typical parameter $\alpha$ at the exclusion of $A^{0}, a_{11}, a_{2 l}$, and $b_{1 i}$, may now be written as

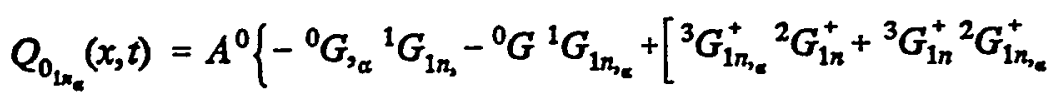

$$
\begin{aligned}
& \left.\left.+{ }^{3} G_{1 n_{\varepsilon}}^{-}{ }^{2} G_{1 n}^{-}+{ }^{3} G_{1 n}^{-}{ }^{2} G_{1 n_{\mathrm{j}}}^{-}\right]\right\}
\end{aligned}
$$




$$
\begin{aligned}
& { }_{1} Q_{t m n_{n}}^{\prime}(x, t)=b_{11}\left\{-{ }^{0} G_{,_{\alpha}}{ }^{1} G_{m n}-{ }^{0} G^{1} G_{m m_{\alpha}}+{ }^{2} G_{m n_{\varepsilon}}^{+}{ }^{3} G_{m n}^{+}+{ }^{2} G_{m n}^{+}{ }^{3} G_{m n_{3}}^{+}\right. \\
& \left.+{ }^{2} G_{m n_{a}}^{-} G_{m n}^{-}+{ }^{2} G_{m n}^{-}{ }^{3} G_{m n_{a}}^{-}\right\} U\left(t-\gamma_{m n}\right) \\
& +\left(a_{11}-b_{1 i}\right)\left\{{ }^{7} G_{i_{\mathrm{g}}}{ }^{6} G_{i m n}{ }^{5} G_{i m n}+{ }^{7} G_{i}\left({ }^{6} G_{i m n_{g}}{ }^{5} G_{i m n}+{ }^{6} G_{i m n}{ }^{5} G_{i m m_{n}}\right)\right. \\
& -{ }^{3} G_{m n_{e}}^{+}{ }^{2} G_{m n}^{+}{ }^{4} G_{i}^{-}-{ }^{3} G_{m n}^{+}{ }^{2} G_{m n_{3}}^{+}{ }^{4} G_{i}^{-}-{ }^{3} G_{m n}^{+}{ }^{2} G_{m n}^{+}{ }^{4} G_{i_{\text {e }}}^{-} \\
& \left.+{ }^{3} G_{m n_{n}}^{-}{ }^{2} G_{m n}^{-}{ }^{4} G_{i}^{+}+{ }^{3} G_{m n}^{-}{ }^{2} G_{m n_{m}}^{-}{ }^{4} G_{i}^{+}+{ }^{3} G_{m n}^{-}{ }^{2} G_{m n}^{-}{ }^{4} G_{i, n}^{+}\right\} U\left(t-\gamma_{m n}\right)
\end{aligned}
$$

$$
\begin{aligned}
& { }_{2} Q_{i m n n_{e}}^{\prime}(x, t)=a_{2 i} \sum_{j=1}^{2}(-1)^{i}\left\{{ }^{9} G_{j i m n}{ }^{8} G_{j i m n}\left[{ }^{10} G_{j j_{u_{s}}}{ }^{14} G_{j i}+{ }^{10} G_{j i}{ }^{14} G_{j i_{\mathrm{s}}}\right]+\right. \\
& { }^{10} G_{j i}{ }^{14} G_{j i}\left[{ }^{9} G_{j i m m_{m}}{ }^{8} G_{j i m n}+{ }^{9} G_{j i m n}{ }^{8} G_{j i m n}\right] \\
& -{ }^{10} G_{j i, \mathrm{a}}\left[{ }^{3} G_{m n n}^{+}{ }^{2} G_{m n}^{+11} G_{j i}^{-}-{ }^{3} G_{m n}^{-}{ }^{2} G_{m n}^{-}{ }^{11} G_{j i}^{+}\right] \\
& -{ }^{10} G_{j i}\left[{ }^{3} G_{m n_{e}}^{+}{ }^{2} G_{m n}^{+}{ }^{11} G_{j i}^{-}+{ }^{3} G_{m n}^{+}{ }^{2} G_{m n, e}^{+}{ }^{11} G_{j i}^{-}+{ }^{3} G_{m n}^{+}{ }^{2} G_{m n}^{+}{ }^{11} G_{j i_{e}}^{-}\right. \\
& \left.\left.-{ }^{3} G_{m n,}^{-}{ }^{2} G_{m n}^{-}{ }^{11} G_{j i}^{+}-{ }^{3} G_{m n}^{-}{ }^{2} G_{m n, n_{a}}^{-}{ }^{11} G_{j i}^{+}-{ }^{3} G_{m n}^{-}{ }^{2} G_{m n}^{-11} G_{j i_{\mathrm{x}}}^{+}\right]\right\} U\left(t-\gamma_{m n}\right)
\end{aligned}
$$

3-12 


$$
\begin{aligned}
& Q_{n_{i g}}(x, t)=a_{2 n} \sum_{j=1}^{2}(-1)\left[{ }^{10} G_{j m_{m e}}{ }^{14} G_{j n}+{ }^{10} G_{j n}{ }^{14} G_{j m_{m}}\right] \\
& {\left[{ }^{12} G_{j n}{ }^{13} G_{j n}+{ }^{15} G_{j n}\left({ }^{16} G_{j n}-1\right)\right]} \\
& +{ }^{10} G_{j n}{ }^{14} G_{j n}\left[{ }^{12} G_{j n_{m e}}{ }^{13} G_{j n}+{ }^{12} G_{j n}{ }^{13} G_{j n_{m}}+{ }^{15} G_{j n_{j e}}\left({ }^{16} G_{j n}-1\right)+{ }^{15} G_{j n}{ }^{16} G_{j m_{g}}\right]
\end{aligned}
$$

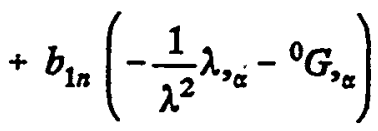

$$
\begin{aligned}
& +\left(a_{1 n}-b_{1 n}\right)\left[{ }^{7} G_{n_{1}}\left({ }^{17} G_{n}{ }^{18} G_{n}+{ }^{19} G_{n}-1\right)\right. \\
& \left.+{ }^{7} G_{n} \cdot\left({ }^{17} G_{n_{\text {e }}}{ }^{18} G_{n}+{ }^{17} G_{n}{ }^{18} G_{n_{\text {eq }}}+{ }^{19} G_{n_{\text {eq }}}\right)\right]
\end{aligned}
$$

The first-order derivatives of Eq. (3-27), with respect to parameters $A^{\circ}, a_{1 i}, a_{2 i}$, and $b_{1 i}$, are given by

$$
\begin{aligned}
& Q_{o_{I_{1, A^{0}}}}(x, t)=\frac{1}{A^{0}} Q_{o_{1 s}}(x, t) U\left(t-\gamma_{1 n}\right) \\
& { }_{1} Q_{i m n a_{a_{1}}}^{\prime}(x, t)=\left\{{ }^{7} G_{i}{ }^{6} G_{i m n}{ }^{5} G_{i m n}-{ }^{3} G_{m n}^{+}{ }^{2} G_{m n}^{+}{ }^{4} G_{i}^{-}\right. \\
& \left.+{ }^{3} G_{m n}^{-2} G_{m n}^{-}{ }^{4} G_{i}^{+}\right\} U\left(t-\gamma_{m n}\right) \\
& { }_{1} Q_{i m n_{B_{1}}}^{\prime}(x, t)=\left\{-{ }^{0} G^{1} G_{m n}+{ }^{2} G_{m n}^{+}{ }^{3} G_{m n}^{+}+{ }^{2} G_{m n}^{-}{ }^{3} G_{m n}^{-}\right. \\
& \left.-{ }^{7} G_{i}{ }^{6} G_{i m n}{ }^{5} G_{i m n}+{ }^{3} G_{m n}^{+}{ }^{2} G_{m n}^{+}{ }^{4} G_{i}^{-}-{ }^{3} G_{m n}^{-}{ }^{2} G_{m n}^{-}{ }^{4} G_{i}^{+}\right\} U\left(t-\gamma_{m n}\right) \\
& { }_{2} Q_{i m n_{a_{2}}}^{\prime}(x, t)=\frac{1}{a_{2 i}}{ }_{2} Q_{i m n}^{\prime}(x, t) U\left(t-\gamma_{m n}\right)
\end{aligned}
$$




$$
\begin{gathered}
Q_{m_{b_{1 n}}}(x, t)={ }^{7} G_{n}\left[{ }^{17} G_{n}{ }^{18} G_{n}+{ }^{19} G_{n}-1\right] \\
Q_{m_{a_{3 n}}(x, t)=} \sum_{j=1}^{2}(-1)\left\{{ }^{10} G_{j n}{ }^{14} G_{j n}\left[{ }^{12} G_{j n}{ }^{13} G_{j n}+{ }^{15} G_{j n}\left({ }^{16} G_{j n}-1\right)\right]\right\} \\
Q_{m_{3 b_{1 n}}}(x, t)=\frac{1}{\lambda}-{ }^{\circ} G-{ }^{7} G_{n}\left[{ }^{17} G_{n}{ }^{18} G_{n}+{ }^{19} G_{n}-1\right]
\end{gathered}
$$

\subsection{NUMERICAL DERIVATIVES}

The numerically achieved derivatives are based on the parameter perturbation technique (see Becker and Yeh, 1972), which uses forward- or central-difference schemes. In such instances, the choice of the step size (or perturbation vector) usually has an important bearing on the choice of the particular scheme. The investigator is commonly confronted with the problem of deciding upon the magnitude of this parameter, which is generally selected by means of a trial-and-error procedure.

The forward-difference approximation (FDA) is given by

$$
\frac{\partial f(A)}{\partial h} \approx \frac{f(A+h)-f(A)}{h}+0(h)
$$

and the central-difference approximation (CDA) is given by

$$
\frac{\partial f(A)}{\partial h} \approx \frac{f(A+h)-f(A-h)}{h}+0\left(h^{2}\right)
$$

where $\mathrm{h}$ is the step size. Ideally, the step size should be small enough to reduce the truncation error and large enough to cause a reasonable change in the significant figures of vector A. Following Bard (1974), we write

$$
\mathrm{h}=\epsilon \mathrm{A}
$$

where $10^{-5}<\epsilon<10^{-2}$.

Dennis and Schnabel (1983) recommended setting $\epsilon$ equal to the square root of the relative computer precision, which in our case corresponds approximately to $10^{-16}$. Note that for a typical parameter, $\mathrm{N}+1$ evaluations of the response vector are required at each iteration by the FDA (compared to $2 \mathrm{~N}+1$ evaluations in the case of $\mathrm{CDA}$ ), where $\mathrm{N}$ corresponds to the number of observation points.

\subsection{VERIFICATION}

The verification of the analytically derived local sensitivities was performed by comparison of the results yielded by this solution scheme with the ones obtained through the two finite-difference appproximations discussed earlier. The exact derivatives as well as the ones yielded by FDA and CDA 
were estimated, based on the data presented in Table 2-1, and values of $\epsilon$ corresponding to $10^{-16}$. Figures (3-1) and (3-2) illustrate the sensitivity of the concentration and cumulative mass of Np-237 in the fracture to a selected choice of parameters (i.e., $b, D_{p}, K_{f}$, and $K_{\uparrow}$ ) in each of the five fracture layers. With the exception of the very low range of sensitivities, the numerical results are in excellent agreement with the analytical ones. Note that the values obtained from both FDA and CDA methods were identical for all the investigated test cases, when the selected values of $\epsilon$ are less than $10^{-2}$. A detailed examination of the sensitivities will be presented in Volume 2 of this report. 


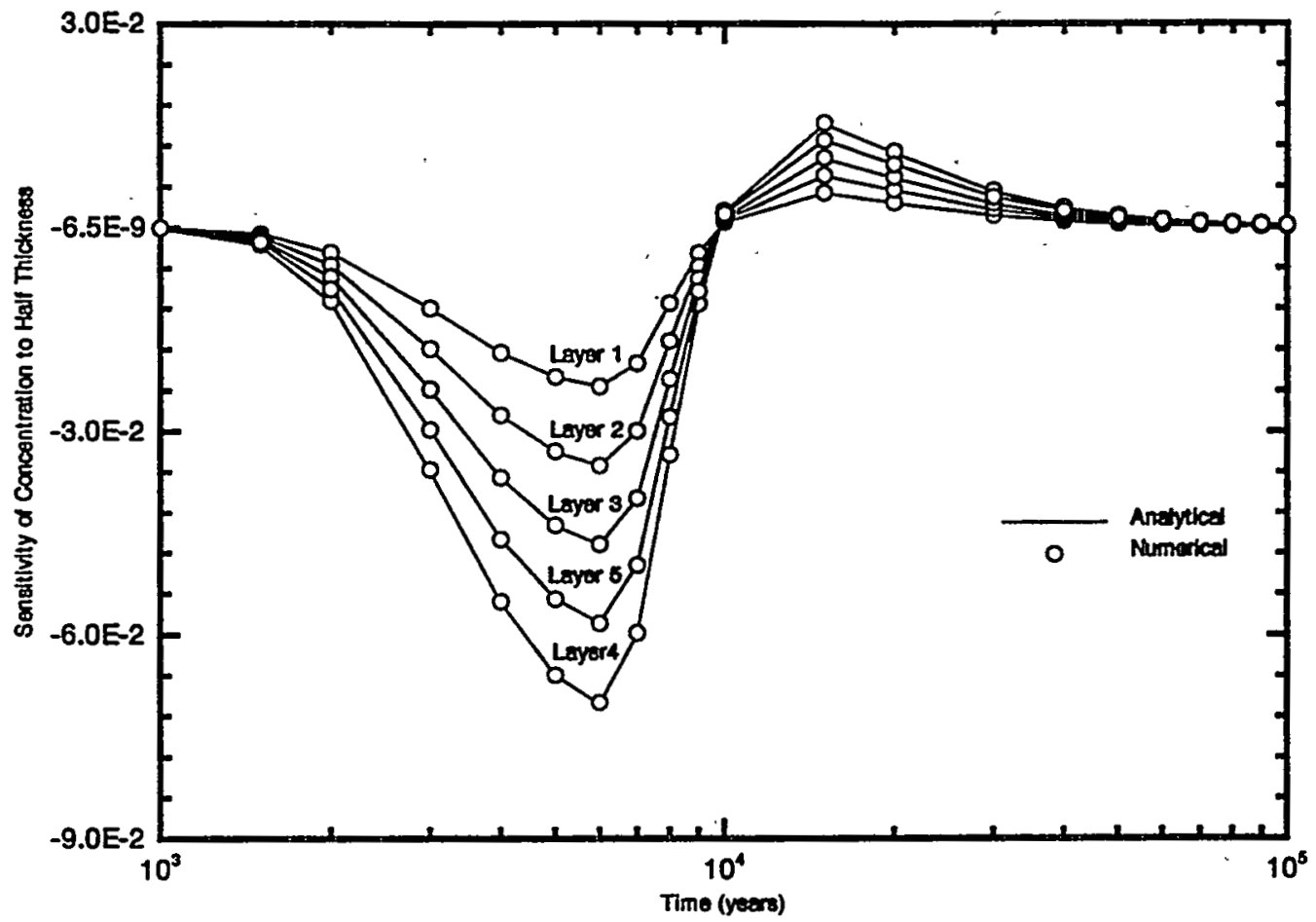

Figure 3-1(a). Sensitivity of concentration to half-thickness versus time for $\mathrm{Np}-237$ (Exponentially decaying source)

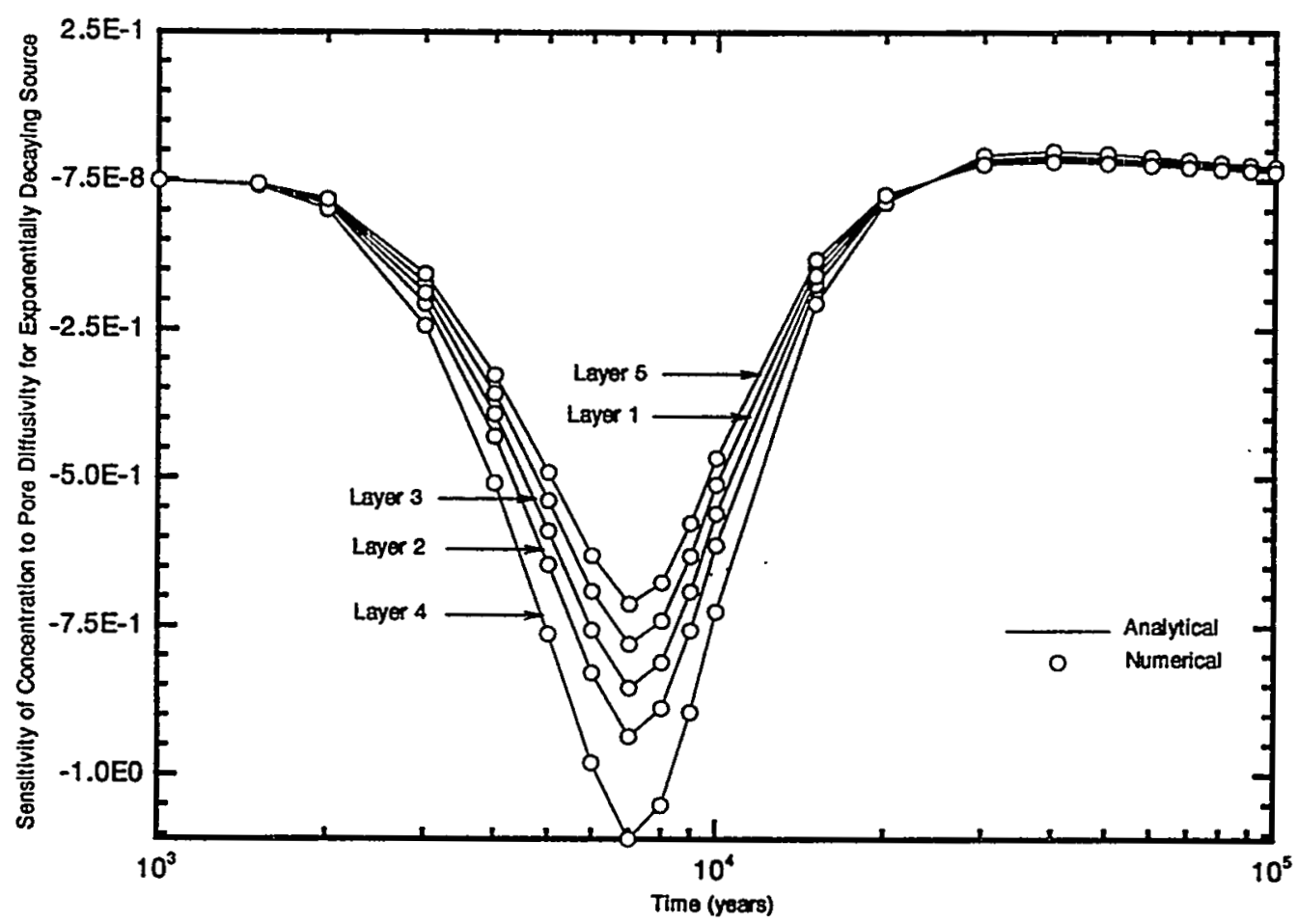

Figure 3-1(b). Sensitivity of concentration to pore diffusivity versus time for $\mathbf{N p - 2 3 7}$ (Exponentially decaying source) 


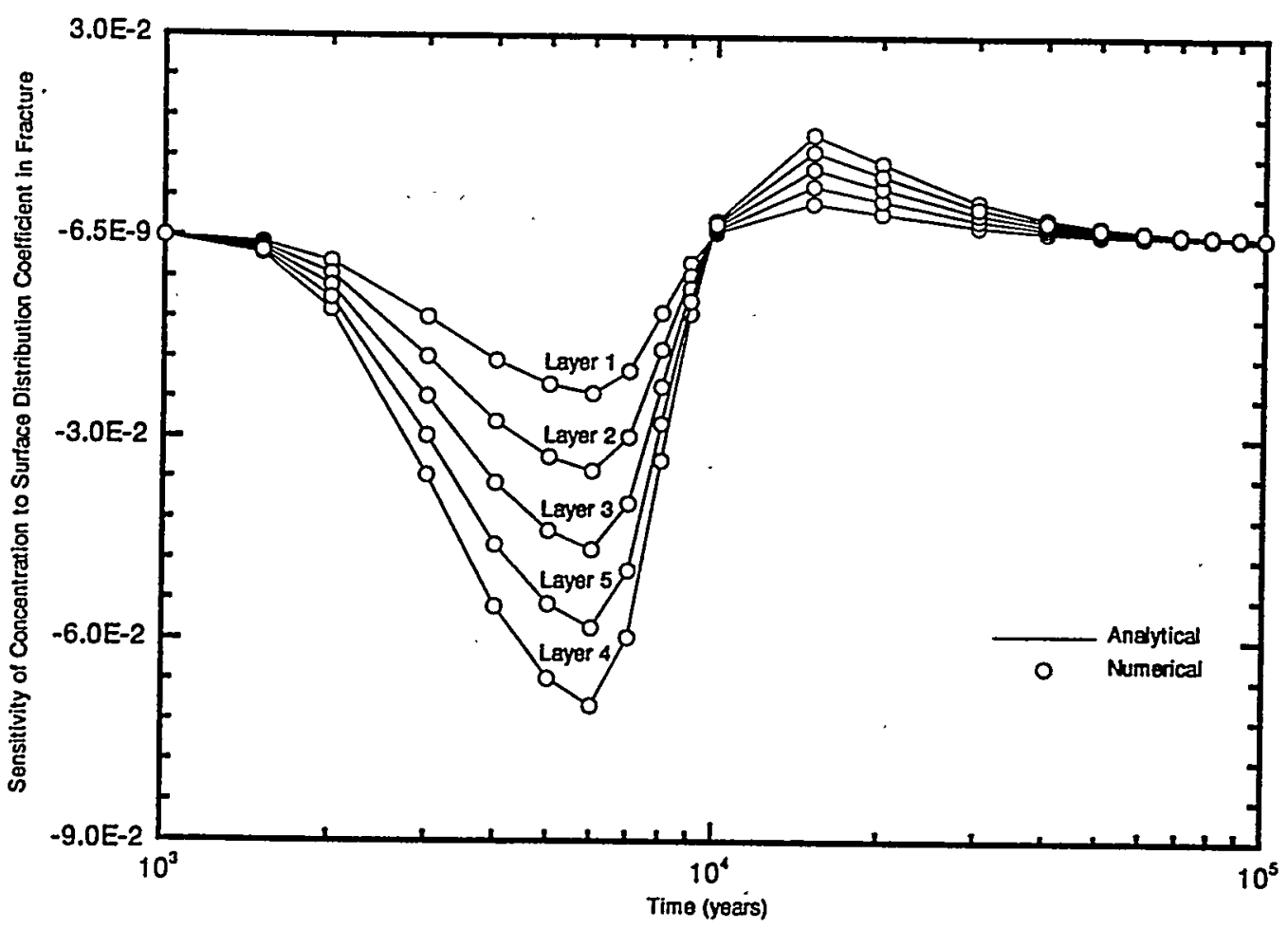

Figure 3-1(c). Sensitivity of concentration to surface distribution coefficient in fracture versus time for Np-237 (Exponentially decaying source)

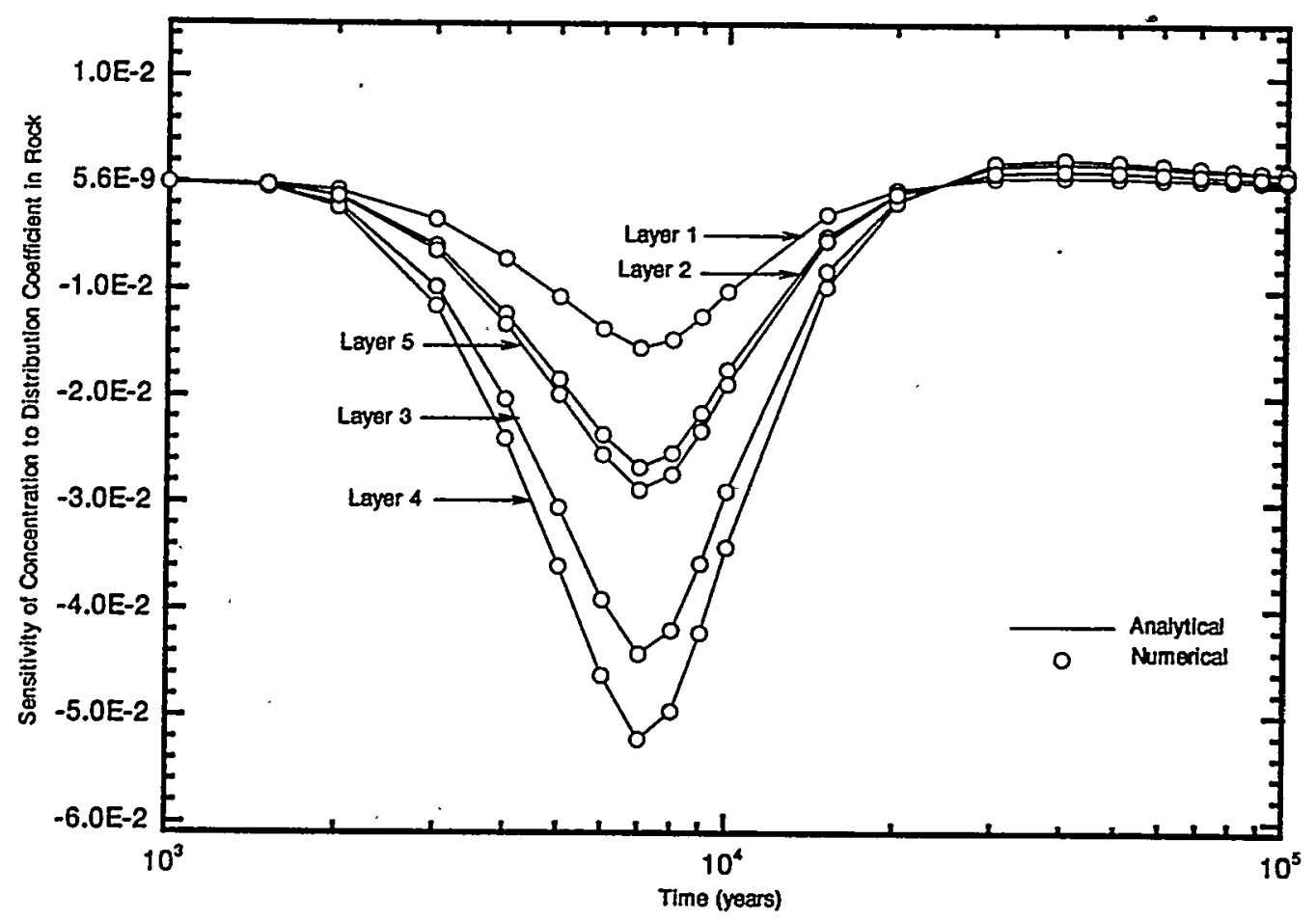

Figure 3-1(d). Sensitivity of concentration to distribution coefficient in rock versus time for Np-237 (Exponentially decaying source) 


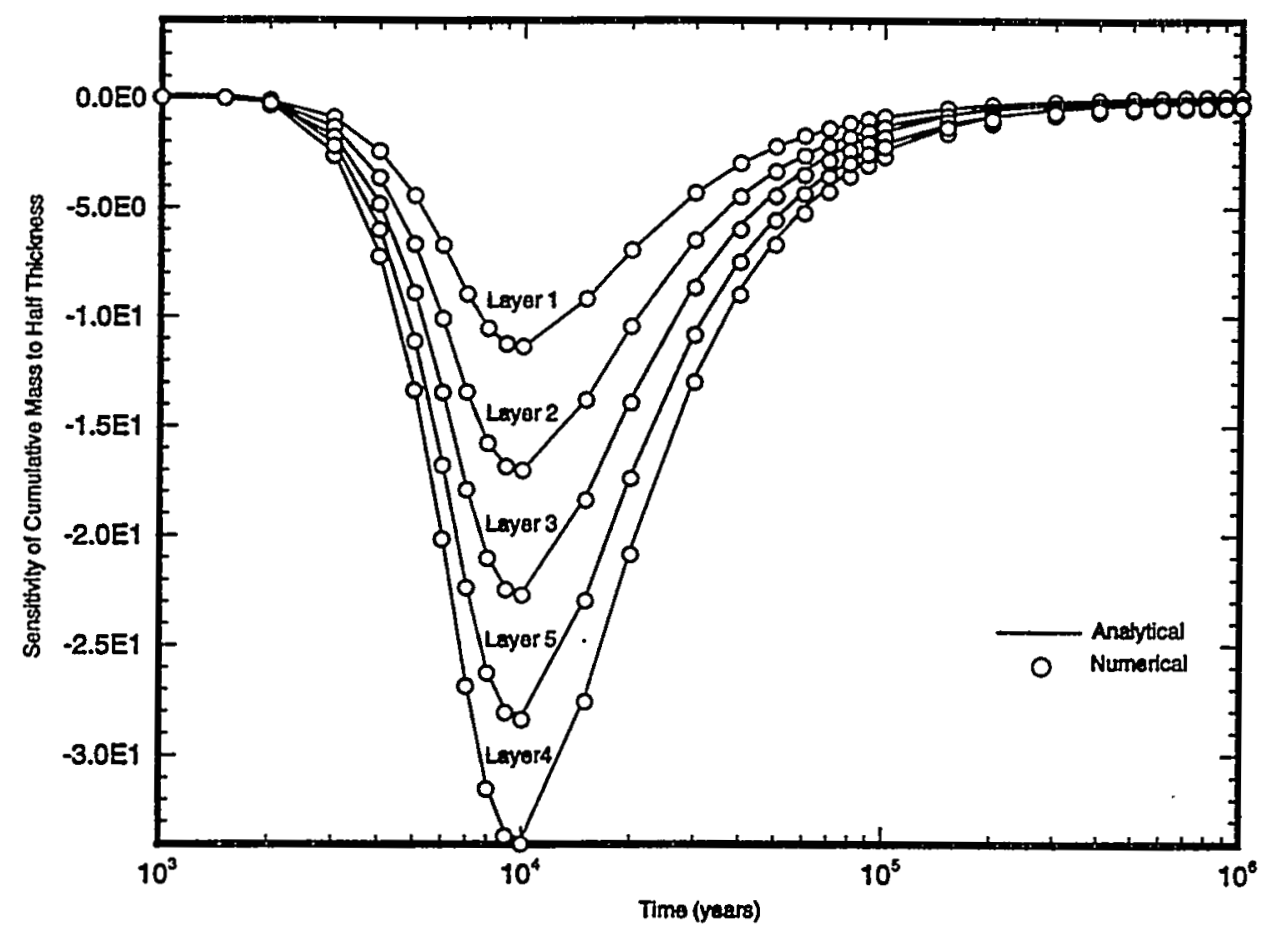

Figure 3-2(a). Sensitivity of cumulative mass to half-thickness versus time for Np-237 (Exponentially decaying source)

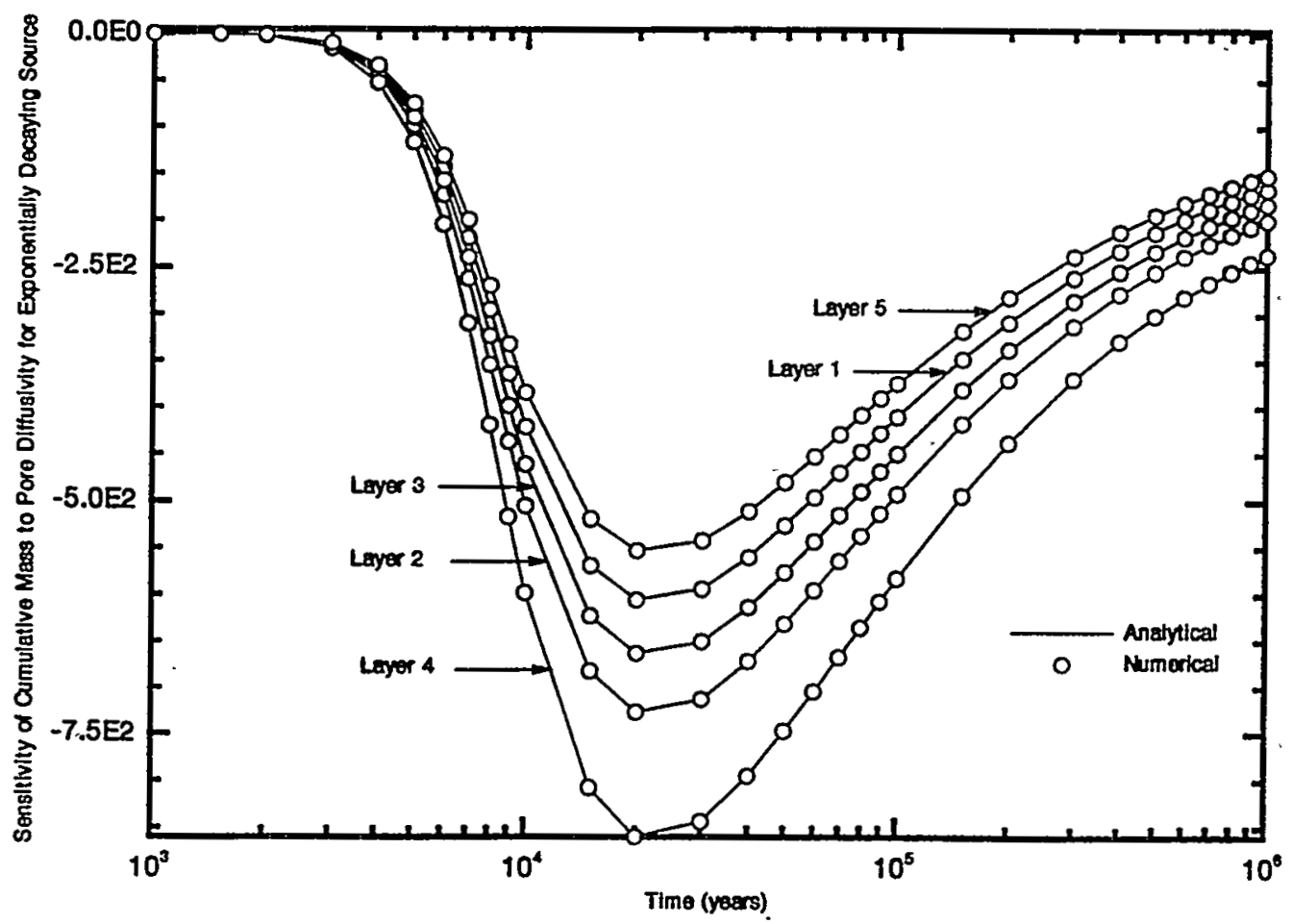

Figure 3-2(b). Sensitivity of cumulative mass to pore diffusivity versus time for Np-237 (Exponentially decaying source) 


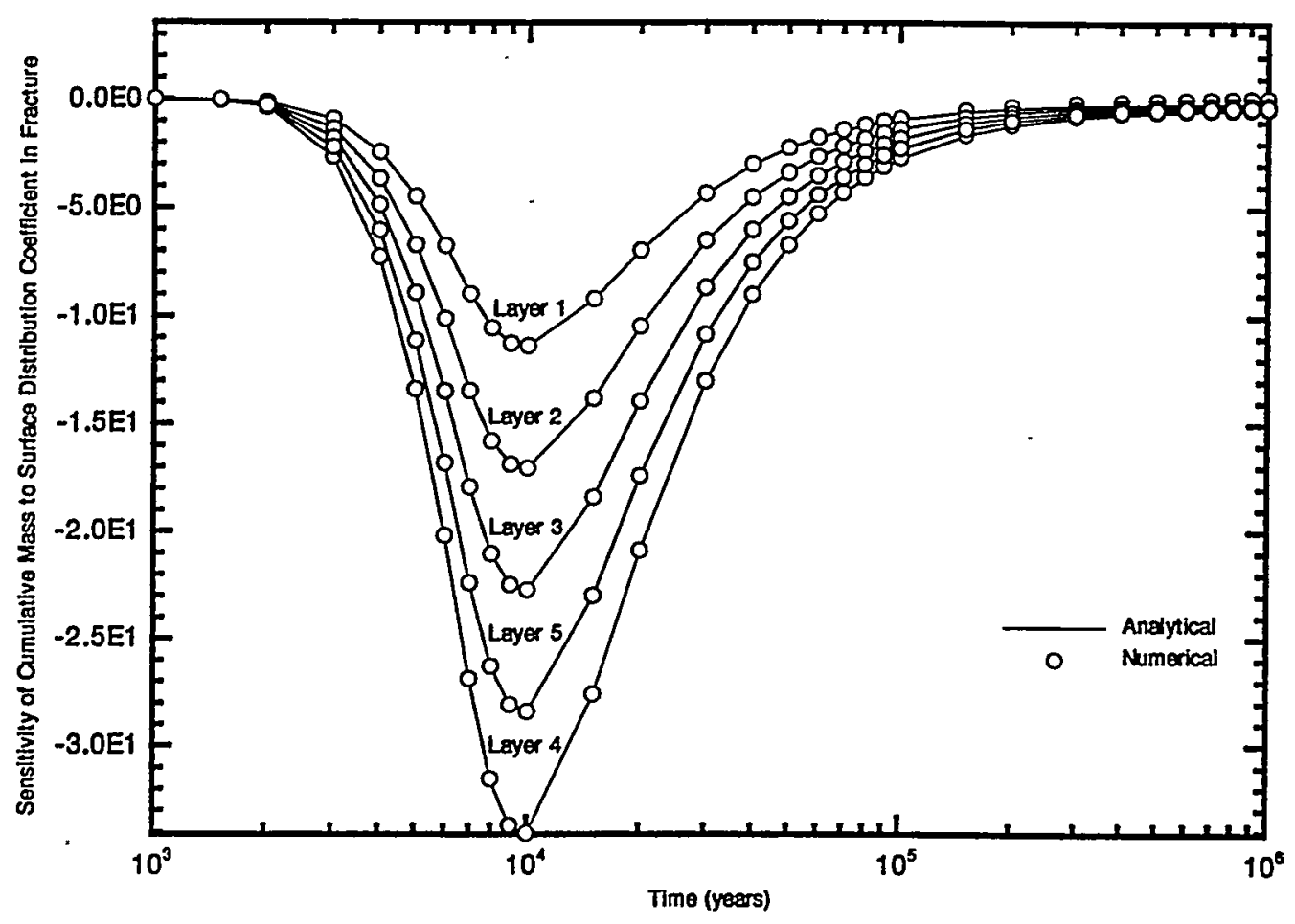

Figure 3-2(c). Sensitivity of cumulative mass to surface distribution coefficient in fracture versus time for Np-237 (Exponentially decaying source)

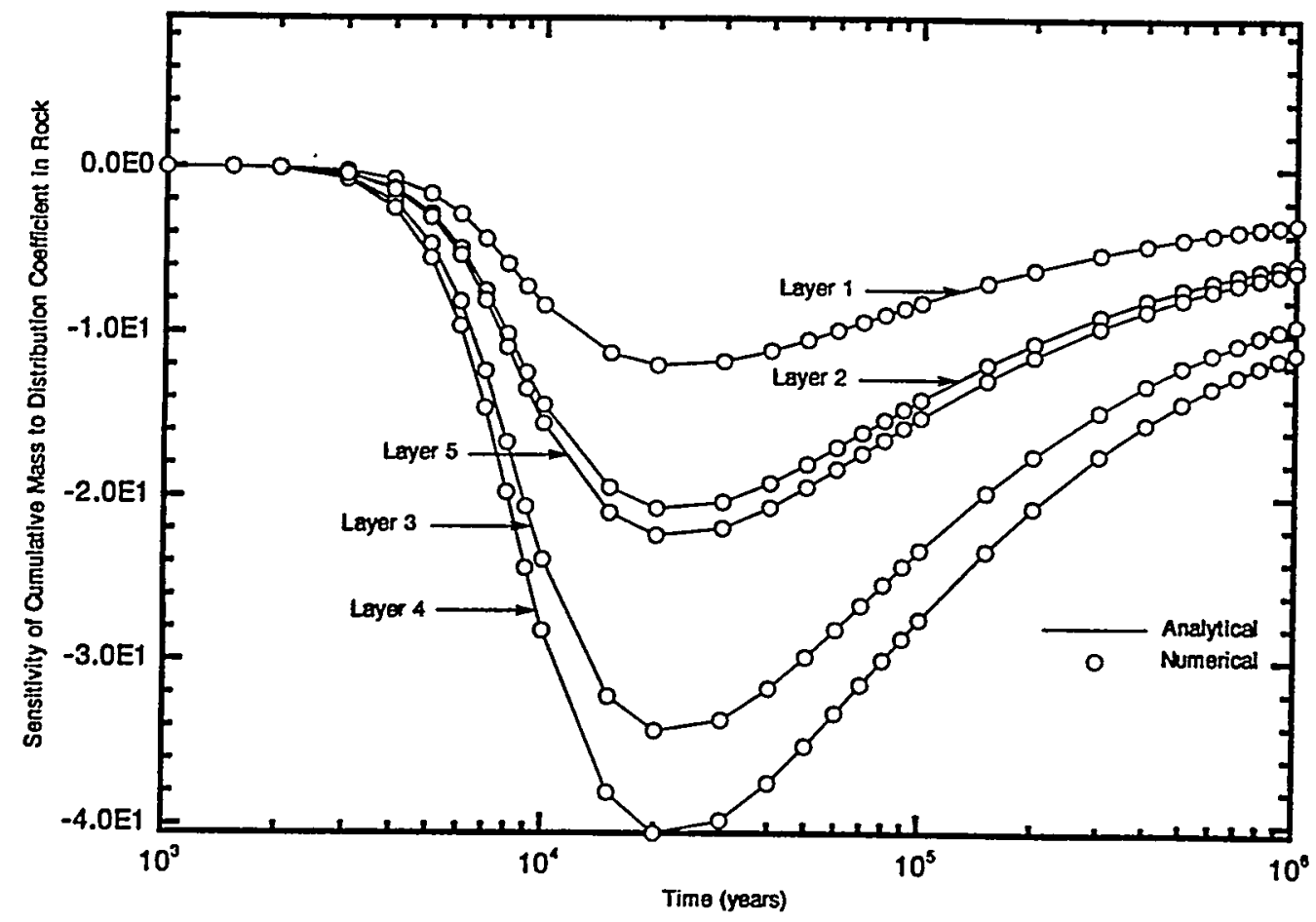

Figure 3-2(d). Sensitivity of cumulative mass to distribution coefficient in rock versus time for Np-237 (Exponentially decaying source) 


\section{CONCLUSIONS}

Analytical solutions based on the Laplace transforms have been derived for predicting the one-dimensional nondispersive isothermal transport of a radionuclide in a layered system of planar fractures coupled with the one-dimensional infinite diffusive transport into the adjacent rock matrix units. The solution for the cumulative mass in the fracture has also been reported.

The particular features of these solutions reside in their analytical capability designed to handle:

- Residual concentrations in both fracture and rock matrix layers respectively; the latter are represented by a constant and/or a spatially dependent function in the case of the fracture, and a constant in the case of the rock matrix;

- Layered nature of the rock mass;

- Length dependency of fracture aperture yielding a nonuniform velocity field; and

- Both exponentially decaying and periodically fluctuating decaying source of solute at the upstream end of the fracture network, which may then be subject to either a step or band release mode.

The reported analytical solutions pertaining to the concentrations and cumulative mass were successfully verified by means of three reliable numerical methods for evaluating the inverse Laplace transform in the real and complex domain, respectively. To this end, two test cases involving the migration of Np-237 and $\mathrm{Cm}-245$, in a five-layered fractured rock system, using synthetic, but realistic data, were investigated. The calculated analytical local sensitivities of nuclide concentration and cumulative mass flux in fractures with respect to all of the model parameters were in excellent agreement with the ones obtained through a finite-difference method of approximation. In this particular instance, no marked evidence of a superior performance of the central over the forward finite-difference method was found, as theory suggests.

In spite of some limitations (i.e., assumptions of zero dispersion in the fracture and infinite matrix diffusion), the new features embedded in the reported solutions allow one to deal with layered media having piece-wise constant properties, as well as nonzero initial conditions, coupled with a realistic option of a periodically fluctuating decaying source. These solutions are useful for verifying the accuracy of numerical codes designed to solve similar problems and, above all, cost effective for performing sensitivity and uncertainty analyses of scenarios likely to be adopted in performance assessment investigations of potential nuclear waste repositories. 


\section{REFERENCES}

Ahn, J., P.L. Chambré, and T.H. Pigford. 1985. Nuclide migration through a planar fissure with matrix diffusion. LBL-19249. LBL and Department of Nuclear Engineering: UCB: Berkeley, California.

Ahn, J., P.L. Chambre, and T.H. Pigford. 1986. Radionuclide migration through fractured rock: effects of multiple fractures and two-member decay chains. Earth Sciences Division: Lawrence Berkeley Laboratory (LBL), and Department of Nuclear Engineering: University of California at Berkeley (UCB): Berkeley, California.

Bard, Y. 1974. Nonlinear parameter estimation. Academic Press: New York, New York.

Becker, L., and W-G. Yeh. 1972. Identification of parameters in unsteady open channel flows. Water Resour. Res: 8(4): 956-965.

Bear, J., 1972. Dynamics of Fluids in Porous Media. American Elsevier Publishing Co.: New York, New York.

Burkholder, H.C., M.O. Cloninger, D.A. Baker, and G. Jansen. 1976. Incentives for partitioning high-level waste. Nuclear Technology: 31: 202.

Chambre, P.L., T.H. Pigford, A. Fujita, T. Kanki, A. Kobayashi, H. Lung, D. Ting, Y. Sato, and S.J. Zavoshy. 1982. Analytical performance models for geologic repositories. Vol. II, LBL-14842. LBL: UCB: Berkeley, California.

Chen, C.S. 1986. Solutions for radionuclide transport from an injection well into a single fracture in a porous formation. Water Resources Research: 22(4): 508-518.

Dennis, Jr., J.E., and R.B. Schnabel. 1983. Numerical methods for unconstrained optimization and nonlinear equations. Prentice Hall: Englewood Cliffs, New Jersey.

Durbin, P. 1974. Numerical inversion of Laplace transforms: An efficient improvement to Dubner and Abate's method. Comp. J.: 17: 371-376.

Foglia, M., F. Iwamoto, M. Harada, P.L. Chambre, and T.H. Pigford. 1979. The superposition equation for the band release of decaying radionuclides through sorbing media. ANS Transactions. UCB-NE-3335. UCB: Berkeley, California: 33: 384-386.

Grisak, G.E., and J.F. Pickens. 1980. Solute transport through fractured media, 1. The effect of matrix diffusion. Water Resour. Res. 16(4): 719-730.

Grisak, G.E., Pickens, J.F., and J.A. Cherry. 1980. Solute transport through fractured media, 2. Column study of fractured till. Water Resour. Res. 16(4): 731-739.

Grisak, G.E., and J.F. Pickens. 1981. An analytical solution for solute transport through fracture media with matrix diffusion. Journal of Hydrology. 52: 47-57. 
Gureghian, A.B. 1990a. FRACFLO: Analytical solutions. for two-dimensional transport of a decaying species in a discrete planar fracture and equidistant multiple fractures with rock matrix diffusion. Office of Waste Technology Development (OWTD), Battelle Memorial Institute (BMI): Willowbrook, Illinois: 5: 244.

Gureghian, A.B. 1990b. FRACVAL: Validation (nonlinear least squares method) of the solution of one-dimensional transport of a decaying species in a discrete planar fracture with rock matrix diffusion. Part 1: Analytical solutions. OWTD, BMI: Willowbrook, Illinois: 8: 79.

Gureghian, A.B. 1987. Analytical solutions for multidimensional transport of a four-member radionuclide decay chain in ground water. Office of Crystalline Repository Development (OCRD), BMI: Columbus, Ohio: 25: 162.

Gureghian, A.B., and G. Jansen. 1983. LAYFLO: A one-dimensional semi-analytical model for the migration of a three-member decay chain in a multilayered geologic medium. Office of Nuclear Waste Isolation (ONWI)-466. BMI: Columbus, Ohio: 87.

Gureghian, A.B., and G. Jansen. 1985. One-dimensional analytical solutions for the migration of a three-member radionuclide decay chain in a multilayered geologic medium. Water Resources Research: 21(5): 733-742.

Hadermann, J. 1980. Radionuclide transport through heterogeneous media. Nuclear Technology: 47: 312-323.

Hodgkinson, D.P., and P.R. Maul. 1985. One-dimensional modelling of radionuclide migration through permeable and fractured rock for arbitrary length decay chains using numerical inversion of Laplace transforms. AERE-11889. AERE-Harwell, Oxfordshire, United Kingdom: 36.

Kanki, T., A. Fujita, P.L. Chambre, and T.H. Pigford. 1981. Transport of radionuclides through fractured media. UCB-NE-4009. Earth Sciences Divison: LBL: UCB: Berkeley, California.

Lester, D.H., G. Jansen, and H.C. Burkholder. 1975. Migration of radionuclide chains through an adsorbing medium. Adsorption and Ion Exchange, AICHE Symposium Series. American Institute of Chemical Engineers 152(71).

Neretnieks, I. 1980. Diffusion in the rock matrix: An important factor in radionuclide retardation? Journal of Geophysical Research: 85: 4379-4397.

Neretnieks, I., T. Eriksen, and P. Tahtinen. 1982. Tracer movement in a single fissure in Granitic rock: Some experimental results and their interpretation. Water Resources Research 18(4): 849-858.

Piessens, R. and R. Huysmans. 1984. Algorithm 619: Automatic numerical inversion of the Laplace transform. ACM Trans. Math. Softw: 10(3): 348-353. 
Pigford, T.H., P.L. Chambré, M. Albert, M. Foglia, M. Harada, F. Iwamoto, T. Kanki, D. Leung, S. Masuda, S. Muraoka, and D. Ting. 1980. Migration of radionuclides through sorbing media analytical solutions - II. Vol. II, ONWI-360(2), LBL-11616. LBL: UCB: Berkeley, California.

Rasmuson, A. and I. Neretnieks. 1986. Radionuclide transport in fast channels in crystalline rock. Water Resources Research: 22: 1247-1256.

Rosinger, E.L.J. and K.K.R. Tremaine. 1978. GARD2 computer program for the geochemical assessment of radionuclide disposal. Whiteshell Nuclear Research Establishment: Atomic Energy of Canada, Ltd. (AECL)-6432.

Shamir, U.Y. and D.R.F. Harleman. 1966. Numerical and analytical solutions of dispersion problems in homogeneous and layered aquifers. Massachusetts Institute of Technology (MIT): Cambridge, Massachusetts: 89: 206.

Stefhest, H. 1970. Numerical inversion of Laplace transforms. Commun. ACM. 13(1): 47-49.

Sudicky, E.A., and E.O. Frind. 1982. Contaminant transpoit in fractured porous media: Analytical solution for a system of parallel fractures. Water Resources Research: 18(6): 1634-1642.

Sudicky, E.A. and E.O. Frind. 1984. Contaminant transport in fractured porous media: Analytical solution for a two-member decay chain in a single fracture. Water Resources Research: 20(7): 1021-1029.

Talbot, A. 1979. The acurate numerical inversion of Laplace's transforms. J. Inst. Math. Applics: 23: 97-120.

Tang, D.H., E.O. Frind, and E.A. Sudicky. 1981. Contaminant transport in fractured porous media: Analytical solution for a single fracture. Water Resources Research: 17(3): 555-564.

van Genuchten, M.Th., and W.J. Alves. 1982. Analytical solutions of the one-dimensional convective-dispersive solute transport equations. U. S. Department of Agriculture: Technical Bulletin No. 1661. 
APPENDIX A

THEOREMS AND LAPLACE TRANSFORMS 
In this appendix, a selected number of theorems and inverse Laplace transforms (see Abramowitz and Stegun, 1972) are reported. These are used in the derivation of the solutions pertaining to the solute concentration in the fracture and rock matrix, respectively.

\section{A.1 THEOREMS}

The operations for the Laplace transformation reported in this report require, in some cases, the use of the following theorems. Note that $f(s)$ corresponds to the Laplace transform of function $F(t)$.

\section{A.1.1 Translation}

$$
L^{-1}\left|e^{-b s} f(s)\right|=F(t-b) U(t-b), b>0
$$

where $U(t)$ is the Heaviside unit step function defined as

$$
U(t)=\left\{\begin{array}{cc}
0, & t<0 \\
\frac{1}{2}, & t=0 \\
1, & t>0
\end{array}\right.
$$

\section{A.1.2 Linear Transformation}

$$
L^{-1}[f(s-a)]=e^{a t} F(t)
$$

\section{A.1.3 Differentiation}

$$
\begin{gathered}
L^{-1} s f(s)-F(+0)=F^{\prime}(t) \\
L^{-1} s^{n} f(s)-L^{-1} s^{n-1} F(+0)-L^{-1} s^{n-2} F^{\prime}(+0)-\cdots-F^{(n-1)}(+0)=F^{(n)}(t)
\end{gathered}
$$

\section{A.1.4 Convolution or Faltung}

$$
L^{-1}\left[f_{1}(s) f_{2}(s)\right]=\int_{0}^{t} F_{1}(t-\tau) F_{2}(\tau) d \tau=F_{1} * F_{2}
$$


In the following, the Laplace transform of the function on the right is given on the left-hand side.

Table A.1. Laplace transforms

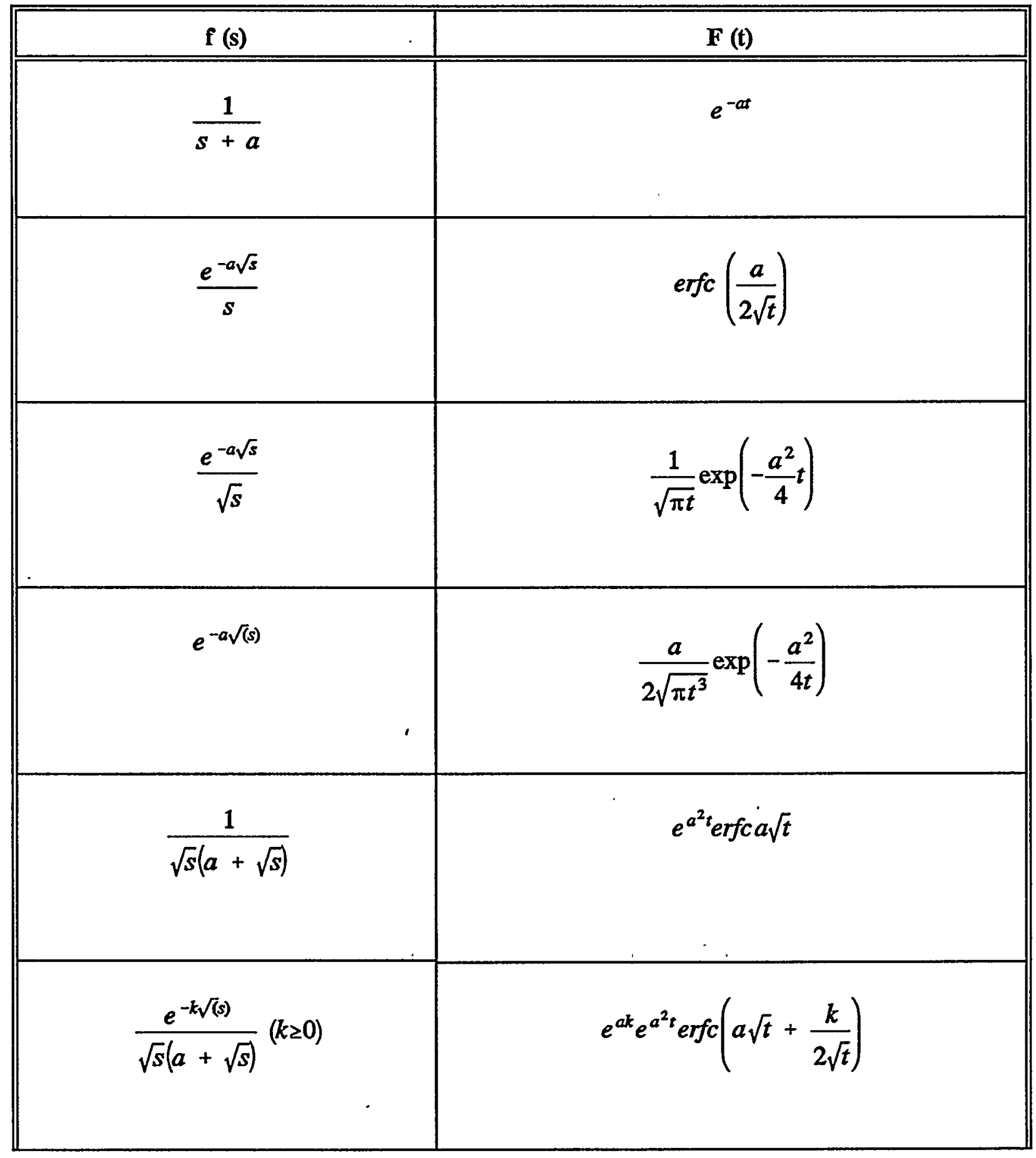




\begin{tabular}{|c|c|}
\hline $\mathrm{f}(\mathrm{s})$ & $\mathrm{F} \mathrm{(t)}$ \\
\hline \hline$\frac{1}{\sqrt{s}+a}$ & $\frac{1}{\sqrt{\pi t}}-a e^{a^{2} t} e r f c a \sqrt{t}$ \\
\hline$\frac{e^{-k \sqrt{s}}(k \geq 0)}{a+\sqrt{s}}$ & $\frac{1}{\sqrt{\pi t}} \exp \left(-\frac{k^{2}}{4 t}\right)-a e^{a k} e^{a^{2} t} e r f c\left(a \sqrt{t}+\frac{k}{2 \sqrt{t}}\right)$ \\
\hline$\frac{e^{-k \sqrt{s}}}{s(a+\sqrt{s})}$ & $\frac{1}{a}\left[\operatorname{erfc}\left(\frac{k}{2 \sqrt{t}}\right)-e^{a k} e^{a^{2} t} e r f c\left(a \sqrt{t}+\frac{k}{2 \sqrt{t}}\right)\right]$ \\
\hline$\frac{1}{s(a+\sqrt{s})}$ & \\
\hline$\frac{b}{(s+a)^{2}+b^{2}}$ & $\frac{1}{a}\left[1-e^{a^{2} t} e r f c(a \sqrt{t})\right]$ \\
\hline
\end{tabular}

The inverse Laplace transform of the product of $1 /\left(\mathrm{s}^{2}+\mathrm{a}^{2}\right)$ and $\mathrm{e}^{-\mathrm{s} / \mathrm{s}}$ may be obtained using their respective inverse transforms given in Table A.1 and applying the convolution theorem, Eq. (A.1-5), to yield 


$$
\begin{aligned}
L^{-1} \frac{e^{-a \sqrt{s}}}{s-i b} & =\frac{a}{2 \sqrt{\pi}} \int_{0}^{t} e^{i b(t-\tau)} \frac{e^{-\frac{a^{2}}{4 \tau}}}{\tau^{3 / 2}} d \tau \\
& =\frac{a e^{i b t}}{2 \sqrt{\pi}} \int_{0}^{s} \frac{1}{\tau^{3 / 2}} e^{-i b \tau-\frac{a^{2}}{4 \tau}} d \tau \\
& =\frac{a e^{i b t}}{\sqrt{\pi}} \int_{t^{-1 / 2}}^{\infty} e^{-\frac{a^{2}}{4} \tau^{2}-\frac{i b}{\tau^{2}}} d \tau
\end{aligned}
$$

Using the integral given by Eq. (C.1), we get

$$
\begin{aligned}
L^{-1} \frac{e^{-a \sqrt{s}}}{s^{2}+b^{2}} & =L^{-1} \frac{e^{-a \sqrt{s}}}{2 i b}\left[\frac{1}{s-i b}-\frac{1}{s+i b}\right] \\
& =\frac{1}{4 i b}[E(t, a, i b)-E(t, a,-i b)]
\end{aligned}
$$

where

$$
E(t, a, i b)=e^{i b b}\left(e^{a \sqrt{i b}} \operatorname{erfc}\left(\frac{a}{2 \sqrt{t}}+\sqrt{i b t}\right)+e^{-a \sqrt{i b}} \operatorname{erfc}\left(\frac{a}{2 \sqrt{t}}-\sqrt{i b t}\right)\right)
$$

Substituting for $\sqrt{ } \mathrm{i}$ in Eq. (A.2-3), using the following relations

$$
\sqrt{i}=\left(e^{(\pi / 2) i}\right)^{1 / 2}=\cos \frac{\pi}{4}+i \sin \frac{\pi}{4}=\frac{1+i}{\sqrt{2}}
$$

yields 


$$
\begin{aligned}
& E(t, a, i b)= \exp \left[a\left(\frac{b}{2}\right)^{\frac{1}{2}}+i\left(b t+a\left(\frac{b}{2}\right)^{\frac{1}{2}}\right)\right] \text { erfc } \\
& {\left[\frac{a}{2 \sqrt{t}}+\left(\frac{b t}{2}\right)^{\frac{1}{2}}+i\left(\frac{b t}{2}\right)^{\frac{1}{2}}\right] } \\
&+\exp \left[-a\left(\frac{b}{2}\right)^{\frac{1}{2}}+i\left(b t-a\left(\frac{b}{2}\right)^{\frac{1}{2}}\right)\right] \text { erfc } \\
& {\left[\frac{a}{2 \sqrt{t}}-\left(\frac{b t}{2}\right)^{\frac{1}{2}}-i\left(\frac{b t}{2}\right)^{\frac{1}{2}}\right] }
\end{aligned}
$$

(A.2-5)

A similar expression to Eq. (A.2-5) may be obtained for $E(t, a,-i b)$ after substituting for $\sqrt{ }-\mathrm{i}$ the following relation

$$
\sqrt{-i}=\left(e^{-(\pi / 2) i}\right)^{1 / 2}=\frac{1-i}{\sqrt{2}}
$$

Hence

$$
\begin{gathered}
E(t, a, i b)-E(t, a,-i b)= \\
\exp (A+i B) \operatorname{erfc}(C+i D)-\exp (A-i B) \operatorname{erfc}(C-i D)+ \\
\exp (\tilde{A}+i \tilde{B}) \operatorname{erfc}(\tilde{C}+i \tilde{D})-\exp (\tilde{A}-i \tilde{B}) \operatorname{erfc}(\tilde{C}-i \tilde{D})
\end{gathered}
$$

where

$$
\begin{aligned}
& A=a\left(\frac{b}{2}\right)^{\frac{1}{2}} ; \quad B=b t+a\left(\frac{b}{2}\right)^{\frac{1}{2}} ; \quad C=\frac{a}{2 \sqrt{t}}+\left(\frac{b t}{2}\right)^{\frac{1}{2}} ; \quad D=\left(\frac{b t}{2}\right)^{\frac{1}{2}} \\
& \tilde{A}=-a\left(\frac{b}{2}\right)^{\frac{1}{2}} ; \tilde{B}=b t-a\left(\frac{b}{2}\right)^{\frac{1}{2}} ; \quad \tilde{C}=\frac{a}{2 \sqrt{t}}-\left(\frac{b t}{2}\right)^{\frac{1}{2}} ; \quad \tilde{D}=-\left(\frac{b t}{2}\right)^{\frac{1}{2}}
\end{aligned}
$$

A-5 
APPENDIX B

EVALUATION OF ERROR FUNCTION AND PRODUCT OF EXPONENTIAL AND COMPLEMENTARY ERROR FUNCTION TERMS 
In this appendix, the formulae of the error functions with real and complex arguments, enabling the evaluation of terms involving the product of exponential and complementary error functions with complex arguments, as implemented in the computer code MULTFRAC, are reported.

\section{B.1 ERROR FUNCTION}

The error or probability function is defined as

$$
e r f(x)=\frac{2}{\sqrt{\pi}} \int_{0}^{x} e^{-\xi^{2}} d \xi
$$

with

$$
\operatorname{erf}(-x)=-\operatorname{erf}(x)
$$

this may be expressed in terms of the complementary error function erfc(x) written as

$$
\operatorname{erf}(x)=1-\operatorname{erfc}(x) .
$$

where

$$
\operatorname{erfc}(x)=\frac{2}{\sqrt{\pi}} \int_{x}^{\infty} e^{-\xi^{2}} d \xi
$$

and

$$
\operatorname{erfc}(-x)=2-\operatorname{erfc}(x)
$$

Note that when $\mathrm{x}$ is small the integrand in Eq. (B.1-1) may be conveniently expanded in a power series convergent everywhere and integrated term by term to yield

$$
\begin{aligned}
e r f(x)= & \frac{2}{\sqrt{\pi}}\left[x-\frac{x^{3}}{3 \cdot 1 !}+\frac{x^{5}}{5 \cdot 2 !}-\frac{x^{7}}{7 \cdot 3 !}+\ldots\right. \\
& \left.+(-1)^{n+1} \frac{x^{2 n+1}}{(2 n+1) \cdot n !}+\ldots\right]
\end{aligned}
$$

A few terms in the expansion are necessary to determine the value of erf(x) to a given number of decimal places. However, as $\mathrm{x}$ becomes large, the loss in accuracy must be compensated by a large number of terms which renders the calculation tedious and impractical. A rational Chebysheb approximation may be used to alleviate this problem when $x \geq 4$ (see Cody, 1969). Alternatively, the asymptotic expansion reported by Abramowitz and Stegun (1972) expressed in terms of the complementary error function $\operatorname{erfc}(\mathrm{x})$ [see Eq. (B.2-3)] is used. 
The derivative of the error function may be written as

$$
\frac{d}{d \alpha}[\operatorname{erf}(x)]=\frac{2}{\sqrt{\pi}} \exp \left(-x^{2}\right) \frac{d x}{d \alpha}
$$

\section{B.2 FORMULAE OF ERROR FUNCTIONS WITH COMPLEX ARGUMENTS}

Let $\mathrm{z}$ be the complex argument written as

$$
z=x \pm i y
$$

and Euler's formula written as

$$
e^{i z}=\cos z+i \sin z
$$

Note that the evolution of the error function for a real argument was based on Cody (1969).

\section{B.2-1 Asymptotic Expansion $|\mathrm{z}|>2$ and $\mathrm{x}<1$ and $|\mathrm{y}| \geq 6$} be written as

In this case, the asymptotic expansion of erfc(z), as given by Abramowitz and Stegun (1972), may

$$
\operatorname{erfc}(z)=\frac{e^{-z^{2}}}{z \sqrt{\pi}}\left[1+\sum_{n=1}^{\infty}(-1)^{n} \frac{1.3 \ldots(2 n-1)}{\left(2 z^{2}\right)^{n}}\right]+R_{n}(x)
$$

where $R(x)$ is the remainder after $n$ terms.

\section{B.2-2 Confluent Hypergeometric Function $|\mathrm{z}|<2$}

In this case, the error function is evaluated from the confluent hypergeometric function [see Abramowitz and Stegun (1972), Eq. (7.1.21)], written as

$$
\operatorname{erf} z=\frac{2 z}{\pi} M\left(\frac{1}{2}, \frac{3}{2},-z^{2}\right)=\frac{2 z}{\pi} e^{-z^{2}} M\left(1, \frac{3}{2}, z^{2}\right)
$$

where $\mathrm{M}$ is the Kummer's function [see Abramowitz and Stegun (1972), p.504, Eq. (13.1.2)], written as

$$
M(a, b, z)=1+\frac{a z}{b}+\frac{(a)_{2} z^{2}}{(b)_{2} 2 !}+\cdots \frac{(a)_{n} z^{n}}{(b)_{n} n !}+\cdots
$$


with

$$
(a)_{n}=a(a+1)(a+2) \cdots(a+n-1),(a)_{0}=1
$$

\section{B.2-3 Continued Fraction Approximation $|\mathrm{z}|>2$ and $\mathrm{x}>1$}

In this case, the error function is evaluated from the continued fractions approximations [see Abramowitz and Stegun (1972), p.298, Eq. (7.1.14)], written as

$$
\operatorname{erfc}(z)=\frac{e^{-z^{2}}}{\sqrt{\pi}}\left[\frac{1}{z^{+}} \frac{1 / 2}{z^{+}} \frac{1}{z^{+}} \frac{3 / 2}{z^{+}} \frac{2}{z^{+}} \cdots\right](R z>0)
$$

\section{B.2-4 Infinite Series Expansion $|\mathrm{z}|>2,0 \leq \mathrm{x} \leq 1, \mathrm{y}<6$}

In this case, the error function is evaluated from the infinite series approximation [see Abramowitz and Stegun (1972), p. 299, Eq. (7.1.29)], written as

$$
\begin{aligned}
& \operatorname{erf}(x+i y)=\operatorname{erf} x+\frac{e^{-x^{2}}}{2 \pi x}[(1-\cos 2 x y)+i \sin 2 x y] \\
& +\frac{2}{\pi} e^{-x^{2}} \sum_{n=1}^{\infty} \frac{e^{-n^{2} / 4}}{n^{2}+4 x^{2}}\left[f_{n}(x, y)+i g_{n}(x, y)\right]+\epsilon(x, y)
\end{aligned}
$$

where

$$
\begin{gathered}
f_{n}(x, y)=2 x-2 x \cosh n y \cos 2 x y+n \sinh n y \sin 2 x y \\
g_{n}(x, y)=2 x \cosh n y \sin 2 x y+n \sinh n y \cos 2 x y \\
|\in(x, y)| \approx 10^{-16}|\operatorname{erf}(x+i y)|
\end{gathered}
$$

\section{B.3 EVALUATION OF PRODUCT OF EXPONENTIAL AND COMPLEMENTARY ERROR FUNCTION WITH COMPLEX ARGUMENTS}

Functions involving the product of exponential and complementary error functions may witness two types of arguments inherent to such functions, that is, real or complex.

When the arguments of the exponential and complementary functions are both real, the scheme reported in Appendix C of Gureghian (1990) is the one adopted in this work. However, where the arguments of these functions are of the complex form, the typical model for the complementary error function as reported in the preceding sections is selected based upon its adequacy to cope with the magnitude of the complex argument of interest. In the case where an infinite series approximation model 
for the complex error function is adopted, such as given by Eq. (B.2-7), it will be subsequently shown that expressions similar to one given by Eq. (A.2-7), which display a combination of products of complex exponential and complementary error functions, may yield either a real or an imaginary number.

Writing

$$
\begin{gathered}
F^{+}(t, A, i B, C, i D)=\exp (A+i B) \operatorname{erfc}(C+i D) \\
+\exp (A-i B) \operatorname{erfc}(C-i D)
\end{gathered}
$$

and using Eqs. (B.2-2) and (B.2-7), it may be shown that the result is a real number given by

$$
\begin{gathered}
F^{+}(t, A, i B, C, i D)=2 \exp (A)[\cos B(\operatorname{erfc}(C)- \\
\left.u(C)(1-\cos 2 C D)-v(C) \sum_{n}^{\infty} r_{n}(C) f_{n}(C, D)\right) \\
\left.+\sin B\left(u(C) \sin 2 C D+v(C) \sum_{n}^{\infty} r_{n}(C) g_{n}(C, D)\right)\right] \\
+\in(A, B, C, D)
\end{gathered}
$$

Similarly, writing

$$
\begin{gathered}
F^{-}(t, A, i B, C, i D)=\exp (A+i B) \operatorname{erfc}(C+i D) \\
-\exp (A-i B) \operatorname{erfc}(C-i D)
\end{gathered}
$$

it may be shown that the result is an imaginary number given by 


$$
\begin{gathered}
F^{-}(t, A, i B, C, i D)=i 2 \exp (A)[\sin B(\operatorname{erfc}(C)- \\
\left.u(C)(1-\cos 2 C D)-v(C) \sum_{n}^{\infty} r_{n}(C) f_{n}(C, D)\right) \\
\left.-\cos B\left(u(C) \sin 2 C D+v(C) \sum_{n}^{\infty} r_{n}(C) g_{n}(C, D)\right)\right] \\
+\in(A, B, C, D)
\end{gathered}
$$

where

$$
\begin{gathered}
u(C)=\frac{e^{-C^{2}}}{2 \pi C} \\
v(C)=\frac{2 e^{-C^{2}}}{\pi} \\
r_{n}(C)=\frac{e^{-\frac{n^{2}}{4}}}{n^{2}+4 C^{2}}
\end{gathered}
$$

and $f_{n}, g_{n}$ and $\epsilon$ are given by Eqs. (B.2-8a) through (B.2-8c). 
Equations (B.3-2) and (B.3-4) may be written in a more explicit form as

$$
\begin{aligned}
& F^{+}(t, A, i B, C, i D)=2[\cos B \exp (A) \operatorname{erf}(C) \\
+ & \frac{\exp \left(A-C^{2}\right)}{2 \pi C}[-\cos B+\cos (B-2 C D)] \\
-\frac{2}{\pi} & \sum_{n=1}^{\infty} \frac{1}{n^{2}+4 C^{2}}\left[-n\left[E_{2}-E_{3}\right] \sin (B-2 C D)\right. \\
+ & \left.\left.2 C\left(E_{1} \cos B-\cos (B-2 C D)\left[E_{2}+E_{3}\right]\right)\right]\right] \\
& +\frac{\exp \left(A-C^{2}\right)}{2 \pi C}[-\sin B+\sin (B-2 C D)] \\
& \left.\left.+2 C\left(E_{1} \sin B-\sin (B-2 C D)\left[E_{2}+E_{3}\right]\right)\right]\right] \\
& \frac{2}{\pi} \sum_{n=1}^{\infty} \frac{1}{n^{2}+4 C^{2}}\left[n\left[E_{2}-E_{3}\right] \cos (B-2 C D)\right. \\
& =2 i[\sin B \exp (A) e r f c(C)
\end{aligned}
$$

where

$$
\begin{gathered}
E_{1}=\exp \left(A-C^{2}-\frac{n^{2}}{4}\right) \\
E_{2}=\frac{1}{2} \exp \left(A-C^{2}-\frac{n^{2}}{4}+n D\right)
\end{gathered}
$$




$$
E_{3}=\frac{1}{2} \exp \left(A-C^{2}-\frac{n^{2}}{4}-n D\right)
$$

\section{REFERENCES:}

Abramowitz, M., and I.A. Stegun. 1972. Handbook of Mathematical Functions. Dover Publications, Inc.: New York, New York.

Cody, W.J. 1969. Rational Chebyshev approximation for the error function. Mathematics of Computation: 23(107): 631-637.

Gureghian, A.B. 1990. FRACVAL Validation (Nonlinear Least Squares Method) of the Solution of One-Dimensional Transport of Decaying Species in a Discrete Planar Fracture with Rock Matrix Diffusion Part 1: Analytical Solutions. BMI/OWTD-8. Battelle Energy Systems Group: Office of Waste Technology Development (OWTD): Battelle Memorial Institute (BMI): Willowbrook, Illinois. 
APPENDIX C

SOME INTEGRALS INVOLVING THE ERROR FUNCTION AND OTHER FUNCTIONS 
In this appendix, the derivation of a set of integrals involving the error function and other functions arising in the solution pertaining to the cumulative mass at any point in the fracture network is reported.

From Abramowitz and Stegun [(1972), p. 304, Eq. (7.4.33)], we have the following indefinite integral:

$$
\int e^{-a^{2} x^{2}-\frac{b^{2}}{x^{2}}} d x=\frac{\sqrt{\pi}}{4 a}\left[e^{2 a b} e r f\left(a x+\frac{b}{x}\right)+e^{-2 a b} e r f\left(a x-\frac{b}{x}\right)\right],(a \neq 0)
$$

\section{C.1 Integral of $\mathbf{I}_{1}(\mathrm{t}, \alpha, \beta, \gamma)$}

Writing

$$
I_{1}(t, \alpha, \beta, \gamma)=\int_{\gamma}^{t} e^{-\alpha \tau} e r f c\left[\frac{\beta}{(\tau-\gamma)^{1 / 2}}\right] d \tau
$$

Integrating Eq. (C.1-1) by parts gives

$$
I_{1}(t, \alpha, \beta, \gamma)=I_{11}+I_{12}
$$

where

$$
\begin{gathered}
I_{11}=-\frac{e^{-\alpha t}}{\alpha} \operatorname{erfc}\left[\frac{\beta}{(t-\gamma)^{1 / 2}}\right] \\
I_{12}=-\frac{2}{\alpha \sqrt{\pi}} \int_{\gamma}^{t} e^{-\alpha \tau-\frac{\beta^{2}}{(\tau-\gamma)} d\left[\frac{\beta}{(\tau-\gamma)^{1 / 2}}\right]} \\
I_{12}=\frac{\beta e^{-\gamma \alpha^{t-\gamma}}}{\alpha \sqrt{\pi}} \int_{0}^{\frac{1}{\sqrt{\tau^{3}}}} e^{-\alpha \tau-\frac{\beta^{2}}{\tau}} d \tau
\end{gathered}
$$

substituting $\eta=1 / \tau^{1 / 2}$ in Eq. (C.1-5), and using Eq. (C.1), will then yield

$$
\begin{aligned}
I_{12} & =\frac{e^{-\alpha \gamma}}{2 \alpha}\left\{e^{2 \beta \sqrt{\alpha}} e r f c\left[\frac{\beta}{\sqrt{t-\gamma}}+\sqrt{\alpha(t-\gamma)}\right]\right. \\
& \left.+e^{-2 \beta \sqrt{\alpha}} e r f c\left[\frac{\beta}{\sqrt{t-\gamma}}-\sqrt{\alpha(t-\gamma)}\right]\right\}
\end{aligned}
$$




\section{C.2 Integral of $\mathbf{I}_{2}\left(t, \alpha, \beta_{1}, \boldsymbol{\beta}_{2}, \gamma\right)$}

Writing

$$
I_{2}\left(t, \alpha, \beta_{1}, \beta_{2}, \gamma\right)=\int_{\gamma}^{t} e^{\alpha \tau} e r f c\left[\beta_{1}(\tau-\gamma)^{1 / 2}+\frac{\beta_{2}}{(\tau-\gamma)^{1 / 2}}\right] d \tau
$$

Integration by parts gives

$$
I_{2}\left(t, \alpha, \beta_{1}, \beta_{2}, \gamma\right)=I_{21}+I_{22}
$$

where

$$
I_{21}=\frac{e^{\alpha t}}{\alpha} \operatorname{erfc}\left[\beta_{1}(t-\gamma)^{1 / 2}+\frac{\beta_{2}}{(t-\gamma)^{1 / 2}}\right]
$$

and

$$
I_{22}=-\frac{2}{\sqrt{\pi} \alpha} \int_{\gamma}^{t} e^{\alpha \tau-\left[\beta_{1}(\tau-\gamma)^{1 / 2}+\frac{\beta_{2}}{(\tau-\gamma)^{1 / 2}}\right]^{p}} d\left[\beta_{1}(\tau-\gamma)^{1 / 2}+\frac{\beta_{2}}{(\tau-\gamma)^{1 / 2}}\right]
$$

substitution of $\eta=\tau-\gamma$ in Eq. (C.2-4) gives

$$
I_{22}=I_{221}+I_{222}
$$

where

$$
I_{221}=\frac{\beta_{1} e^{\alpha \gamma-2 \beta_{1} \beta_{2}}}{\sqrt{\pi} \alpha} \int_{0}^{t-\gamma} \frac{1}{\eta^{1 / 2}} e^{-\left(\beta_{1}^{2}-\alpha\right) \eta-\frac{\beta_{2}^{2}}{\eta}} d \eta
$$

and

$$
I_{222}=-\frac{\beta_{2} e^{\alpha \gamma-2 \beta_{1} \beta_{2}}}{\sqrt{\pi} \alpha} \int_{0}^{t-\gamma} \frac{1}{\eta^{3 / 2}} e^{-\left(\beta_{1}^{2}-\alpha\right) \eta-\frac{\beta_{2}^{2}}{\eta}} d \eta
$$


substitution of $\tau=\eta^{1 / 2}$ in $\mathbf{I}_{221}$ and $\tau=1 / \eta^{1 / 2}$ in $\mathbf{I}_{222}$ respectively, gives

$$
\begin{aligned}
& I_{221}=2 \beta_{1} \frac{e^{\alpha \gamma-2 \beta_{1} \beta_{2}}}{\sqrt{\pi} \alpha} \int_{0}^{(t-\gamma)^{1 / 2}} e^{-\left(\beta_{1}^{2}-\alpha\right) \tau^{2}-\frac{\beta_{2}^{2}}{\tau_{2}}} d \tau \\
& I_{222}=-2 \beta_{2} \frac{e^{\alpha \gamma-2 \beta_{1} \beta_{2}}}{\sqrt{\pi} \alpha} \int_{(t-\gamma)^{-1 / 2}}^{\infty} e^{-\beta_{2}^{2} \tau^{2}-\frac{\left(\beta_{1}^{2}-\alpha\right)}{\tau^{2}}} d \tau
\end{aligned}
$$

Using the results given by Eq. (C.1), we then have

$$
\begin{gathered}
I_{221}=-\frac{\beta_{1} e^{\alpha \gamma-2 \beta_{1} \beta_{2}}}{2 \alpha\left(\beta_{1}^{2}-\alpha\right)^{1 / 2}}\left[e^{2 \beta_{2}\left(\beta_{1}^{2}-\alpha\right)^{1 / 2}} e r f c\right. \\
\left(\left(\beta_{1}^{2}-\alpha\right)^{1 / 2}(t-\gamma)^{1 / 2}+\frac{\beta_{2}}{(t-\gamma)^{1 / 2}}\right) \\
\left.-e^{-2 \beta_{2}\left(\beta_{1}^{2}-\alpha\right)^{1 / 2}} e r f c\left(-\left(\beta_{1}^{2}-\alpha\right)^{1 / 2}(t-\gamma)^{1 / 2}+\frac{\beta_{2}}{(t-\gamma)^{1 / 2}}\right)\right] \\
I_{222}=-\frac{e^{\alpha \gamma-2 \beta_{1} \beta_{2}}}{2 \alpha}\left[e^{2 \beta_{2}\left(\beta_{1}^{2}-\alpha\right)^{1 / 2}} e r f c\right. \\
\left(\frac{\beta_{2}}{(t-\gamma)^{1 / 2}}+\left(\beta_{1}^{2}-\alpha\right)^{1 / 2}(t-\gamma)^{1 / 2}\right) \\
\left.+e^{-2 \beta_{2}\left(\beta_{1}^{2}-\alpha\right)^{1 / 2}} e r f c\left(\frac{\beta_{2}}{(t-\gamma)^{1 / 2}}-\left(\beta_{1}^{2}-\alpha\right)^{1 / 2}(t-\gamma)^{1 / 2}\right)\right]
\end{gathered}
$$




$$
\begin{aligned}
I_{22}=-\frac{e^{\alpha \gamma-2 \beta_{1} \beta_{2}}}{2 \alpha}\left[e^{2 \beta_{2}\left(\beta_{1}^{2}-\alpha\right)^{1 / 2}} \operatorname{erfc}\left(\left(\beta_{1}^{2}-\alpha\right)^{1 / 2}(t-\gamma)^{1 / 2}+\frac{\beta_{2}}{(t-\gamma)^{1 / 2}}\right)\right. \\
\quad\left(\frac{\beta_{1}}{\left(\beta_{1}^{2}-\alpha\right)^{\frac{1}{2}}}+1\right)-e^{-2 \beta_{2}\left(\beta_{1}^{2}-\alpha\right)^{1 / 2}} \\
\left.\quad \operatorname{erfc}\left(-\left(\beta_{1}^{2}-\alpha\right)^{1 / 2}(t-\gamma)^{1 / 2}+\frac{\beta_{2}}{(t-\gamma)^{1 / 2}}\right)\left(\frac{\beta_{1}}{\left(\beta_{1}^{2}-\alpha\right)^{\frac{1}{2}}}-1\right)\right]
\end{aligned}
$$

\section{C.3 Integral of $\mathbf{I}_{3}\left(\mathbf{t}_{1}, \mathbf{t}_{2}, \alpha, \beta\right)$}

Writing

$$
I_{3}\left(t_{1}, t_{2}, \alpha, \beta\right)=\int_{t_{1}}^{\zeta} e^{\alpha \tau} e r f c\left(\beta \tau^{1 / 2}\right) d \tau
$$

Integration by parts yields

$$
\begin{gathered}
I_{3}\left(t_{1}, t_{2}, \alpha, \beta\right)=\frac{1}{\alpha} \sum_{i=1}^{2}(-1)^{i}\left[e^{\alpha t_{1}} \operatorname{erfc}\left(\beta t_{i}^{1 / 2}\right)+\right. \\
\left.\frac{\beta}{\left(\beta^{2}-\alpha\right)^{1 / 2}} \operatorname{erf}\left(\sqrt{\left(\beta^{2}-\alpha\right) t_{i}}\right)\right]
\end{gathered}
$$

\section{C.4 Integral of $\mathbf{I}_{4}(t, \alpha, \mathrm{ib}, \lambda, \gamma)$}

Writing

$$
I_{\triangleleft}(t, a, i b, \lambda, \gamma)=\int_{\gamma}^{t} \frac{e^{-\lambda \tau}}{4 i b}[E(\tau-\gamma, a, i b)-E(\tau-\gamma, a,-i b)] d \tau
$$

where $E(t, a, i b)$ is given by Eq. (A.2-3). Integration by parts gives

$$
I_{4}(t, a, i b, \lambda, \gamma)=I_{41}+I_{42}
$$

using the following definitions 


$$
E_{1}(t, a, i b)=e^{-i b k} E(t, a, i b)
$$

and

$$
E_{2}(t, a,-i b)=e^{i b t} E(t, a,-i b)
$$

$\mathbf{I}_{41}$ may then be written as

$$
I_{41}=\frac{1}{4 i b}\left[-\frac{e^{-(\lambda-i b) t}}{\lambda-i b} E_{1}(t-\gamma, a, i b)+\frac{e^{-(\lambda+i b) t}}{\lambda+i b} E_{2}(t-\gamma, a,-i b)\right]
$$

Multiplying the first and second terms in square brackets in Eq. (C.4-4), by the conjugate of their respective denominators, we then get

$$
\begin{aligned}
I_{41}=- & \frac{e^{-\lambda s}}{4\left(\lambda^{2}+b^{2}\right)}\left[\left(E_{1}(t-\gamma, a, i b)+E_{2}(t-\gamma, a,-i b)\right)\right. \\
& \left.+\frac{\lambda}{i b}\left(E_{1}(t-\gamma, a, i b)-E_{2}(t-\gamma, a,-i b)\right)\right]
\end{aligned}
$$

Note that $\mathrm{I}_{41}$ corresponds to a real number, since it has been shown earlier (see Section B.3) that the sum and difference of $E_{1}[\cdot]$ and $E_{2}[\cdot]$ will yield a real and an imaginary number, respectively.

$$
\begin{gathered}
I_{42}=\frac{1}{4 i b(\lambda-i b)} \int_{\gamma}^{t} e^{-(\lambda-i b) \tau} d\left[E_{1}(\tau-\gamma, a, i b)\right]- \\
\frac{1}{4 i b(\lambda+i b)} \int_{\gamma}^{t} e^{-(\lambda+i b) \tau} d\left[E_{2}(\tau-\gamma, a,-i b)\right]
\end{gathered}
$$

substituting $\tau^{\prime}=\tau-\gamma$ in Eq. (C.4-6), and after some simplification, leads to

$$
I_{42}=\frac{1}{4 \sqrt{\pi} i b}\left[\frac{e^{-(\lambda-i b) \gamma}}{(\lambda-i b)}-\frac{e^{-(\lambda+i b) \gamma}}{(\lambda+i b)}\right] \int_{0}^{t-\gamma} \frac{a}{\tau^{\prime 3 / 2}} e^{-\lambda \tau^{\prime}-\frac{a^{2}}{4 \tau^{\prime}}} d \tau^{\prime}
$$

substituting $\eta=1 / \tau^{1 / 2}$ in Eq. (C.4-7) yields

$$
I_{42}=\frac{a e^{-\lambda \gamma}}{2 \sqrt{\pi} i b}\left[\frac{e^{i b \gamma}}{(\lambda-i b)}-\frac{e^{-i b \gamma}}{(\lambda+i b)}\right] \int_{(t-\gamma)^{-\frac{1}{2}}}^{\infty} \exp \left[-\frac{a^{2}}{4} \eta^{2}-\frac{\lambda}{\eta^{2}}\right] d \eta
$$


Using the integral given by Eq. (C.1), and the following properties of a complex variable

$$
\begin{aligned}
& \sin z=\frac{e^{i z}-e^{-i z}}{2 i} \\
& \cos z=\frac{e^{i z}+e^{-i z}}{2}
\end{aligned}
$$

we then get

$$
\begin{gathered}
I_{42}=\frac{e^{-\lambda \gamma}(\lambda \sin b \gamma+b \cos b \gamma)}{2 b\left(\lambda^{2}+b^{2}\right)}\left[e^{a \sqrt{\lambda}} e r f c\right. \\
\left(\frac{a}{2 \sqrt{t-\gamma}}+\sqrt{\lambda(t-\gamma)}\right)+e^{-a \sqrt{\lambda}} e r f c \\
\left.\left(\frac{a}{2 \sqrt{t-\gamma}}-\sqrt{\lambda(t-\gamma)}\right)\right]
\end{gathered}
$$

\section{REFERENCES:}

Abramowitz, M., and I.A. Stegun. 1972. Handbook of Mathematical Functions. Dover Publications, Inc.: New York, New York. 
APPENDIX D

FIRST-ORDER DERIVATIVES OF THE COMPONENTS OF THE CONCENTRATION SOLUTION IN THE FRACTURE LAYERS 
This appendix reports the first-order derivatives of the components of the solution of the concentration in the fracture layers as reported in Section 3.2.2 of Chapter 3..

$$
\begin{aligned}
& { }^{1} P_{m n}=\operatorname{erfc}\left({ }^{1} f_{m n}\right) \\
& { }^{1} f_{m n}=\frac{\theta_{m n}}{2\left(t-\gamma_{m n}\right)^{1 / 2}} \\
& { }^{1} P_{m n, k}={ }_{1}^{1} P_{m n}{ }^{1} f_{m n, k} \\
& { }^{1} f_{m n_{\alpha}}=\frac{1}{2\left(t-\gamma_{m n}\right)^{1 / 2}}\left[\theta_{m n_{\alpha}}+\frac{1 f_{m n} \gamma_{m n_{a}}}{\left(t-\gamma_{m n}\right)^{1 / 2}}\right] \\
& { }_{1}^{1} P_{m n}=-\frac{2}{\sqrt{\pi}} \exp \left[-{ }^{1} f_{m n}^{2}\right] \\
& { }^{2} P_{i m n}=\operatorname{erfc}\left[{ }^{1} f_{m n}+{ }^{2} f_{i m n}\right] \\
& { }^{2} f_{i m n}=\left(\frac{c_{f i}}{R_{t}}\right)\left(t-\gamma_{m n}\right)^{1 / 2} \\
& { }^{2} P_{i m n_{n_{g}}}={ }_{1}^{2} P_{i m n}\left[{ }^{1} f_{m n_{n_{k}}}+{ }^{2} f_{i m n_{k}}\right] \\
& { }_{1}^{2} P_{i m n}=-\frac{2}{\sqrt{\pi}} \exp \left[-\left({ }^{1} f_{m n}+{ }^{2} f_{i m n}\right)^{2}\right]
\end{aligned}
$$

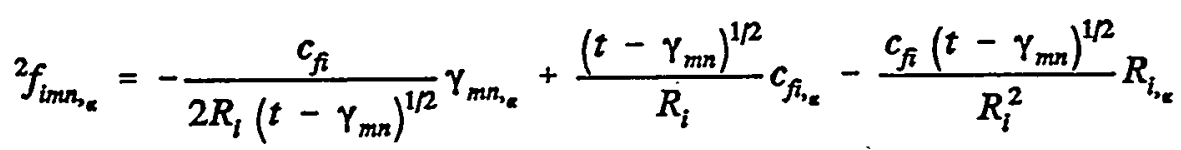




$$
\begin{aligned}
& { }^{3} P_{i m n}=\exp \left({ }^{3} f_{i m n}\right) \\
& { }^{3} f_{i m n}=\frac{\theta_{m n} c_{f i}}{R_{i}} \\
& { }^{3} P_{i m n, k}={ }^{3} P_{i m n s}{ }^{3} f_{i m n r_{k}}
\end{aligned}
$$

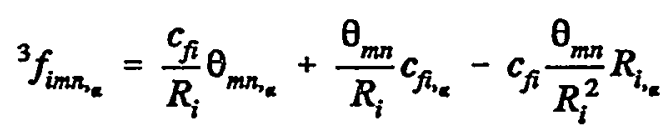

$$
\begin{aligned}
& { }^{4} P_{i m n}=\exp \left[{ }^{2} f_{i m n}^{2}\right] \\
& { }^{4} P_{i m n_{, k}}=2{ }^{4} P_{i m n}{ }^{2} f_{i m n}{ }^{2} f_{i m n n_{, k}} \\
& { }^{5} P_{i}=\exp \left[{ }^{5} f_{i}^{2}\right] \\
& { }^{5} f_{i}=\frac{c_{f i}}{R_{i}} t^{1 / 2} \\
& { }^{5} P_{i_{\mathrm{se}}}=2^{5} P_{i}{ }^{5} f_{i}^{5} f_{i_{\mathrm{se}}} \\
& { }^{5} f_{i_{\mathrm{g}}}=\frac{t^{1 / 2}}{R_{i}} c_{f_{i_{\mathrm{g}}}}-\frac{c_{f i}}{R_{i}^{2}} t^{1 / 2} R_{i_{\mathrm{G}}} \\
& { }^{6} P_{i}=\operatorname{erfc}\left({ }^{5} f_{i}\right) \\
& { }^{6} P_{i_{\alpha}}={ }_{1}^{6} P_{i}{ }^{5} f_{i_{\alpha}}
\end{aligned}
$$




$$
\begin{aligned}
& { }_{1}^{6} P_{i}=-\frac{2}{\sqrt{\pi}} \exp \left[-{ }^{5} f_{i}^{2}\right] \\
& { }^{7} P_{\text {jimn }}=\operatorname{erfc}\left({ }^{7} f_{j i m n}+{ }^{1} f_{m n}\right) \\
& { }^{7} f_{j i m n}=\dot{\beta}_{j l}\left(t-\gamma_{m n}\right)^{1 / 2} \\
& { }^{7} P_{j i m n_{\varepsilon}}={ }_{1}^{7} P_{j i m n}\left(f_{j i m n_{, k}}+f_{m n_{a}}\right)
\end{aligned}
$$

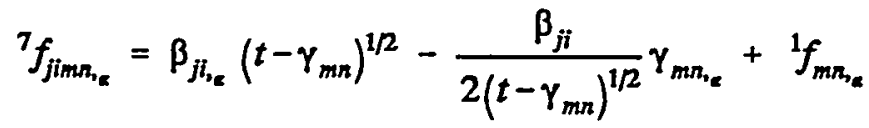

$$
\begin{aligned}
& { }_{1}^{7} P_{j i m n}=-\frac{2}{\sqrt{\pi}} \exp \left[-\left({ }^{7} f_{j i m n}+{ }^{1} f_{m n}\right)^{2}\right] \\
& { }^{8} P_{j i n n}=\exp \left[{ }^{8} f_{j i m n}\right] \\
& { }^{8} f_{j l m n}=\beta_{j i} \theta_{m n}+\beta_{j i}^{2}\left(t-\dot{\gamma}_{m n}\right) \\
& { }^{8} P_{j i m n_{\varepsilon}}={ }^{8} P_{j i m n}{ }^{8} f_{j i m n_{k}} \\
& { }^{8} f_{j i m n_{k}}=\beta_{j l_{k}} \theta_{m n}+\beta_{j i} \theta_{m n_{k}}+2 \beta_{j i} \beta_{j j_{k}}\left(t-\gamma_{m n}\right)-\beta_{j i}^{2} \gamma_{m n n_{k}} \\
& { }^{9} \dot{P}_{j i}=\frac{\beta_{j i}}{q_{i}} \\
& { }^{9} P_{j l_{\mathrm{e}}}=\frac{q_{i} \beta_{j i_{\mathrm{eg}}}-\beta_{j i} q_{i_{\mathrm{g}}}}{q_{i}^{2}}
\end{aligned}
$$




$$
\begin{aligned}
& { }^{10} P_{\text {in }}=\exp \left[{ }^{10} f_{i n}\right] \\
& { }^{10} f_{i n}=-\alpha_{n} \chi_{n}+\beta_{i n}^{2} t \\
& { }^{10} P_{i n_{n_{\varepsilon}}}={ }^{10} P_{i n}{ }^{10} f_{i \eta_{, k}} \\
& { }^{10} f_{i n_{, \varepsilon}}=-\alpha_{n_{\varepsilon}} \chi_{n}-\alpha_{n} \chi_{n_{s_{\varepsilon}}}+2 \beta_{i n} \beta_{i n_{\varepsilon}} t \\
& { }^{11} P_{i n}=\operatorname{erfc}\left({ }^{11} f_{i n}\right) \\
& { }^{11} f_{i n}=\beta_{i n} t^{1 / 2} \\
& { }^{11} P_{i n, \mathrm{~g}}={ }_{1}^{11} P_{i n}{ }^{11} f_{i n_{i_{\mathrm{g}}}} \\
& { }^{11} f_{i n_{\varepsilon}}=\beta_{i m_{k}} t^{1 / 2} \\
& { }_{1}^{11} P_{i n}=-\frac{2}{\sqrt{\pi}} \exp \left[-{ }_{11} f_{i n}^{2}\right]
\end{aligned}
$$


APPENDIX E

FIRST-ORDER DERIVATIVES OF THE COMPONENTS OF THE CUMULATIVE MASS SOLUTION IN THE FRACTURE LAYERS 
This appendix reports the first-order derivatives of the cumulative mass in the fracture layers as reported in Section 3.2.3 of Chapter 3.

$$
{ }^{0} G=\frac{e^{-\lambda t}}{\lambda}
$$

$$
\begin{gathered}
{ }^{0} G_{{ }^{*}}=-{ }^{0} G\left(t+\frac{1}{\lambda}\right) \lambda_{\text {s }} \\
{ }^{1} G_{m n}=\operatorname{erfc}\left({ }^{1} h_{m n}\right)
\end{gathered}
$$

$$
\begin{aligned}
& { }^{1} h_{m n}=\frac{\theta_{m n}}{2\left(t-\gamma_{m n}\right)^{1 / 2}} \\
& { }^{1} G_{m n_{m}}={ }_{1}^{1} G_{m n}{ }^{1} h_{m m_{m}}
\end{aligned}
$$

$$
\begin{aligned}
& { }^{1} h_{m m_{m a}}=\frac{1}{2\left(t-\gamma_{m n}\right)^{1 / 2}}\left[\theta_{m n_{m}}+\frac{1 h_{m n} \gamma_{m m_{m}}}{\left(t-\gamma_{m n}\right)^{1 / 2}}\right] \\
& { }_{1}^{1} G_{m n n}=-\frac{2}{\sqrt{\pi}} \exp \left[-{ }^{1} h_{m n}^{2}\right] \\
& { }^{2} G_{m n n}^{ \pm}=\operatorname{erfc}\left[{ }^{1} h_{m n} \pm{ }^{2} h_{m n}\right] \\
& { }^{2} h_{m n}=\sqrt{\lambda\left(t-\gamma_{m n}\right)} \\
& { }^{2} G_{m n_{\text {se }}}^{ \pm}={ }_{1}^{2} G_{m n}^{ \pm}\left[{ }^{1} h_{m h_{k}}-{ }^{2} h_{m n_{n_{k}}}\right] \\
& { }_{1}^{2} G_{m n}^{ \pm}=-\frac{2}{\sqrt{\pi}} \exp \left[-\left({ }^{1} h_{m n} \pm{ }^{2} h_{m n}\right)^{2}\right]
\end{aligned}
$$

E-1 


$$
\begin{aligned}
& { }^{2} h_{m n_{a}}=\frac{\lambda g_{\alpha}\left(t-\gamma_{m n}\right)-\lambda \gamma_{m n_{a}}}{2\left[\lambda\left(t-\gamma_{m n}\right)\right]^{1 / 2}} \\
& { }^{3} G_{m n}^{ \pm}=\frac{1}{2 \lambda} \exp \left({ }^{3} h_{m n}^{ \pm}\right) \\
& { }^{3} h_{m n}^{ \pm}=-\lambda \gamma_{m n} \pm \theta_{m n} \sqrt{\lambda} \\
& { }^{3} G_{m n_{\varepsilon}}^{ \pm}={ }^{3} G_{m n}^{ \pm}\left({ }^{3} h_{m n_{\varepsilon}}^{ \pm}-\frac{\lambda}{\lambda}\right)
\end{aligned}
$$

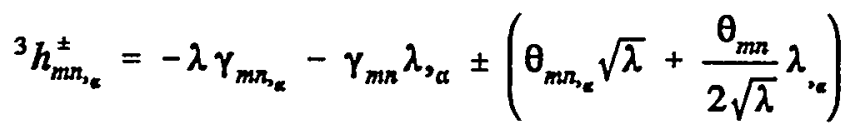

$$
\begin{aligned}
& { }^{4} G_{i}^{ \pm}=\left(\frac{c_{f i}}{R_{i} \sqrt{\lambda}} \pm 1\right)^{-1} \\
& { }^{4} G_{i_{\mathrm{se}}}^{ \pm}=-{ }^{4} G_{i}^{ \pm 2}\left[\frac{R_{i}\left(c_{f_{i_{\mathrm{eg}}}} \sqrt{\lambda}-\frac{c_{f i}}{2 \sqrt{\lambda}} \lambda\right)-c_{f_{i,}} \sqrt{\lambda} R_{i_{\mathrm{ge}}}}{R_{i}^{2} \lambda}\right] \\
& { }^{5} G_{i m n}=\operatorname{erfc}\left[{ }^{1} h_{m n}+{ }^{5} h_{i m n}\right] \\
& { }^{5} h_{i m n}=\left(\frac{c_{f i}}{R_{i}}\right)\left(t-\gamma_{m n}\right)^{1 / 2} \\
& { }^{5} G_{i m n_{y_{k}}}={ }_{1}^{5} G_{i m n}\left[{ }^{1} h_{m n_{z_{k}}}+{ }^{5} h_{i m n_{k}}\right]
\end{aligned}
$$

E-2 


$$
\begin{aligned}
& { }_{1}^{5} G_{i m n}=-\frac{2}{\sqrt{\pi}} \exp \left[-\left({ }^{1} h_{m n}+{ }^{5} h_{i m n}\right)^{2}\right] \\
& { }^{5} h_{i m n_{h_{\mathrm{s}}}}=-\frac{c_{f i}}{2 R_{i}\left(t-\gamma_{m n}\right)^{1 / 2}} \gamma_{m h_{\mathrm{e}}}+\frac{\left(t-\gamma_{m n}\right)^{1 / 2}}{R_{i}} c_{f_{i_{\mathrm{z}}}} \\
& -\frac{c_{f i}\left(t-\gamma_{m n}\right)^{1 / 2}}{R_{i}^{2}} R_{i=} \\
& { }^{6} G_{i m n}=\exp \left[{ }^{6} h_{i m n}\right] \\
& { }^{6} h_{i m n}=\frac{c_{f i}}{R_{i}}\left[\theta_{m n}+\left(\frac{c_{f i}}{R_{i}}\right)\left(t-\gamma_{m n n}\right)\right]-\lambda t \\
& { }^{6} G_{i m n_{k}}={ }^{6} G_{i m n}{ }^{6} h_{i m n n_{\varepsilon}}
\end{aligned}
$$

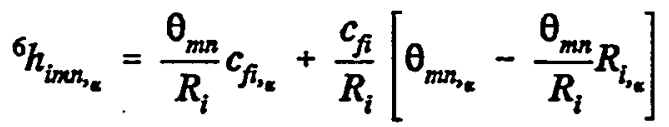

$$
\begin{aligned}
& +\frac{2 c_{f i}}{R_{i}^{3}}\left(R_{i} c_{f_{i_{\mathrm{g}}}}-c_{f i} R_{i_{\mathrm{g}}}\right)\left(t-\gamma_{m n}\right)-\left(\frac{c_{f i}}{R_{i}}\right)^{2} \gamma_{m n n_{\mathrm{g}}}-\lambda_{\mathrm{D}_{\mathrm{g}}} t \\
& { }^{7} G_{i}=\left[\left(\frac{c_{f_{i}}}{R_{i}}\right)^{2}-\lambda\right]^{-1}
\end{aligned}
$$

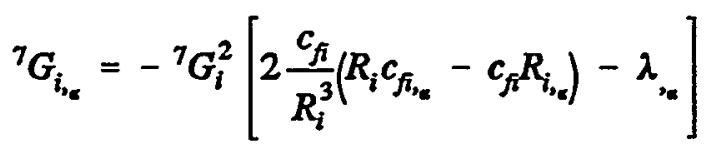

$$
\begin{aligned}
& { }^{8} G_{j i m n}=e r f c\left({ }^{8} h_{j i m n}+{ }^{1} h_{m n}\right)
\end{aligned}
$$




$$
\begin{aligned}
& { }^{8} h_{j i m n}=\beta_{j i}\left(t-\gamma_{m n}\right)^{1 / 2} \\
& { }^{8} G_{j i m n n_{, g}}={ }_{1}^{8} G_{j i m n}\left({ }^{8} h_{j i m n_{, \varepsilon}}+{ }^{1} h_{m n n_{k}}\right) \\
& { }^{8} h_{j i m m_{3}}=\beta_{j i_{e}}\left(t-\gamma_{m n}\right)^{1 / 2}-\frac{\beta_{j i}}{2\left(t-\gamma_{m n}\right)^{1 / 2}} \gamma_{m n_{3}} \\
& { }_{1}^{8} G_{j i m n}=-\frac{2}{\sqrt{\pi}} \exp \left[-\left({ }^{8} h_{j i m n}+{ }^{1} h_{m n}\right)^{2}\right] \\
& { }^{9} G_{j i m n}=\exp \left({ }^{9} h_{j i m n}\right) \\
& { }^{9} h_{j i m n}=\beta_{j i} \theta_{m n}+\beta_{j i}^{2}\left(t-\gamma_{m n}\right)-\lambda t \\
& { }^{9} G_{j i m n n_{\mathrm{g}}}={ }^{9} G_{j i \mathrm{mnn}}{ }^{9} h_{j i \mathrm{mn} n_{\mathrm{g}}}
\end{aligned}
$$

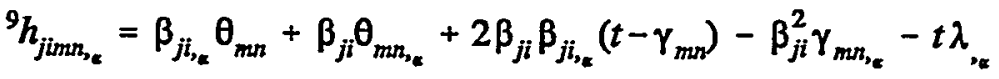

$$
\begin{aligned}
& { }^{10} G_{j i}=\frac{\beta_{j i}}{q_{i}} \\
& { }^{10} G_{j i_{\text {e }}}=\frac{q_{i} \beta_{i i_{j_{e}}}-\beta_{i j} q_{i_{\text {e }}}}{q_{i}^{2}} \\
& { }^{11} G_{j i}^{ \pm}=\left(\frac{\beta_{j i}}{\sqrt{\lambda}} \pm 1\right)^{-1}
\end{aligned}
$$




$$
\begin{aligned}
& { }^{11} G_{j j_{e}}^{ \pm}=-{ }^{11} G_{j i}^{ \pm 2}\left(\frac{\sqrt{\lambda} \beta_{j i_{e}}-\frac{\beta_{j i}}{2 \sqrt{\lambda}} \lambda,_{\alpha}}{\lambda}\right) \\
& { }^{12} G_{i n}=\exp \left({ }^{12} h_{\text {in }}\right) \\
& { }^{12} h_{i n}=-\alpha_{n} \chi_{n}+\beta_{i n}^{2} t-\lambda t \\
& { }^{12} G_{i h_{\mathrm{s}}}={ }^{12} G_{i n}{ }^{12} h_{i n_{\mathrm{s}}}
\end{aligned}
$$

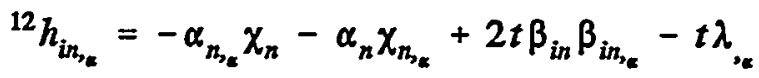

$$
\begin{aligned}
& { }^{13} G_{i n}=\operatorname{erfc}\left({ }^{13} h_{i n}\right) \\
& { }^{13} h_{i n}=\beta_{i n} t^{1 / 2} \\
& { }^{13} G_{i h_{\varepsilon}}={ }_{1}^{13} G_{i n}{ }^{13} h_{i n_{, k}} \\
& { }^{13} h_{i n_{j_{k}}}=\beta_{i n_{n_{\varepsilon}}} t^{1 / 2} \\
& { }_{1}^{13} G_{i n}=-\frac{2}{\sqrt{\pi}} \exp \left(-{ }^{13} h_{i n}{ }^{2}\right) \\
& { }^{14} G_{j i}=\frac{1}{\beta_{j i}^{2}-\lambda} \\
& { }^{14} G_{j i j_{\mathrm{e}}}=-{ }^{14} G_{j i}^{2}\left(2 \beta_{j i} \beta_{j i_{\mathrm{eg}}}-\lambda_{\mathrm{se}_{\mathrm{e}}}\right) \\
& { }^{15} G_{i}=e^{-\alpha_{i} x_{i}}
\end{aligned}
$$

(E.16a)

E-5 


$$
\begin{aligned}
& { }^{15} G_{i_{\mathrm{se}}}={ }^{15} G_{i}\left(-\alpha_{i_{\mathrm{g}}} \chi_{i}-\alpha_{i} \chi_{i_{\mathrm{ag}}}\right) \\
& { }^{16} G_{i n}={ }_{1}^{16} h{ }_{2}^{16} h_{i n} \\
& { }_{1}^{16} h=\operatorname{erf}\left[(\lambda t)^{1 / 2}\right] \\
& { }_{2}^{16} h_{i n}=\frac{\beta_{i n}}{\sqrt{\lambda}} \\
& { }^{16} G_{i h_{\mathrm{g}}}={ }_{1}^{16} h_{, \mathrm{g}}{ }_{2}^{16} h_{i n}+{ }_{1}^{16} h_{2}^{16} h_{i h_{\mathrm{g}}} \\
& ={ }_{1}^{16} h_{\text {,e }}=\sqrt{\frac{t}{\lambda \pi}} \exp (-\lambda t) \lambda_{\text {, }} \\
& { }_{2}^{16} h_{i n_{\mathrm{ig}}}=\frac{\beta_{i n_{i_{\mathrm{c}}}}}{\sqrt{\lambda}}-\frac{1}{2} \frac{\beta_{i n}}{\lambda^{3 / 2}} \lambda_{\mathrm{ie}_{\mathrm{e}}} \\
& { }^{17} G_{n}=\exp \left({ }^{17} h_{n}\right) \\
& { }^{17} h_{n}=\left[\left(\frac{c_{f_{n}}}{R_{n}}\right)^{2}-\lambda\right] t \\
& { }^{17} h_{n_{\text {e }}}=\left[\frac{2 c_{f_{n}} t\left(R_{n} c_{f_{n_{\mathrm{g}}}}-c_{f_{n}} R_{n_{\mathrm{se}}}\right)}{R_{n}^{3}}-\lambda_{v_{\mathrm{s}}} t\right] \\
& { }^{17} G_{n_{\text {, }}}={ }^{17} G_{n}{ }^{17} h_{n_{\text {, }}}
\end{aligned}
$$




$$
\begin{aligned}
& { }^{18} G_{n}=\operatorname{erfc}\left[{ }^{18} h_{n}\right] \\
& { }^{18} h_{n}=\frac{c_{f_{n}}}{R_{n}} t^{1 / 2} \\
& { }^{18} G_{m_{\text {ge }}}=-\frac{2}{\sqrt{\pi}} \exp \left(-{ }^{18} h_{n}^{2}\right){ }^{18} h_{m_{\text {be }}}
\end{aligned}
$$

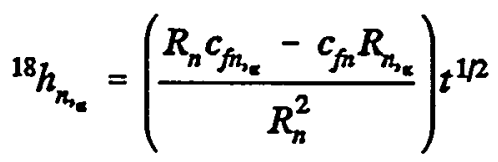

$$
\begin{aligned}
& { }^{19} G_{n}={ }_{1}^{16} h{ }^{19} h_{n} \\
& { }^{19} h_{n}=\frac{c_{f n}}{R_{n} \sqrt{\lambda}} \\
& { }^{19} G_{n_{\text {g }}}={ }_{1}^{16} h_{, \alpha}{ }^{19} h_{n}+{ }_{1}^{16} h^{19} h_{n_{g}}
\end{aligned}
$$

where ${ }_{1}^{16} \mathrm{~h}$ is given by Eq. (E.17b), and its derivative by Eq. (E.17e)

$$
{ }^{19} h_{n_{n_{e}}}=\frac{\left[R_{n} \sqrt{\lambda} c_{f_{n_{k}}}-c_{f_{n}}\left(R_{n_{k}} \sqrt{\lambda}+\frac{R_{n}}{2 \sqrt{\lambda}} \lambda_{\nu_{e}}\right)\right]}{R_{n}^{2} \lambda}
$$




\section{APPENDIX F}

NOTATIONS 
$a_{1 i}, a_{2 i}, \alpha_{i} \quad$ constants in the model for residual concentrations in the ith fracture layer

$A_{i} \quad$ concentration of the species in the ith fracture layer

$\mathrm{A}^{\circ} \quad$ concentration of the species at the source at time equals to zero

$b_{i} \quad$ half-thickness of the ith fracture layer

$\mathrm{b}_{1 \mathrm{i}} \quad$ residual concentration in the ith rock matrix layer

$\mathrm{B}_{\mathrm{i}} \quad$ concentration of the species in the ith rock matrix layer

$\mathrm{D}_{\mathrm{ei}} \quad$ effective diffusivity in the ith rock matrix layer

$\mathrm{D}_{\mathrm{d}} \quad$ molecular diffusion of nuclide in water

$\mathrm{D}_{\mathrm{pi}} \quad$ pore diffusivity in the ith rock matrix layer

$\mathrm{g}_{\mathrm{fi}} \quad$ geometric factor of the ith rock matrix layer

$\mathrm{J}_{\mathrm{i}} \quad$ diffusive rate of nuclide at surface of ith fracture layer per unit area of fracture surface

$\mathrm{K}_{\mathrm{fi}} \quad$ surface distribution in the ith fracture layer

$\mathrm{K}_{\mathrm{ri}}$ distribution coefficient in the ith rock matrix layer

$L_{i} \quad$ thickness of ith rock matrix layer

n total number of layers

Q steady water flow rate in fracture

$\mathbf{R}_{\mathbf{i}} \quad$ retardation factor in the $i$ th fracture layer

$\mathbf{R}_{\mathbf{i}}^{\prime} \quad$ retardation factor in the ith rock matrix layer

t time

T leaching time

$\mathrm{T}_{\mathrm{p}} \quad$ time period of a complete cycle $(2 \pi / \omega)$

$\mathrm{T}_{1 / 2} \quad$ half-life 


$\begin{array}{ll}\mathrm{u}_{\mathrm{i}} & \text { average fluid velocity in the ith fracture layer } \\ \mathrm{z} & \text { position vector in the fracture } \\ \alpha_{\mathrm{i}} & \text { position vector in the rock matrix } \\ \delta_{\mathrm{di}} & \text { constant in model of initial concentration in the ith fracture layer } \\ \lambda & \text { constrictivity for diffusion in the ith rock layer } \\ \nu_{1}, \nu_{2} & \text { constants in model of periodically fluctuating decaying source } \\ \rho_{\mathrm{ri}} & \text { rock density in the ith layer } \\ \tau_{\mathrm{ri}} & \text { tortuosity of the ith rock layer } \\ \Phi_{\mathrm{i}} & \text { porosity of the ith rock layer } \\ \omega & \text { frequency of oscillation }\end{array}$

\section{Abbreviated Forms}

$$
\begin{gathered}
c_{f i}=\frac{\phi_{i}}{b_{i}}\left(R_{i}^{\prime} D_{p i}\right)^{1 / 2} \\
c_{r i}=\left(R_{i}^{\prime}{ }_{i} / D_{p i}\right)^{1 / 2} \\
D_{e i}=\phi_{i} D_{p i} \\
\tilde{L}_{i}= \begin{cases}L_{i}, & i<n \\
x-x_{i-1}, & i=n\end{cases} \\
p_{i}=u_{i} \alpha_{i} .
\end{gathered}
$$




$$
\begin{gathered}
q_{i}=2\left[\left(\frac{c_{f i}}{2 R_{i}}\right)^{2}+\frac{p_{i}}{R_{i}}\right]^{1 / 2} \\
Q=2 u_{i} b_{i} \\
R_{i}=1+\frac{K_{f i}}{b_{i}} \\
R_{i}^{\prime}=1+\left[\left(1-\Phi_{i}\right) / \Phi_{i}\right] \rho_{r i} K_{r i} \\
\beta_{1 i}=\frac{c_{f i}}{2 R_{i}}-\frac{q_{i}}{2} \\
\beta_{2 i}=\frac{c_{f i}}{2 R_{i}}+\frac{q_{i}}{2} \\
\theta_{n}^{\prime}=\theta_{m n}+c_{r n}\left(z-b_{n}\right) \\
\theta_{m n}=\sum_{i=m}^{n-1} c_{f i} \bar{\eta}_{i}+c_{f n} \eta_{n} \\
\bar{\eta}_{i}=\frac{L_{i}}{u_{i}} \\
\eta_{i}=\frac{x-x_{i-1}}{u_{i}}
\end{gathered}
$$




$$
\begin{aligned}
& \gamma_{m n}=\sum_{i=m}^{n-1} R_{i} \bar{\eta}_{i}+R_{n} \eta_{n} \\
& x_{i}= \begin{cases}x, & i=1 \\
x-x_{i}, & i>1\end{cases}
\end{aligned}
$$

\section{F-4}


APPENDIX G

MODEL PARAMETERS 
The following parameters are used in the computer code ${ }^{1}$ (written in ANSI Standard FORTRAN 77) that implements the analytic solutions described in Section 2.

FORTRAN NAME

ALFA(I)

$\mathrm{CCO}$

$\operatorname{CINF}(1, \mathrm{I})$

$\operatorname{CINF}(2, \mathrm{I})$

$\operatorname{CINR}(\mathbf{I})$

CNS(1)

CNS(2)

DENSR(I)

$\operatorname{DIFFR(I)}$

\section{EXPLANATION}

Constant alpha in the exponential term in residual concentration mode in the ith fracture layer $(1 / \mathrm{L})$

Concentration of the species at the source at time equals zero (units of activity/ $/ \mathrm{L}^{3}$ )

Constant in residual concentration model in the ith fracture (units of activity $/ \mathrm{L}^{3}$ )

Coefficient of exponential term in residual concentration model in the ith fracture (units of activity/ $\mathrm{L}^{3}$ )

Residual concentration in the ith rock matrix layer (units of activity/L $\mathbf{L}^{3}$ )

Constant in periodically fluctuating decaying source term model $($ NPERIOD $=1)$

Coefficient of sine function term in periodically fluctuating decaying source term model (NPERIOD = 1)

ith Rock matrix layer bulk density $\left(\mathrm{M} / \mathrm{L}^{3}\right.$ ) (used if IDIST(1) = 2)

Pore diffusivity $\left(\mathrm{L}^{2} / \mathrm{T}\right)$

1 (Gureghian, A.B., Medrano, D., and E. King. 1992. MULTFRAC User's Guide, Version 1.0: Analytical solutions for one-dimensional transport of a radionuclide in a layered fractured rock with rock matrix diffusion. - CNWRA92-023. Center for Nuclear Waste Regulatory Analyses: San Antonio, Texas. In press.) 
FORTRAN NAME

$\cdot \operatorname{DIMENS}(\mathrm{I}, \mathrm{J})$

$\operatorname{DISTX}(\mathrm{l})$

DISTRB_F(I)

DISTRB_R(I)

EXMAX

FLOWR

HALFL

HALF_THICK(I)

IAUTO

TIME

IBAND

ICONCF

ICONCR

\section{EXPLANATION}

Dimensions used in the problem; each must be $\leq 12$ characters in length.

$$
\begin{aligned}
& (1, \mathrm{~J})=\text { Species name } \\
& (2, J)=\text { Time (year) } \\
& (3, \mathrm{~J})=\text { Length (meter) } \\
& (4, J)=\mathrm{L} / \mathrm{T} \text { (meter/year) } \\
& (5, \mathrm{~J})=\mathrm{L}^{2} / \mathrm{T}\left(\mathrm{m}^{2} / \text { year }\right) \\
& (6, \mathrm{~J})=\text { Mass/Volume }(\mathrm{g} / \mathrm{cc}) \\
& (7, \mathrm{~J})=\text { Volume/Mass (cc/g) } \\
& (8, \mathrm{~J})=1 / \text { Time }(1 . / \text { year }) \\
& (9, \mathrm{~J})=\text { Units of Activity/Volume }\left(\mathrm{UA} / \mathrm{L}^{3}\right) \\
& (10, \mathrm{~J})=1 / \mathrm{L}(1 . / \text { meter })
\end{aligned}
$$

Thickness of ith fracture or rock layer (L)

ith Fracture layer surface distribution coefficient (L) (IDIST(1) $=1)$

ith Rock matrix layer distribution coefficient $\left(\mathrm{L}^{3} / \mathrm{M}\right)$ (IDIST(2) = 1)

Largest allowed magnitude for exponential arguments (machine dependent)

Steady water flow rate per unit width of fracture $\left(\mathrm{L}^{2} / \mathrm{T}\right)$

Half-life of species (T)

Half-thickness of the ith fracture layer $(\mathrm{L})$

$=0$ User supplies arrays REFX, REFZ, and TIME, including parameters NX, NZ, and NT

$=1$ Automatic generation of arrays REFX, REFZ and TIME

including parameters NX, NZ, and NT (see Note)

$=0$ Step release mode at source

$=1$ Band release mode at source

$=0$ Do not calculate fracture concentrations

$=1$ Do calculate fracture concentrations

$=0$ Do not calculate rock concentrations

$=1 \mathrm{Do}$ calculate rock concentrations 
FORTRAN NAME

ICUMF

IDIST(1)

IDIST(2)

IGRAPH

$\operatorname{INDEX}(1)$

LAYER

NCONC_SENSIT

NPERIOD

NRUNMAX

NT

\section{EXPLANATION}

$=.0$ Do not calculate cumulative mass flux

$=1$ Do calculate cumulative mass flux

$=0$ RETARD_F corresponds to retardation factor in fracture

= 1 RETARD_F corresponds to surface distribution coefficient in fracture (i.e., DISTRB_F)

$=0$ RETARD_R corresponds to retardation factor in rock matrix

$=1$ RETARD_R corresponds to distribution coefficient in rock matrix (i.e., DISTRB_R)

$=0$ Graphics output disabled

$=1$ Graphics output enabled; formatted graphics written to logical unit $30,31,32,35,36$

Logical Unit 30: Concentrations in Fracture

" " 31: Concentrations in Rock Matrix

" " 32: Cumulative Mass

" "35: Concentration Sensitivities

" " 36: Cumulative Mass Sensitivities

$=1$ Evaluate sensitivity computation related to parameter $\mathrm{i}$ (i.e., - NCONC_SENSIT $\geq 2$ )

$=0$ Skip

Number of fracture/rock matrix layers

$=1$ Execute Module 1 (i.e., calculate concentrations and cumulative mass in the fractures and concentrations in the rock matrix

$=2$ Execute Module 2 (calculate sensitivity coefficients, relative sensitivies and variance

$=3$ Execute both Modules 1 and 2

$=0$ Continuously Decaying Source

$=1$ Periodically Fluctuating Decaying Source

Number of data sets to be run

$\leq 500$, number of time values to be evaluated (skip if IAUTO = 1) 
FORTRAN NAME

NVAL

NX

NZ

PERIOD

POROSR(I)

REFX(I)

REFZ(I)

RETARD_F(I)

RETARD_R(I)

STDV(I)

TIME(I)

TIML

TITLE

VELX(I)
EXPLANATION

Index for selecting solution module

$=0$ Option for analytical solutions

$=1$ Option for sensitivity module

$\leq 500$, number of positions to be evaluated in $\mathrm{x}$ direction (skip if IAUTO = 1)

$\leq 500$, number of positions to be evaluated in $\mathrm{x}$ direction (skip if IAUTO $=1$ )

Time period for a complete cycle of variation in periodically fluctuating decaying source term model (NPERIOD $=1$ )

Average porosity in ith rock matrix layer

$\mathrm{x}$-position in space $(\mathrm{L})$ (read if IAUTO $=0$ )

z-position in space (L) (read if IAUTO $=0$ )

Retardation factor in the ith fracture layer (IDIST $(1)=0$ ) or Surface distribution coefficient (i.e., DISTRB_F) in the ith fracture layer (IDIST $(1)=1$ )

Retardation factor in the ith rock matrix layer (IDIST(2) $=0$ ) or Distribution coefficient (i.e., DISTRB_R) in the ith rock matrix layer $(\operatorname{IDIST}(2)=1)$

Standard deviation of parameter I (i.e., NCONC_SENSIT $\geq 2$ )

Position in time $(\mathrm{T})(\mathrm{read}$ if IAUTO $=0)$

Leaching time (T) (used if IBAND = 1)

2 Lines, $\leq 80$ characters per line, title of data set

Average fluid velocity in the ith fracture layer $(\mathrm{L} / \mathrm{T})$

Note: The following parameters are read-in if IAUTO $=1$ in order to generate arrays REFX, REFZ, and TIME and their associated parameters NX, NZ, and NT.

X0

DX

ENDX

$\mathrm{ZO}$
First value of spatial coordinate $X=\operatorname{REFX(1)}$

Spatial increment along $\mathrm{X}$-axis

Final value of spatial coordinate $X=\operatorname{REFX}(N X)$

First value of spatial coordinate $Z=R E F(1)$ 


\section{FORTRAN NAME}

DZ

ENDZ

T0

DT

ENDT

NLOG

DSTEP

\section{EXPLANATION}

\section{Spatial increment along Z-axis}

Final value of spatial coordinate $Z=R E F Z(N Z)$

First value of simulation time $=$ TIME(1)

Time increment

End value of simulation time $=$ TIME(NT)

$=0$ Position in space or time are equally spaced

$=1$ Log scale used for splitting space or time arrays: REFX, REFZ, and TIME (i.e., 10 divisions per log cycle)

Step length for evaluating first order sensitivities 
(See instructions on the reverse)

NUREG/CR-5917

CNWRA $91-010$

2. TITLE AND SUBTITLE

Sensitivity and Uncertainty Analyses Applied to One-Dimensional Radionuclide Transport in a Layered Fractured Rock:

MULTFRAC - Analytic Solutions and Local Sensitivities
Vol: 1

5. AUTHOR(S)

A.B. Gureghian, Y.-T. Wu, B. Sagar, R.B. Code11*

3. DATE REPORT PUBLISHEO

\begin{tabular}{c|c} 
MONIII & YEA \\
December & 1992
\end{tabular}

4. FIN OF GRANT NUMBER D 1035

6. TYPE OF REPORT

1. PERIOD COVERED (Inclusive D.U(m)

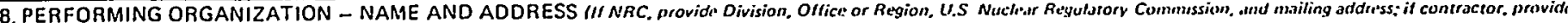
manir and nailing address)

Center for Nuclear Waste Regulatory Analyses

*U.S. Nuclear Regulatory Commission

Southwest Research Institute

6220 Culebra Road

San Antonio, TX 78228-0510

9. SPONSORING ORGANIZATION - NAME AND ADDRESS III NRC. type "Same as above"; if contractor, provide" NRC Ouvision, Other or Region, U.S. Nuclear Rigulatary Commission, and mailing address.

Division of High-Level Waste Management

Office of Nuclear Materials Safety \& Safeguards

U.S. Nuclear Regulatory Commission

Washington, DC 20555

10. SUPPLEMENTARY NOTES

11. ABSTRACT (200 words or less)

This report documents the derivation and verification of the closed form analytical solutions of the onedimensional nondispersive and isothermal transport of a radionuclide in a layered system of saturated planar fractures coupled with diffusion into the adjacent saturated rock matrix. The analytical solutions are based on the Laplace transform method where the domains of radionuclide migration in both fractures and rock layers are one-dimensional and of the semi-infinite type, implying in this instance that radionuclide diffusion from the fractures wall to the rock matrix may extend to infinity. The sorption phenomena in both fracture and rock matrix layers are described by a linear equillibrium sorption isotherm. Two types of radionuclide release modes are considered: the continuously decaying, and the periodically fluctuating decaying source, which may, in turn, be subject to step and band release modes. The initial concentrations in the fracture and rock matrix layers may be assigned spatially varying values in the case of the first, whereas uniform. ones may be implemented in both cases.

12. KEY WORDS/DESCR!PTORS (List words or phrases that will dssist ressearchers in locating the report.)

radionuclide migration, analytic solutions, fractured media, Laplace transforms, sensitivity analysis

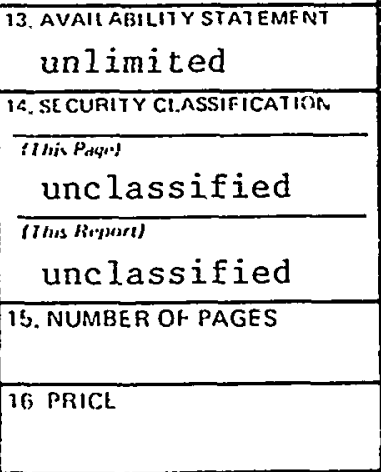

